\title{
Promoting Cognitive and Fine Motor Development in the Art Room for Young Students with Exposure to Trauma: an Exploratory Case Study.
}

\author{
Tiffany Marie Minuci \\ tml0024@mix.wvu.edu
}

Follow this and additional works at: https://researchrepository.wvu.edu/etd

Part of the Art Education Commons

\footnotetext{
Recommended Citation

Minuci, Tiffany Marie, "Promoting Cognitive and Fine Motor Development in the Art Room for Young Students with Exposure to Trauma: an Exploratory Case Study." (2019). Graduate Theses, Dissertations, and Problem Reports. 7448.

https://researchrepository.wvu.edu/etd/7448

This Thesis is protected by copyright and/or related rights. It has been brought to you by the The Research Repository @ WVU with permission from the rights-holder(s). You are free to use this Thesis in any way that is permitted by the copyright and related rights legislation that applies to your use. For other uses you must obtain permission from the rights-holder(s) directly, unless additional rights are indicated by a Creative Commons license in the record and/ or on the work itself. This Thesis has been accepted for inclusion in WVU Graduate Theses, Dissertations, and Problem Reports collection by an authorized administrator of The Research Repository @ WVU. For more information, please contact researchrepository@mail.wvu.edu.
} 
Promoting Cognitive and Fine Motor Development in the Art Room for Young Students with Exposure to Trauma: an Exploratory Case Study.

\title{
Tiffany M. Minuci
}

Thesis submitted

to the West Virginia University School of Art \& Design

at West Virginia University

In partial fulfillment of the requirements for the degree of

Master of Arts in

Art Education

\author{
Alison Helm, MFA, Chair \\ Annie McFarland, MS-ATR \\ Joseph Lupo, MFA \\ Departments of Art Education
}

Morgantown, West Virginia

2019

Keywords: Art Education, Cognitive Development, Fine Motor Development, Trauma

Exposure, Adverse Childhood Experiences

Copyright 2019 Tiffany M. Minuci 


\section{Abstract \\ Promoting Cognitive and Fine Motor Development in the Art Room for Young Students with Exposure to Trauma: an Exploratory Case Study.}

\section{Tiffany M. Minuci}

Despite the overwhelming research that suggests visual artmaking experiences can produce positive outcomes for individuals, many state art education policies fail to implement and integrate the arts into core academic curriculums. Specifically in the state of West Virginia, kindergarten through twelfth grade students often lack the access to a quality and consistent art education. With high teacher-pupil ratios and inclusive learning environments, educators face the difficult task of meeting all the individual needs of their students' in the classroom. This not only affects whole student populations, but also poses risks for children who have been exposed to trauma. Traumatic experiences in early childhood can cause a range of severe negative outcomes. West Virginia has seen a rise in child victims and the occurrence of traumatic childhood e since 2015, making it more apparent than ever that children need resources to help them heal and mitigate the impact trauma can have on their lives. School communities are increasingly implementing trauma-informed programs that provide students with the proper interventions they need. Although these programs already have invaluable benefits, there seems to be a gap in research between the interventions of currently established programs and the possibilities artmaking experiences can provide for trauma exposed students. This exploratory case study investigates how to design art lessons that promote the development of students in the kindergarten through second grade classroom who have been identified with exposure to trauma. This research particularly focuses on understanding how art lessons can promote cognitive and fine motor development for these students in the art room. Finally, this research examines the role an art education can play in supporting these students within trauma-informed school communities. 


\section{Acknowledgement}

I would like to extend my sincerest thanks to my committee chair Alison Helm and committee members Joseph Lupo and Annie McFarland for their insight and contributions. I would like to express special appreciation to Annie McFarland for advising and providing me with invaluable guidance during the writing process. I would also like to thank Amie Perriello, Irma Barazzone, and Sonda Cheesebrough for their dedication as educators and for helping me navigate through my first experiences as an art educator.

The completion of this thesis would not have been possible without the constant love and support of my parents, family, and close friends. Finally, I want to express my deepest gratitude to my husband Eduardo Minuci for always inspiring me and for his unwavering encouragement. 


\section{Table of contents}

Cover Page

$\begin{array}{ll}\text { Abstract } & \text { ii }\end{array}$

Acknowledgement iii

Table of Contents $\quad$ iv

List of Tables

List of Figures

$\begin{array}{lc}\text { Definition of Terms } & \mathbf{x}\end{array}$

$\begin{array}{ll}\text { Chapter 1: Introduction } & 1\end{array}$

Statement of the Problem 1

Background to the Study $\quad 3$

Research Question $\quad 4$

Significance of the Research

Methodology $\quad 6$

$\begin{array}{ll}\text { Participants } & 8\end{array}$

Limitations 9

$\begin{array}{ll}\text { Summary } & 10\end{array}$

$\begin{array}{ll}\text { Chapter 2: Literature Review } & 11\end{array}$

Introduction 11

Brain Development $\quad 11$

Cognitive Development $\quad 14$

Piaget's Theory of Cognitive Development 14

The Preoperational Stage of Cognitive Development 15

The Critique of Piaget's Theory 16

The Information Processing Theory of Learning 17

Fine Motor Development $\quad 19$

The Impact of Trauma on Child Development $\quad 20$

The Brain $\quad 21$

Cognitive Functions $\quad 24$

Fine Motor Functions $\quad 25$

Children in the Classroom $\quad 27$

Trauma-Informed School Communities $\quad 29$

Handle with Care $\quad 30$

Impact of Art Education on Young Students 31

The Trauma-Informed Art Room 33 
Summary

$\begin{array}{ll}\text { Chapter 3: Methodology } & 36\end{array}$

Introduction $\quad 36$

Participants and Site $\quad 38$

$\begin{array}{lr}\text { Procedures } & 40\end{array}$

Preparing the Environment $\quad 40$

Class Period 1

Geometric and Organic Shapes 44

Moving Forward $\quad 46$

Class Period $2 \quad 46$

When Pigasso met Mootisse $\quad 47$

Explaining the Project 51

Class Periods 3 and $4 \quad 51$

Class Period 5

Differentiated Instruction $\quad 55$

Collaging $\quad 55$

Class Period $6 \quad 58$

Class Period 7

Research Design $\quad 59$

Data Collection and Instruments $\quad 60$

$\begin{array}{ll}\text { Data Analysis } & 62\end{array}$

$\begin{array}{ll}\text { Cognitive abilities } & 62\end{array}$

Fine motor abilities $\quad 65$

$\begin{array}{ll}\text { Summary } & 66\end{array}$

$\begin{array}{lr}\text { Chapter 4: Results } & 68\end{array}$

$\begin{array}{ll}\text { Introduction } & 68\end{array}$

$\begin{array}{ll}\text { Exploratory Case Study 1: Kindergarten } & 68\end{array}$

Kindergarten Results $\quad 68$

Kindergarten Participants with no Known Exposure to Trauma 69

Student 24's Artwork Analysis $\quad 70$

Kindergarten Participants Identified with Exposure to Trauma 70

Student 16's Exposure to Trauma $\quad 71$

Student 16's Artwork Analysis $\quad 71$

Exploratory Case Study 2: First Grade

First Grade Results $\quad 72$

First Grade Participants with no Known Exposure to Trauma 72

Student 2's Artwork Analysis 73

First Grade Participants Identified with Exposure to Trauma 73

Student 15's Exposure to Trauma $\quad 74$

Student 15's Artwork Analysis $\quad 74$

$\begin{array}{ll}\text { Exploratory Case Study 3: Second Grade } & 74\end{array}$ 
Second Grade Participants with no Known Exposure to Trauma 75

Student 3's Artwork Analysis 76

Second Grade Participants Identified with Exposure to Trauma 76

Student 18's Exposure to Trauma $\quad 77$

Student 18's Artwork Analysis 77

Summary

Chapter 5: Discussion

Introduction

Exploratory Case Study Results $\quad 79$

Emerging Themes 81

All Struggling Students Deserve Help Tailored to Their Needs 81

Students who have Experienced Trauma may not Always have Difficulty Performing Cognitive and Fine Motor Tasks in the Classroom 82 Fine Motor Skills Develop Quicker than Cognitive Functions 84 Promoting Cognitive and Fine Motor Development is a Gradual Process 


\section{List of Tables}

Table 1. Class Periods: instructional strategies, student activities, learning tasks, \& assessments

Table 2. Kindergarten First Portrait Results

Table 3. Kindergarten Second Portrait Results

Table 4. Kindergarten Completed Project Results

Table 5. First Grade First Portrait Results

Table 6. First Grade Second Portrait Results

Table 7. First Grade Complete Project Results

Table 8. Second Grade First Portrait Results

Table 9. Second Grade Second Portrait Results

Table 10. Second Grade Complete Project Results 


\section{List of Figures}

Figure 1. Site Setup

Figure 2. Cut-out Shape Containers

Figure 3. Collage Papers Setup

Figure 4. Cooperating Teacher's Pigasso Portrait Example

Figure 5. Student Teacher's Pigasso and Mootisse Portrait Examples

Figure 6. Blackboard Display of Assessment Tasks

Figure 7. Student Teacher's Step-by-Step Portrait Example

Figure 8. Lightbox Display for Tracing

Figure 9. Class Period 1 Shape Drawing Activity

Figure 10. Class Period 1 Lego Shape Activity

Figure 11. Class Period 1 Lego Shape Activity

Figure 12. When Pigasso met Mootisse Book Cover, Nina Laden, 1998

Figure 13. A Mootisse Painting, Laden, 1998, p. 2

Figure 14. A Pigasso Painting, Laden, 1998, p. 1

Figure 15. Mootisse's House, Laden, 1998, p. 15

Figure 16. Pigasso's House, Laden, 1998, p. 18

Figure 17. Mootisse and Pigasso Shapes Guide Sheets

Figure 18. Student Tracing with Shapes Guide Sheet

Figure 19. How to Trace Cut-out Shapes Step 1

Figure 20. How to Trace Cut-out Shapes Step 2

Figure 21. Student Tracing with Paint Palette.

Figure 22. Mrs. Mootisse 
Figure 23. How to Create Shapes for Collaging Step 1

Figure 24. How to Create Shapes for Collaging Step 2

Figure 25. How to Create Shapes for Collaging Step 3

Figure 26. How to Create Shapes for Collaging Step 4

Figure 27. Student Example of Mootisse with Correct Elements and Style

Figure 28. Student Example of Pigasso with Correct Elements and Style

Figure 29. Student Example of Same Artworks

Figure 30. Student Example of Similar Artworks

Figure 31. Student Example of Different Artworks

Figure 32. Progression of Fine Motor Scores in Kindergarten Student Artworks

Figure 33. Progression of Fine Motor Scores in First Grade Student Artworks

Figure 34. Progression of Fine Motor Scores in Second Grade Student Artworks

Figure 35. Kindergarten Student 16's Artworks

Figure 36. Kindergarten Student 24's Artworks

Figure 37. First Grade Student 2's Artwork

Figure 38. First Grade Student 15's Artwork

Figure 39. Second Grade Student 3's Artwork

Figure 40. Second Grade Student 18's Artwork 


\section{Definition of Terms}

The CDC-Kaiser Permanente Adverse Childhood Experience (ACE) Study is one of the largest investigations of childhood abuse and neglect and its association with household challenges, later-life health, and well-being. ACE is the term used to describe any type of abuse, neglect, and other potentially traumatic experiences that occur to people under the age of 18 .

Art therapy is therapy based on engagement in artistic activities as a means of creative expression and symbolic communication especially in individuals affected with a mental or emotional disorder or cognitive impairment.

Brain development is a complex, organized, and highly multistep process that begins during the third week of gestation and continues throughout birth and adolescence in the human brain.

Cognitive development is the field of study in neuroscience and psychology focusing on a child's development in terms of information processing, conceptual resources, perceptual skill, language learning, and other aspects of the developed adult brain and cognitive psychology.

Collage is an artistic composition made of various materials (such as paper, cloth, or wood) glued on a surface.

A developmental delay is defined as slow to meet or not reaching milestones in one or more of the areas of development (communication, motor, cognition, social-emotional, or adaptive skills).

An exploratory case study investigates the distinct phenomena characterized by a lack of detailed preliminary research, especially formulated hypotheses that can be tested, and/or by a specific research environment that limits the choice of methodology.

Fine motor development is the development of coordination with smaller muscles, like muscles in the hands, fingers, and wrists.

West Virginia's Handle with Care (HWC) is a trauma-informed collaborative program that promotes safe and supportive homes, schools and communities that protect children, and help traumatized children heal and thrive. HWC was first piloted at Mary C. Snow West Side Elementary School in Charleston, WV in 2013.

An inclusive education or classroom refers to a environment where all students, regardless of any challenges they may have, are placed in age-appropriate general education classes that are in their own neighborhood schools to receive high-quality instruction, interventions, and supports that enable them to meet success in the core curriculum.

The information processing theory is the leading orientation in experimental psychology that focuses on how people select, process, and internalize information and how they use it to make decisions and guide their behavior. 
Piaget's four stages of cognitive development is the theory developed by Jean Piaget in 1936 that suggest children progress through four chronological stages of cognitive development including the sensorimotor stage (newborn to two years old), the preoperational stage (two to seven years old), the concrete-operational stage (seven to twelve years old) and finally the formal-operational stage (twelve years and beyond).

Resilience is the ability to recover from or adjust easily to misfortune or change.

Trauma can include any event that is experienced by an individual as physically or emotionally harmful because the individual perceives their life or the life of a loved one threatened.

Trauma-informed school community refers to the adults in a school community such as administrators, teachers, staff, parents, and law enforcement that are prepared to recognize and respond to those who have been impacted by traumatic stress.

Trauma-related disorders are the group of emotional and behavioral problems that may result from childhood traumatic and stressful experiences. The most prominently discussed traumarelated disorder within this research is post-traumatic stress disorder (PTSD).

Traumatic events can include community violence, domestic violence, sex trafficking, serious medical illness, natural disasters, neglect, physical abuse, displacement and refugee trauma, school violence, sexual abuse, terrorism, loss of a loved one, traumatic grief, or psychological maltreatment.

Visual art is the term that refers to art forms such as painting, drawing, printmaking, sculpture, ceramics, photography, video, filmmaking, design, crafts, and architecture. 
PROMOTING COGNITIVE AND FINE MOTOR DEVELOPMENT

\section{Chapter 1: Introduction}

\section{Statement of the Problem}

Participation in the visual arts has proven to provide individuals of all ages with a range of positive learning outcomes. When discussing cognitive growth and the work of Elliot Eisner, one of the leading professors of arts education, author David A. Sousa states in The Brain and The Arts, "The arts develop cognitive competencies that benefit learners in every aspect of their education and prepare them for the demands of the 21 st century" (as cited in Fischer, K. W. \& Immordino-Yang, 2008, p. 333). Despite the overwhelming research suggesting the affirmative influences of visual arts on individuals (Bolwerk, Mack-Andrick, Lang, Dörfler \& Maihöfner, 2014), art educators and advocates face an uphill battle in defending the implementation and integration of art programs into core curriculums. In West Virginia, the state does not define the arts in statute or code as a core or academic subject. In addition to lack of integration, West Virginia does not require state, district, or school-level assessment of student learning in the arts (Education Commission of the States and Arts Education Partnership, n.d.). Lack of access to a quality and consistent art education not only affects student populations as a whole, but also limits the resources for children who have Adverse Childhood Experiences. Adverse Childhood Experiences (ACEs) is a term that refers to any type of abuse, neglect, and other potentially traumatic experiences that occur to an individual under the age of eighteen ("About Adverse Childhood Experiences", 2019).

With maximum teacher-pupil ratios reaching twenty to twenty-five students to one teacher in a classroom (West Virginia Code, §18-5-18a.), educators cannot always give individual students the attention and care they need, which especially impacts the students exposed to trauma. Additionally, art educators are faced with difficult decisions of how to 


\section{PROMOTING COGNITIVE AND FINE MOTOR DEVELOPMENT}

address the needs of all students in the classroom in a time span of less than an hour. This issue is especially prominent in the elementary school where this research was conducted. Since the population of the school contains over 800 students, children often do not receive consistent or quality time in the art room. In fact, the student body is so large the kindergarten through second grade classes only meet for art class every sixth school day, while the third through fifth grade classes meet every fifth school day. Students are in the art room for a total of forty minutes each class, and the only students who receive extra art class are selected fourth and fifth graders who are chosen to be in the school's art club. This presents a challenge for educators to introduce art lessons that can have a positive impact on students with ACEs.

According to a 2015 report published by the West Virginia Department of Health and Human Resources Bureau for Public Health, data collected from adult residents presents striking evidence about the prevalence of ACEs in the state of West Virginia ("Adverse Childhood Experiences", 2015). In this report, West Virginia adults reported an average of 1.4 ACEs throughout the first 18 years of their lives $(2015, \mathrm{p} .2)$. When discussing the types of ACEs individuals were exposed to, the report states, "The ACE reported most often by West Virginia adults was household substance abuse (28.8\%), followed by separation and divorce $(26.6 \%)$, verbal abuse (22.7\%), mental illness (17.0\%), domestic violence (16.1\%), physical abuse (12.8\%), sexual abuse (10.1\%), and incarceration of a household member (7.7\%)" $(2015, \mathrm{p} .5)$. More importantly, the statistics published by the Child Welfare League of American in 2018 indicate more children in West Virginia are becoming victims of Adverse Childhood Experiences than previous years. This 2018 report stated that 5,938 children were victims of abuse or neglect in 2016, which is a $22.3 \%$ increase of child victims reported in 2015 (West Virginia's Children at a Glance, 2018, p.1). This data indicates the number of children exposed 


\section{PROMOTING COGNITIVE AND FINE MOTOR DEVELOPMENT}

to trauma is not fading but becoming more prominent, which means these adverse experiences will continue to have lasting impacts in West Virginia.

Although the clinical field of art therapy has made vast contributions to the connection between trauma and the healing that can take place when a person participates in the visual arts, there is limited research on the role art education can play in helping reduce risk factors and improve the learning experiences of students exposed to trauma. Children who endure ACEs often acquire emotional, immune, and metabolic abnormalities within their bodies and minds that contribute to an elevated risk of age-related diseases throughout life (Danese et al., 2009). This research investigates how to design specific artmaking activities that promote healthy development of students in the kindergarten through second grade classroom who have been identified as having known exposure to trauma by their school counselor. This research particularly focuses on understanding the positive impact these experiences can have on students' cognitive and fine motor development. Cognitive delays are not always accompanied by motor impairments but research surrounding the cerebellum and prefrontal cortex of the brain suggests, "When there are perturbations, genetic or environmental, that affect the motor system or cognition it is often the case that both motor and cognitive functions are affected, not just one or the other" (Diamond, 2000, p. 50).

\section{Background to the Study}

My interest in working with students who have been exposed to trauma began in June of 2018. I was working at a child development center as an assistant teacher during the summer months. The classroom consisted of children between the ages of five and nine years old. As I began working with this particular group of students, it was brought to my attention that two of the children had experienced traumatic events in their home lives. The likelihood that both 


\section{PROMOTING COGNITIVE AND FINE MOTOR DEVELOPMENT}

students experienced multiple traumatic events seemed high due to the behavior and developmental capabilities they were exhibiting in the classroom. The male student exhibited severe and often violent behaviors while the female student showed signs of cognitive and fine motor impairments. At the time, one student was in the care of his aunt permanently while the other was living with a family in foster care. My observations and interactions with both students over the summer caused me to reevaluate how I approached being an art educator. Ultimately, the experience resulted in my desire to investigate specific instructional approaches in the art classroom that could foster the cognitive and fine motor development of students exposed to trauma.

\section{Research Questions}

The primary question of this research inquires: How can art educators design specific artmaking activities in the kindergarten through second grade classroom that promote cognitive and fine motor development in students exposed to trauma? The secondary question investigates: What role can art education play in supporting these students within trauma-informed school communities?

\section{Significance of the Research}

Dr. Eva Lloyd, a professor of Early Childhood as the University of East London, believes children are like sponges because they constantly absorb the information in their environments and in turn, their brains try to actively make sense of the incoming data (Hunter, 2018). While this fact is normally seen through a positive lens, the fact that children soak up information from surrounding stimuli (Polloni, 2019) means they also absorb negative experiences from the world around them. A major source of the information they receive from birth comes from the adults in their lives such as their parents, guardians, care takers, and siblings (Polloni, 2019). As they 


\section{PROMOTING COGNITIVE AND FINE MOTOR DEVELOPMENT}

grow older and enter school, they begin to learn from their teachers, school personnel, and peers as well. Positive interactions and experiences with adults can provide children with a solid foundation for development. However, if a child has adverse experiences with surrounding adults, their foundation can severely falter beneath them. Especially in young adolescence, children often acquire observed habits and behaviors without even understanding a sense of what is right or wrong. In fact, neuroscientists claim, early environments that house inadequate or inappropriate social and emotional experiences can compromise the neural systems within the body that influence a child's ability to bond, imitate and respond in future social situations (Cynader and Frost, 2000). When children experience abuse, neglect, economic hardships, or other troubling circumstances, it can severely impact the way they perceive the world and develop. Moreover, research conducted at the McLean Hospital in Belmont, Massachusetts suggests, children who experience maltreatment and psychological abuse early in life will most likely experience enduring negative changes to their brain development (Teicher, 2000). These experiences can have severe and long-term consequences on a child's health and well-being. This can happen by causing high levels of toxic stress in the mind and body that disrupt healthy physical, social, emotional, and cognitive development. (Westby, 2018, p.1).

Statistics surrounding the prevalence of childhood trauma and the negative impacts these experiences can have on young children paint a severe picture about human experience in the 21 st century. A report published by the Substance Abuse and Mental Health Services Administration (SAMHSA) in 2011 states that sixty percent of adults have reported experiencing abuse or other troubling family circumstances during childhood. The SAMHSA also reported that twenty-six percent of children in the United States will witness or experience a traumatic event before they reach the age of four years old (National Center for Mental Health Promotion 


\section{PROMOTING COGNITIVE AND FINE MOTOR DEVELOPMENT}

and Youth Violence Prevention, n.d.). Even further, as the prevalence of ACEs increases to five or more incidences in the first three years of life, so does the likelihood of a child suffering from one or more delays in language, emotional, or brain development. (Substance Abuse and Mental Health Services Administration, n.d.).

If children do not grow up in a nurturing or safe home environment, they can still receive the help they need at school to lessen the chance of negative outcomes due to childhood trauma. In fact, school districts have increasingly implemented trauma-sensitive programs and training to help lessen the impact of trauma on children. The West Virginia program Handle with Care was first piloted in Charleston, WV in 2013 and has since spread across the state. The program includes training educators and school personnel on the impact of trauma and can include solutions such as sending students to the clinic to rest, re-teaching lessons, postponing assignments, offering counseling, and ensuring access to advocacy programs. (Handle with Care, n.d.). Although these trauma informed programs do not seem to incorporate artmaking activities into this list, early interventions to improve development stunted by traumatic experiences could be addressed through specially planned art lessons and one-on-one artmaking experiences with the school's art educator.

Although the case studies presented in this research focus on developing cognitive and fine motor development through an intentionally designed art lesson, the results of this study could be translated into other developmental areas such as language, emotional, behavioral, and social growth. As more literature and research progresses in the field of art education, art teachers can learn how to directly target the developmental needs of students in the classroom and can better promote positive learning experiences for all students.

\section{Methodology}




\section{PROMOTING COGNITIVE AND FINE MOTOR DEVELOPMENT}

This research project analyzed content found in literature and available data surrounding art education and children exposed to trauma, field notes of in-class observations, informal student and school counselor interviews, and photographs documenting the progress of participants' artwork. The information collected through in-class observations, interviews and photographs represent the qualitative data of this research and are supported by the data found in the literature review section.

The participants in this study were recruited during the student teaching field experience of the researcher. Written permission to conduct research was obtained by the school's principal and parental cover letters and consent forms were collected before any research was conducted in the classroom. Once participants were enrolled, the art lesson was taught to all of the students within the classroom. Interviews with the school guidance counselor helped identify students who had known exposure to trauma and provided essential information surrounding their situations outside of school. Since the lesson took place in the general art education classroom, all students created the portraits, but no photographs, interviews, or observations were taken from nonconsenting individuals.

To begin the project, the researcher read aloud the book titled When Pigasso Met Mootisse, written by Nina Laden, published in 1998. This reading was followed by a game created to help students identify visual elements from the book. The game consisted of visual references to the paintings created by the characters Pigasso and Mootisse in the book. Students participated by responding to the pictures with a "moo" or an "oink" to signify whether Pigasso or Mootisse painted the image. Students were then asked to explain their responses. The class was then instructed to create two portraits of either Pigasso or Mootisse using the visual elements demonstrated by each painter in the book. The medium of the portraits were differentiated based 


\section{PROMOTING COGNITIVE AND FINE MOTOR DEVELOPMENT}

on grade level as well as student abilities within each class. The kindergarten students drew their portraits; first grade students had the choice of using drawing or collage; second grade students created portraits using collage. Students were given cut out shapes and shape guide sheets so they could trace and replicate the shapes from the book. As student projects progressed, observations into student behaviors and artistic abilities were made. Data was collected from both whole class and individual interactions with students during this time and at the completion of the lesson.

Exploratory case studies of this data have been created for each grade level that contains students who have known exposure to trauma and describes the background information of identified students, grade level results, and comparisons between individual students. The case studies include information about the students' known traumatic experiences or situations, photographs of them working throughout the project and their final artworks, and conclusions surrounding the collected data.

\section{Participants}

This research consisted of 218 kindergarten through second grade students. All participants live in the rural city of Morgantown, West Virginia. Although Morgantown is a relatively high socio-economic community, $21 \%$ of students at this elementary school receive free or reduced lunch and about $8 \%$ of residents in the area live below the poverty line (Cheat Lake, WV, n.d.). Two kindergarten students, three first grade students, and three second grade students were identified by the guidance counselor as having known Adverse Childhood Experiences outside of school. This research consists of three case studies. The students have been gathered into case studies for each grade level and will discuss the observations and artworks of the participants. 


\section{PROMOTING COGNITIVE AND FINE MOTOR DEVELOPMENT}

\section{Limitations}

A significant limitation to this research was the time frame in which students completed their artwork. Due to the researcher's student teaching field experience taking place in the winter and early spring months, several school days were delayed or cancelled because of inclement weather. Thus, there were several interruptions to the rotating related arts schedule. On school days with two-hour delay, students only attended art class for thirty minutes rather than forty minutes. Since there were significant breaks between art classes in some weeks, one can argue the students did not receive consistent or enough time with their artmaking experiences to fully benefit their development. While the always shifting schedules of school communities present limitations for this research, it does also represent the reality of teaching art education or any related arts subjects.

Another limitation to this research included generalizability of results from each case study. Since there were only eight students identified with known exposure to trauma, it is impossible to make overarching conclusions about all traumatized children and their experiences in the art classroom. Additionally, limited background information was obtained about the trauma exposed participants and no background information was obtained about children who have not been identified with exposure to trauma by the school counselor. Thus, student deficiencies found in this study could come from multiple factors other than exposure to trauma, such as learning disabilities and school readiness, making it difficult to make conclusions about non-identified students' performance, behaviors, and developmental abilities in the classroom. The conclusions that resulted from each case study explains the phenomenon that took place within this specific classroom and more research must be conducted in order to make generalized statements about all children with trauma exposure in the art room. The researcher's statements 
PROMOTING COGNITIVE AND FINE MOTOR DEVELOPMENT

are based on her specific experiences within this study and her goal is to provide this study as a resource to help other art educators tailor their lessons to meet the needs of trauma exposed students in the future.

\section{Summary}

Lessons created by an art educator can be tailored to support the varying developmental needs of all students and can greatly impact their learning experiences. As school communities continue to implement individual, class and whole school trauma-informed strategies, it is important to consider the possibilities artmaking experiences can particularly offer students who have experienced trauma. If students who have had detrimental ACEs receive early interventions, severe outcomes such as cognitive and fine motor impairment could be lessened. All children, including those effected by trauma, deserve to have consistent access to artmaking experiences tailored to their needs. The purpose of the research conducted is to support this argument and further contribute to the promotion of integrated art education programs into trauma-informed school communities. 
PROMOTING COGNITIVE AND FINE MOTOR DEVELOPMENT

\section{Chapter 2: Literature Review}

\section{Introduction}

This chapter presents a literature review that offers a background for understanding the normal developmental milestones of children between the ages of five and seven years old and the impact trauma can have on these milestones. First, the literature focuses on explaining three approaches to development and the normal growth that takes place in students before they reach school age, specifically between their kindergarten and second grade years. The three approaches addressed include brain, cognitive, and fine motor development. Following this discussion, the literature presents information about the impact of trauma on young students' normal development and how it affects their ability to learn in the classroom. Finally, this chapter describes the trauma informed program called Handle with Care that has been set in motion to combat the impact of trauma for students in West Virginia. The end of this review reflects on the gap in literature between the benefits of a trauma-informed school community and an education that embraces the arts. Artmaking activities in the classroom do not only hold value to students in general but could provide positive outcomes for students who have experienced trauma if incorporated into trauma-informed school interventions (Durham, 2016).

\section{Brain Development}

A neurological approach to understanding how the human brain develops is extremely relevant to this research because it gives elementary educators a foundation for understanding the normal development a child's brain goes through before they begin learning in the classroom. Although not required, basic comprehension of the changes that occur in the brain during early childhood can help an educator establish solid ground to build upon for specific lessons that foster growth in certain developmental areas. Understanding how to promote a child's learning 


\section{PROMOTING COGNITIVE AND FINE MOTOR DEVELOPMENT}

begins with considering the development the student has already undergone and what has not yet developed within their brain. The dynamic progression of brain development is still one of the most captivating aspects of the human condition and can have a lasting impact on a young child's ability to learn and succeed in the future (Toga, Thompson, \& Sowell, 2006). Within the perspective of cognitive science, Joan Stiles and Terry L. Jernigan (2010) suggest, "The processes that contribute to brain development range from the molecular events of gene expression to environmental input. Critically, these very different levels and kinds of processes interact to support the ongoing series of events that define brain development" (p.328). Thus, the development that takes place before birth and in infancy as well as the environment a child grows up in, significantly determines whether or not the brain develops in a healthy manner.

Although the brain already contains most of the neurons it will ever possess in a lifetime at birth, these cells are not yet connected to any networks (National Institute of Neurological Disorders and Stroke, 2019). Brain connections enable humans to move, think and communicate, which is why establishing and strengthening network connections are the key tasks of early brain development (Shore, 1997). The initial phases of brain growth begin while a fetus is maturing inside its mother's womb and dramatically takes shape during early childhood (Toga et al., 2006). At birth, neurons in the brain and spinal cord are housed in dark tissue called gray matter, which is especially abundant in the cerebellum, cerebrum, and stem of the brain (Villines, 2015). Gray matter is mostly housed along the outside layer of the brain and aids in the processing of information (Robertson, 2018). Additionally, white matter is housed within the inner layer of the brain (2018). While gray matter is responsible for the brain's ability to think and calculate, white matter is responsible for controlling signals shared between neurons, which ultimately allows the brain regions to coordinate and work together (Fields, 2008, p. 54) Specifically, white matter is 


\section{PROMOTING COGNITIVE AND FINE MOTOR DEVELOPMENT}

composed of axons insulated with myelin (Filley, 2003, p. 992). Millions of myelinated fibers gradually connect and combine to form the tracts that travel within the brain and between the right and left hemisphere (Filley, p. 992). The myelination of axons is a very critical stage of development and plays an important role in normal brain function (Filley, p. 992)

White matter begins to develop during the third trimester of pregnancy and reaches its most rapid growth period in the first two years of life (Larsen \& Stensaas, 2019). In addition to the production of white matter, around two to three years old, the brain reaches its peak of synaptic growth and begins to undergo a process called selective synaptic pruning of gray matter, which means this tissue dies off as it is no longer needed to make room for the developing white matter (Gill, 2018). When studying white matter development in the brain Barnea-Goraly and colleagues (2005) concluded, "Maturation of white matter pathways is an important factor in cognitive, behavioral, emotional and motor development during childhood and adolescence. (Barnea-Goraly et al., 2005, p.1848). Though a child's brain reaches about $90 \%$ of its adult volume by six years of age, changes in the brain structure continue to take place until adulthood (Brown \& Jernigan, 2012). Specifically, rapid synaptic pruning continues to occur between the ages of two and ten years old, at which point approximately fifty percent of no longer needed synapses are eliminated (Gill, 2018).

The participants of this research range from the ages of five to seven years old, which means their brains have likely already undergone significant structural and functional changes. However, as stated above, the development of white matter and the pruning of gray matter is still swiftly taking place within their brains. Children of this age range are still forming connections in their minds, which greatly influences their cognitive abilities. It is important to understand that young elementary students may have already had life experiences that have significantly altered 
PROMOTING COGNITIVE AND FINE MOTOR DEVELOPMENT

the development of their brains, which will ultimately affect their performance within the classroom.

\section{Cognitive Development}

The two main cognitive perspectives used to develop the framework for this research are Jean Piaget's theory of cognitive development and the field of cognitive psychology's information-processing theory of learning. The two perspectives helped shape an understanding of the cognitive capabilities as well as the educational needs of children in the kindergarten through second grade classroom. Piaget's stages of cognitive development primarily served as a foundation for understanding the basic characteristics and capabilities of kindergarten through second grade students, while the information-processing perspective was used to design the artmaking activities students participated in throughout the project.

\section{Piaget's Theory of Cognitive Development}

At one point in history, humans believed infants and young children simply lacked the ability to think and form complex ideas and did not engage in any cognition until they learned language (Bransford, Cocking, \& Brown, 2000, p. 79) In fact, it is now known that infants and young children have much more complex and sophisticated minds than their physical development allows them to display (Allen \& Kelly, 2015). Jean Piaget was a major contributor to this shift in perspective. Jean Piaget was a 20th century psychologist who conducted extensive research of children in their learning and natural environments (Molnar \& Hertenstein, 2005). He viewed the acquisition of cognitive development as an active process, where the infant, child, and adolescent organize their experiences with their environment, adapt, and try to maintain a sense of balance with old and new knowledge (Lumen Learning, n.d.). As Piaget's work with children and adolescents expanded, he identified four stages of cognitive development he 


\section{PROMOTING COGNITIVE AND FINE MOTOR DEVELOPMENT}

believed all children pass through as they grow older. (Orey, 2010, 37). In each of Piaget's stages, a child demonstrates new cognitive abilities and a progressively more complex understanding of the world around them. (Orey, 2010, p. 37). Developmental psychologist Christina Schonberg describes the four stages as follows: The first stage of development is the sensorimotor stage which begins at birth and ends when a child reaches two years old. The second stage is the preoperational stage and takes place between the ages of two and seven years old. The third stage is the concrete operational stage which takes place between seven and eleven years old. Finally, the fourth stage with the formal operational stage which begins at twelve years old and continues from that age on (Schonberg, 2013).

\section{The Preoperational Stage of Cognitive Development}

The participants in this research are between the ages of five and seven years old. Therefore, the students fall into the tail end of the preoperational stage of cognitive development. During this stage, a child's thinking is limited, and they lack the ability to use logic, transform, combine, or separate ideas (McLeod, 2018). By five years old, a child can sort and name colors, shapes, and numbers (Lumen Learning, n.d.). Children at this age are also learning to make some decisions on their own, such as what wear to school (Lumen Learning, n.d.). When explaining the abilities of preoperational children, Dr. Christopher Dwyer at the National University of Ireland suggests, "Children at this stage acquire the ability to represent objects and events with symbols, but are incapable of logical thought" (Dwyer, 2010, p.5). The preoperational stage is also the time when children start using language as well as develop their memory and imagination (Orey, 2010, p. 38). Due to the development of their imagination they often engage in make believe and dramatic play (Orey, 2010, p. 38). As they develop their symbolic and imaginative thoughts, they enjoy creating elaborate characters while they engage in dramatic 


\section{PROMOTING COGNITIVE AND FINE MOTOR DEVELOPMENT}

play (Lumen Learning, n.d.). To children in this stage, inanimate objects can be alive and have feelings and intentions like human beings (McLeod, 2018). Thus, reading a book that has unusual characters such as animal painters, can actively hold a preoperational child's curiosity and attention as the story develops. Although most children develop at the same rate, it is possible that some show more difficulty with tasks or develop slower than others. Some possible signs of a child struggling to progress through the preoperational stage and in the operational stage may include quick to become frustrated, a seemingly inability to understand, confusion, and unmet curriculum objectives in the classroom (Child Development Network, 2003).

\section{The Critique of Piaget's Theory}

Although Piaget has greatly contributed to understanding children's cognitive development, critics of his theory suggest Piaget neglected the social nature of human development and underestimated the intellectual capabilities of children. (Matusov \& Hayes, 2000, p.215). Specifically, psychologists argue that his four stages of cognitive development only operate within specific age norms and their connections to developmental milestones (Lourenco \& Machado, 1996, p.146) However, these claims failed to see age as an indicator rather than a criterion within the Piagetian framework (Lourenco \& Machado, 1996, p.147). What Piaget claimed and what this research aims to prove is that the previous experiences of individuals has immense effects on the stages of development a child undergoes (Lourenco \& Machado, 1996, p.147). Within the case studies presented in this research, Piaget's theory was used as a theoretical foundation for understanding the general stage of cognitive development kindergarten through second grade students belong to and the capabilities they possess. Children within each grade level did in fact exhibit an array of abilities and arguably, some students in the second grade were exiting the preoperational stage more rapidly than their peers. 


\section{PROMOTING COGNITIVE AND FINE MOTOR DEVELOPMENT}

\section{The Information Processing Theory of Learning}

The information processing theory is based on the cumulative ideas and research of cognitive scientists and psychologists who studied how humans perceive, analyze, manipulate, use, and remember information. (Lally \& Valentine-French, 2019, p.21). When explaining the information processing theory within the book entitled Lifespan Development, authors Dr. Martha Lally, Instructor of Psychology at the College of Lake County and Suzanne ValentineFrench, Instructor of Psychology at the College of Lake County state:

We are born with the ability to notice stimuli, store, and retrieve information. Brain maturation enables advancements in our information processing system. At the same time, interactions with the environment also aid in our development of more effective strategies for processing information (p.21).

The most widely accepted theory of how information is stored in memory is based on the work of Dr. Richard Atkinson and Dr. Richard Shriffin (1968). The Atkinson-Shiffrin memory model developed while both were at Stanford University proposes that humans store information in three stages; the sensory register, short-term or working memory, and finally long-term memory (Huitt \& Hummel, 2003, p.6-9). The human brain constantly notices stimuli through the senses (Gaines Lewis, 2015). However, it is impossible for all of the incoming information a person sees, hears, smells, touches, or tastes to be stored in short-term memory (McLeod, 2017). The brain relies on the sensory register to notice and sort through potentially important data and only registers information that is actively paid attention to (Huitt \& Hummel, 2003, p.6). The information that was paid attention to is retained and manipulated within short-term memory, which has the capacity to hold usually five to nine pieces of information for a duration of about thirty seconds (McLeod, 2009). In order for information to be sent into long-term memory 


\section{PROMOTING COGNITIVE AND FINE MOTOR DEVELOPMENT}

storage, it must be processed, practiced, and manipulated. (Huitt \& Hummel, 2003, p.7). When discussing the purpose of long-term memory in Lifespan Development in Context, Dr. Tara Kuther, professor of psychology at Western Connecticut State University, indicates, "Long-term memory is an unlimited store that holds information indefinitely. Information is not manipulated or processed in long-term memory; it is simply stored until it is retrieved to manipulate in working memory" (Kuther, 2019, p.240).

There are several strategies that help a student transfer information into long-term memory. However, to create lessons that promote cognitive development and the storing of important information in long-term memory, this research focused on the strategies of Elaborative Rehearsal, Retrieval Practice, and Priming. Elaborative Rehearsal strategies refer to the active process of expanding on incoming information by relating it to already learned information in an in-depth way (Thorne, 2003; Heerema, 2019). Retrieval Practice is when a student engages in an activity in the classroom that requires them to access information that has already been stored in their long-term memory (Thorne, 2003). Finally, Priming refers to exposing students to the information they are expected to process throughout a lesson before they actually begin processing and learning the information (Thorne, 2003). Each of the memory strategies explained formed the framework for developing the art lesson of this research and will be expanded upon within the later methodology chapter.

A child's memory steadily improves between four and ten years old, but it improves at an especially accelerated rate between the ages of five and seven (Kuther, 2019, p. 250). In fact, when describing the information processing abilities of school-aged children Dr. Tara Kuther states, "they are better able to determine what information is important, attend to it, and use their understanding of how memory works to choose among strategies to retain information more 
PROMOTING COGNITIVE AND FINE MOTOR DEVELOPMENT

effectively" (Kuther, 2019 p. 244). Although children at this age can better attend to incoming information, other capabilities such as paying attention for longer periods of time continue to develop throughout middle childhood (Oswalt Morelli, n.d.)

\section{Fine Motor Development}

Before creating art lessons that directly benefit the fine motor development of children between the ages of five and seven, one must first be aware of the developmental milestones these children should be exhibiting in the kindergarten through second grade classroom. Fine motor skills refer to a child's ability to use small muscles in the hands and fingers as well as the strength of their visual and cognitive skills (Crawford \& Weber, 2013, p. 99). Motor development is one of the quickest forms of development that take place in the early years of a child's life (Hurlock, 1956, p.136)

However, an important point to be made in the context of all this research is that children who do not meet developmental milestones at the same time as others does not necessarily indicate there is an issue to be concerned about (Morin, 2015). Children develop at different rates and it is not always due to exposure to trauma or an underlying disorder not yet diagnosed. A developmental delay is often complicated and refers to a child continually falling behind and not gaining the skills they are expected to at a given age (Morin, 2015). Some signs that may indicate developmental delays or disabilities with fine motor skills can include, shaky movements, weak arms and hands, an inability to cut along a straight line with scissors and/or an inability to draw simple geometric shapes ("Preschool Developmental Milestones", 2011).

According to psychotherapist May Morin, five-year-old children are moving away from their years as toddlers and are growing quickly in all developmental areas (Morin, 2019). By five to six years of age, most children can copy numbers, shapes, simple words, and geometric shapes 


\section{PROMOTING COGNITIVE AND FINE MOTOR DEVELOPMENT}

as well as cut along a line with scissors (Kuther, 2016, p. 6). Artmaking activities that involve using scissors and collaging can help strengthen the muscles in the hands and fingers, which ultimately promotes fine motor skill development (Gruetman, 2017, p. 48). At five years old, a child who is developing normally in their fine motor skills can also draw recognizable human features and figures and show rapid improvement in these abilities until they reach the age of seven (Hurlock, 1956, p.153). It is important for educators to understand that children around this age have small fingers that have not fully developed and cortical areas in the brain that have not yet fully myelinated (Snaidero, N. \& Simons, M., 2014, p. 3000). Therefore, while children at this age can cut out increasingly more complex shapes with practice, they can still become very frustrated with the task even with expected development (Kuther, 2016, p.7). During this time children are also rapidly developing more intricate motor processes such as movement control and visuomotor coordination (Wassenberg et al., 2005, p. 1093; Ferrel-Chapus, Hay, Oliver, Bard, \& Fleury, 2002), which allows children to perform more complex fine motor functions as they grow older.

Fine motor skills are an area of development that requires extensive practice (Hurlock, 1956, p. 151). When children are given opportunities to develop their fine motor skills, they gain the tools they need to not only explore and interact within their environment, but to also become independent in daily and self-care activities. (Hoffman, 2012).

\section{The Impact of Trauma on Child Development}

"Trauma by nature drives us to the edge of comprehension"

-Van Der Kolk, The Body Keeps the Score, 2015.

Adverse Childhood Experiences and the serious consequences that follow are a critical issue for the victims involved and society as a whole. Although the complex implications of trauma on children are still being uncovered, significant leaps in research have already aided in 


\section{PROMOTING COGNITIVE AND FINE MOTOR DEVELOPMENT}

the awareness of how the brain changes and how it affects the victim's ability to thrive in life. This section of the literature review focuses on explaining what happens to the structure and tasks of the brain when an individual has traumatic experiences and how it affects one's cognitive and fine motor functioning. Since the 1970's, clinicians have worked towards publishing a diagnosis that could encompass all of the symptoms trauma exposure can rally (Sykes Wylie, 2010). However, the landmark CDC-Kaiser Permanente ACE study which took place between 1995 and 1997, was the first to successfully track and publish the relationship between traumatic childhood experiences and the well-being of individuals in later life. (Sykes Wylie, 2010; “Adverse Childhood Experiences", 2013). Particularly, the ACE study results showed a direct correlation between adverse childhood experiences and "a remarkably large proportion of all the physical, mental, and social ills that beset society" (2010, p.25).

\section{The Brain}

The early life experiences of a child shape the development of brain circuitry and play a significant role in determining the nature of an individual's intelligence, emotions and even personality (Child Welfare Information Gateway, 2017, p.2). When children feel safe and nurtured, their brains are free to develop normally. However, a bulletin published by the Child Welfare Information Gate in 2017 stated, "When children feel unsafe or threatened, their brains shift into survival mode, making learning particularly difficult" (Child Welfare Information Gateway, 2017, p.2). In fact, developmental psychopathology researchers from the ACE study found that "abuse also disrupts the neuroendocrine system, altering the production of the stressregulating hormone cortisol and neurotransmitters like epinephrine, dopamine, and serotoninchemicals affecting mood and behavior" (Sykes Wylie, 2010, p. 25). Since the original ACE study was published, researchers who focus on the neurobiological effects of childhood trauma 


\section{PROMOTING COGNITIVE AND FINE MOTOR DEVELOPMENT}

have tried to understand the exact structural and functional changes the brain undergoes during adverse experiences (Mclaughlin, Sheridan, \& Lambert, 2014). Adverse experiences such as maltreatment and neglect have since been associated with abnormalities in different brain areas. This section focuses on explaining areas of the brain such as the prefrontal cortex, amygdala, hippocampus, and corpus callosum that are susceptible to change when traumatic experiences occur (De Bellis, 2005).

Located in the frontal lobe, the prefrontal cortex (PFC) is vitally connected to a person's ability to reason and think logically (Davis, 2018). The PFC is highly sensitive to stress and when a child's body is continuously flooded with stress hormones caused by adverse experiences, this portion of the brain may experience smaller volumes in size and lower amounts of white matter (Davis, 2018; Bick \& Nelson, 2016). Referring to white matter, children who have been neglected have shown a delayed myelination of axons in their brains, which resulted in loss of executive function capacities and self-regulatory behaviors (De Bellis, 2005). Thus, significantly impacting a child's emerging “complex emotional and cognitive functions, including attention, executive function, and self-regulatory abilities" (Bick \& Nelson, p.9).

The limbic system houses both the amygdala and hippocampus structures of the brain (Davis, 2018) The amygdala is responsible for the regulation of emotions and the memory of fear. If a person encounters a fearful situation, the amygdala is the first part of the brain activated to perceive and react to the danger they are facing (2018). When discussing the activation of the amygdala in The Body Keeps the Score, Dr. Bessel van der Kolk, M.D., founder and medical director of the Trauma Center in Brookline, Massachusetts and professor of psychiatry at Boston University School of Medicine notes, "We depend on the amygdala to warn us of impending danger and to activate the body's stress response" (van der Kolk, 2015, p.42). Dr. Van der Kolk 


\section{PROMOTING COGNITIVE AND FINE MOTOR DEVELOPMENT}

later refers to the amygdala as the body's smoke detector, "while the smoke detector is usually pretty good at picking up danger clues, trauma increases the risk of misinterpreting whether a situation is dangerous or safe" (van der Kolk, pp.61-62). Childhood trauma can cause the amygdala to become enlarged and more reactive, which can lead to the development of traumarelated psychiatric and anxiety disorders (as cited in Hoon Oh, 2012, pp.326-327; Echo, 2018). Since it is so pertinent in developing the perception of fear and danger, a child with a hyperactive amygdala may become incapable of appropriately reacting to the stimuli in their environment (Wlassoff, 2015).

Another portion of the limbic system known as the hippocampus is a critical structure responsible for retrieving information and memories as well as creating contextual representations of information in the brain. (Preston \& Eichenbaum, 2013). Research on the long-term effects of childhood maltreatment have found smaller hippocampal volumes in trauma exposed participants between the ages of 6 and 18 years old (McLaughlin, Sheridan, Gold et al., 2015). Additionally, studies on adults who suffer from PTSD (Bremner, Randall, Vermetten, et al., 1997) and unipolar major depressive disorder (Vythlingam, Heim, Newport, et al., 2002) with histories of early life trauma have found reduced left hippocampal volumes in participants. When researching the hippocampal activity of adolescents between the ages of 10 and 17, Dr. Victor G. Carrion, MD, who teaches in the Psychiatry and Child Development at Stanford University, discovered that participants who displayed posttraumatic stress symptoms (PTSS) due to interpersonal trauma exhibited reduced activation in the right hippocampus during memory retrieval tasks. Thus, if an individual's hippocampus does not reach its fullest capacity, they may have difficulty learning new information and forming memories. In fact, research conducted by Dr. Endel Tulving, Dr. Daniel Schacter, and Dr. Heather A. Stark (1982) found 


\section{PROMOTING COGNITIVE AND FINE MOTOR DEVELOPMENT}

that traumatic or unwanted memories can become "stuck" in a child's body and remain difficult to manage, causing them to suffer from ongoing fear, anger or states of unease (as cited in Miller-Karas, 2015, p. 71).

Finally, the corpus callosum is responsible for connecting the left and right hemispheres of the brain. Similar to the prefrontal cortex and hippocampus, research using neuroimaging has found reduced corpus callosum volumes in individuals who have histories of childhood maltreatment (Hart \& Rubia, 2012). Therefore, a reduction in volume can lessen the connections and communication that occurs between the two hemispheres, causing issues in motor movements and cognitive functions (Musiek, 1986).

Duke Professor Dr. Michael De Bellis MD and Abigail Zisk A.B. specifically highlight the severity of trauma by stating, "Experiencing trauma during development along with dysregulation of biological stress systems can adversely impact childhood brain development" (De Bellis \& Zisk, 2014, p.3) The common factors that adversely affect early brain development appear to be the events and conditions in which the child experiences or repeatedly experiences, in a prolonged and uncontrolled manner, circumstances they perceive as significantly life threatening (Delima \& Vimpani, 2011).

\section{Cognitive Functions}

Research on the effects of early trauma on cognitive function demonstrates that early traumatic experiences are associated with adverse cognitive development because of the changes that occur while the brain is still developing (De Bellis \& Zisk, 2014, p. 23). A study conducted by Dr. De Bellis and colleagues (2009) used standardized tests to investigate the neurocognitive functioning in neglected children. This study compared neglected children who did and did not suffer from Post-Traumatic Stress Disorder (PTSD) to a controlled group of non-traumatized 


\section{PROMOTING COGNITIVE AND FINE MOTOR DEVELOPMENT}

children (De Bellis et al., 2009). Regardless of whether or not a participant was diagnosed with PTSD, neglected children scored significantly lower on intelligence quotient (IQ) than the control group and had significant ranges in cognitive functions such as language, memory and executive functioning (De Bellis et al., 2009). Similar results emerged from research pertaining to orphans. When discussing the intellectual performance of children who experienced early life stress, Dr Pia Pechtel at the University of Exeter in the UK and Harvard Professor of Psychiatry Dr. Diego A. Pizzagalli MD indicated, "Children who spent the first part of life in institutionalized care showed decreased intellectual performance, language difficulties, poorer cognitive abilities, and impaired psychomotor development compared to never institutionalized children" (Pechtel \& Pizzagalli, 2010, p.59; Cohen et al. 2008; Loman et al. 2009; Rutter \& O’Connor, 2004).

\section{Fine Motor Functions}

Just like cognition, fine motor functions are crucial to a child's development. Fine motor skills are extremely necessary for an individual's ability to perform daily self-care tasks such as getting dressed, brushing teeth, bathing, and toileting (Majute, 2018). They are also strong predictors of academic achievement and school readiness for young students (Cameron, Brock, Murrah, et al., 2012). While researching the contributing factors of kindergarten achievement, Dr. Claire E. Cameron PhD, Associate Professor of Learning and Instruction at the University at Buffalo and colleagues found that children who lack satisfactory fine motor skills are more likely to suffer in other academic areas (Cameron, Brock, Murrah, et al., 2012).

Children who come from lower socioeconomic families may especially be at risk for experiencing delays in their fine motor development (Marr, Cermak, Cohn, \& Henderson, 2003). In a national study conducted by the U.S. Department of Education (1998) involving 22,000 


\section{PROMOTING COGNITIVE AND FINE MOTOR DEVELOPMENT}

kindergarten students, data results revealed that $44 \%$ of children whose families utilized federal assistance programs scored at least one standard deviation below the mean in fine motor skills (Marr, Cermak, Cohn, \& Henderson, 2003, p. 552; West, Denton, \& Germino-Hausken, 2000). Living in poverty or low socioeconomic conditions does not necessarily indicate the presence of ACEs (Poverty and Adverse Childhood Experiences, 2018). However, children living in poverty may be at greater risk of accumulating ACEs because of factors such as parental distress and parental exposure to ACEs (Hughes \& Tucker, 2018; Woods-Jaeger, Cho, Sexton, et al., 2018) The combination of economic hardship and ACEs makes it extremely difficult for families to provide children with the nurturing and safe environments needed for healthy development (Woods-Jaeger, Cho, Sexton, et al., 2018)

According to a study that determined the relationship between maternal and paternal exposures to ACEs and the impact they have on offspring development, as the number of ACEs increase for mothers and fathers, there is a significant increased risk in possible developmental delays in their children (Folger, Eismann, \& Stephenson, 2018). More specifically, a higher number of maternal ACEs was linked to an increased chance of their child having suspected motor, social, and communicative delays (Folger et al., 2018). Thus, ACEs do not only affect an individual as a child, but the implications of these experiences can also be passed along to future generations. Additionally, since all structures within the brain connect to each other during development, motor and cognitive abilities can be simultaneously affected by adverse experiences. In fact, when studying the connection between motor and cognitive development in the prefrontal cortex and the cerebellum, Adele Diamond PhD Professor of Developmental Cognitive Neuroscience at the University of British Columbia, has indicated the two functions may be more fundamentally intertwined than originally realized (Diamond, 2000, pp.44-50). She 


\section{PROMOTING COGNITIVE AND FINE MOTOR DEVELOPMENT}

contended, "Developmental psychologists tend to focus on the protracted developmental progression in cognitive achievements, often forgetting that motor development is equally protracted." (2000, p.50). Diamond concluded her research findings by indicating, "When there are perturbations, genetic or environmental, that affect the motor system or cognition it is often the case that both motor and cognitive functions are affected not just one or the other" (Diamond, 2000, p. 50). For instance, the cerebellum, which is a structure located behind the top part of the brain stem, is responsible for a person's fine motor movement, balance, coordination as well as cognitive functions and decision-making abilities (Cherry, 2019; De Bellis \& Zisk, 2014, p.17). Similar to the changes that take place in the prefrontal cortex, the hippocampus, and the corpus callosum, smaller cerebellum volumes have been linked to consistent traumatic experiences (De Bellis \& Zisk, 2014, p.17).

\section{Children in the Classroom}

A study conducted in Spokane, WA in 2010 studied the influence of trauma exposure on children's ability to succeed in school (Blodgett \& Lanigan, 2018). The results of this research found that children who were identified as having three or more ACEs were extremely susceptible to academic failure, attendance problems, behavior issues, and poor health compared to children with no known ACEs (Blodgett \& Lanigan, 2018, p. 141). As stated previously, children with ACEs have such a high risk of educational and health issues because they endure prolonged activation of stress response systems in their bodies that derail healthy brain development (Center on the Developing Child, Toxic Stress, 2017). Thus, understanding how high levels of stress affect a child with trauma exposure can give thorough insight into why a child struggles in a classroom environment. 


\section{PROMOTING COGNITIVE AND FINE MOTOR DEVELOPMENT}

Severe behaviors can result from exposure to chronically stressful situations such anxiety, hostility, suicidal tendencies and impaired self-regulation (De Bellis, 2001). Even more so, neurobiological research conducted by the Children's Bureau suggests “trauma-induced changes to the brain can result in varying degrees of cognitive impairment and emotional dysregulation that can lead to difficulty with attention and focus, learning disabilities, low self-esteem, impaired social skills, and sleep disturbances" (Child Welfare Information Gateway, 2017). When a child is struggling to stay awake or concentrate in school, their ability to learn suffers immensely. Since it is necessary for students to pay attention to incoming information in order to store it in their memory and learn (Huitt \& Hummel, 2003), adequate sleep and concentration is the key to success in any classroom (Sleep, Learning, and Memory, 2007).

Another important factor in determining a student's ability to succeed in the classroom is the relationship they have with their teachers. Since students are only in the art room about once a week, it can be very difficult for them to form a high-quality and trusting relationship with their art teacher. It can be especially difficult in schools such as the one this research was conducted in because of the large student population and only one art educator in the entire school. A highquality relationship between a student and a teacher can greatly impact a child's working memory and their ability to persist in school (de Wilde, Koot, \& Van Lier, 2016). Additionally, studies have shown that positive relationships with teachers can help students feel safer at school, improve self-esteem and well-being, become more engaged in learning, and stray away from risky behaviors such as substance abuse (Committee for Children, 2012). Thus, a positive and strong teacher-student relationship can powerfully affect students with ACEs. Robertson (2018) claims this connection is so crucial because, "for ACEs students, the teacher-student relationship can disrupt the pervasive alienation of trauma and abuse while providing the 
PROMOTING COGNITIVE AND FINE MOTOR DEVELOPMENT

emotional nutrients necessary for these young people to develop healthy coping mechanisms" (Romero, Robertson, \& Warner, 2018, p. 81)

\section{Trauma-Informed School Communities}

The purpose of education in the United States has historically evolved depending on the needs of society (Sloan, 2012). As society and developing research continues to shed light on the prevalence and consequences of adverse childhood experiences, it is necessary that schools evolve to fit the needs of affected students. Although the overarching mission of schools is usually to support students' learning and educational achievement, they must now expand these concepts to include the recognition of students' personal experiences and how their experiences affect their ability to learn (National Child Traumatic Stress Network, 2017, p. 1). A report published in 2016 found communities with higher prevalence of ACEs also experience higher rates of student suspensions and unexcused absences, as well as lower high school graduation rates than communities with moderately low prevalence of ACEs (National Child Traumatic Stress Network, 2017, p. 1; Blodgett, C. \& Dorado, J., 2016). Regardless of the type of adversity a child may experience, having established trauma-informed support systems in schools can offer a wide variety of resources to help students exposed to ACEs heal. By cultivating a school community that understands the educational impacts of trauma, students can experience a safe and supportive learning environment that gives them the freedom to make positive connections with adults and their peers (Cole, Greenwald O’Brien, Gadd, et al., 2005). To create this type of learning environment, Meg Walkley MSW/PPSC and Tory L. Cox, LCSW/PPS, Clinical Assistant Professor at the University of Southern California, believe school communities must work together to gain a trauma-informed perspective to education and implement interventions that productively aid in the healing process (Walkley \& Cox, 2013). They argue that without the 
PROMOTING COGNITIVE AND FINE MOTOR DEVELOPMENT

presence of trauma-informed school programs, students affected by ACEs are at risk of being mislabeled with behavioral or attention disorders. On top of being misdiagnosed, they may not receive the effective interventions needed to help them develop healthier behaviors and heal from trauma (Walkley \& Cox, 2013).

\section{Handle with Care}

The state of West Virginia has made crucial efforts to establish this type of traumainformed care into its school communities. The Handle with Care (HWC) program was first piloted in Charleston, West Virginia in 2013 and focuses on promoting safe environments at home, school, and in the community that allow trauma-exposed students to heal and thrive (Bray, 2016). The goals of HWC are threefold. First, the HWC program aspires to prevent children's exposure to ACEs. Secondly, it aims to diminish the damaging effects of trauma exposure. Finally, it works to spread knowledge and awareness of the issue (Handle with Care, n.d.).

The program starts with law enforcement. When police officers respond to calls, they are trained to identify children who may have been involved or affected by traumatic incidents on scene. Within 24 hours, the child's school receives a confidential "handle with care" notice. This notice does not disclose any details about the experiences the child faced, but rather informs the school that the student may need extra attention or interventions throughout the school day (Bray, 2015). All school personnel within the HWC program, from administrators and teachers to bus drivers and cafeteria staff, receive trauma-informed training and work together to help affected students feel safe. HWC programs have implemented a wide variety of interventions for students such as counseling sessions, quiet and private resting spaces, postponing assignments, re-teaching lessons, adult mentors, and therapy animals (Handle with Care, n.d.). Although these interventions cover several areas of care, there seems to be a missing link between the benefits of 


\section{PROMOTING COGNITIVE AND FINE MOTOR DEVELOPMENT}

art education and the benefits of trauma-informed care. Artmaking activities not only help reduce stress (Romero, Robertson, \& Warner, 2018, p. 83), but they can also promote growth in developmental areas that may have been impaired due to prolonged exposure to adverse experiences. Trauma exposed students should receive opportunities to not only attend consistent and frequent art classes with their peers, but to also spend one-on-one time with their art educator if they wish to do so. This research seeks to demonstrate the developmental qualities artmaking activities can have for young students as well as advocate for the integration of these interventions into trauma-informed school communities.

\section{Impact of Art Education on Young Students}

Early interventions are necessary for young students to help lessen the negative consequences trauma evokes on brain development. Children can still survive and in many instances thrive despite the adverse experiences they have suffered throughout their young lives (American Academy of Pediatrics, 2014). When protective measures are taken in schools to offset the consequences of ACEs, a child has the potential to rise through resilience (American Academy of Pediatrics, 2014). Resilience is the ability to adapt to and overcome hardships experienced throughout life (Center on the Developing Child, Resilience, 2017). When discussing resilience and trauma, Elaine Miller-Karas, LCSW, executive director and co-founder of the Trauma Resource Institute, writes in her book Building Resilience to Trauma: The Trauma and Community Resiliency Model, "As adverse events can reorganize brain functioning to respond in maladaptive ways, building resiliency in a child can 'remodel' the brain to respond in more adaptive ways, and this remodeling can endure into adulthood" (as cited in Miller-Karas, 2015, pp.66-67). As stated previously, positive teacher-student relationships can have an immense impact on trauma exposed students' success in the classroom, but it can also affect their 


\section{PROMOTING COGNITIVE AND FINE MOTOR DEVELOPMENT}

ability to build resilience. In the book entitled, Building Resilience in Students Impacted by Adverse Childhood Experience: A Whole-Staff Approach, Behavior Specialist Ricky Roberston (2018) discusses the link between adult relationships and children who have been exposed to adverse experiences. He states, "Research has illustrated that positive adult relationships can help ACEs students to build resilience and can mitigate the impact of trauma" (Romero, Robertson, \& Warner, 2018, p. 81) Robertson continues this discussion by presenting classroom interventions that can foster positive teacher-student relationships and resilience. He argues that art-making experiences not only foster communication between students and their teacher, but it also reduces cortisol levels and calms the nervous system (Romero et al., 2018, p. 83).

An art education can promote a child's development across all domains. Depending on the nature of the artmaking activity, experiences in the art room can support a child's physical, social, cognitive and emotional development (Childcare, 2019). Although this research focuses on promoting cognitive and fine motor development for students exposed to trauma, what is apparent is each area of development is intertwined through the neural connections created in the brain (Center on the Developing Child, Brain Architecture, 2015). Thus, if an art educator focuses on one area of development, it is likely to have positive effects on a child's overall development and well-being. Specifically, Elliot Eisner (2008) encouraged an art education because it involves several areas of the brain simultaneously, which gives students an opportunity to develop crucial and complex forms of thinking (as cited in Baker, 2013, p. 2).

Just like other educators, art teachers have specific standards that guide them through creating quality art lessons and learning experiences for their students (National Coalition for Core Arts Standards, 2014). The National Core Arts Standards used by visual arts educators are based on the artistic processes of creating, presenting, responding, and connecting and help 


\section{PROMOTING COGNITIVE AND FINE MOTOR DEVELOPMENT}

define the links between the art being made and the student (National Core Arts Standards: A Conceptual Framework for Arts Learning, 2014, p. 11). When students, especially those with ACEs, have consistent opportunities to create, present, respond, and connect to art, they are more likely to "find joy, inspiration, peace, intellectual stimulation, meaning, and other life-enhancing qualities through participation in all of the arts" (National Core Arts Standards: A Conceptual Framework for Arts Learning, 2014, p. 10).

\section{The Trauma-Informed Art Room}

With the increased implementation of inclusive learning environments and dependable research that has uncovered the prevalence of ACEs and their risk factors, it is necessary that teachers incorporate trauma-informed strategies into their classroom to help students who have been exposed to trauma. A key concept when working within a trauma-informed scope is being sensitive to the fact that student behaviors and performance may be a result of traumatic life events (McKlindon \& McInerney, 2014). As research has shown, exposure to trauma can translate to multiple problematic behaviors in the classroom. Students may be absent more frequently, fall asleep in class, have difficulty focusing, and more. Rather than jumping to conclusions as an educator, it is important to provide trauma exposed students with a safe learning environment and appropriate accommodations. (Trauma-Informed Strategies to Use in Your Classroom, 2018). Some trauma-informed strategies that could benefit students who have been affected by trauma include maintaining a routine, giving students choices in their work, setting clear limitations for inappropriate behaviors with logical consequences, and warning students when something out of the ordinary may occur (National Child Traumatic Stress Network Schools Committee, 2008). Any educator can implement these strategies into their daily routines with the proper training. Art educators have a unique opportunity to create a trauma- 


\section{PROMOTING COGNITIVE AND FINE MOTOR DEVELOPMENT}

informed classroom environment as well as offer students artmaking experiences that allow them to express themselves and relieve stress.

Although there are very distinct differences between the fields of art therapy and art education, it is still possible for art educators to provide students with a trauma-informed and therapeutic learning environment without crossing ethical boundaries. Therapeutic practices can be incorporated as long as the teacher maintains an educational framework and the acquisition of knowledge as the central goal in lessons (Andrus, 2006). Another very important distinction between art therapy practices that art educators must shy away from is the engagement in psychotherapy practices (Andrus, 2006). Since engaging in artistic endeavors can help individuals gain inner peace (Losinski, Hughey, \& Maag, 2016) as well as reduce cortisol levels (Kaimal, Ray, \& Muniz, 2016), it is important that students receive adequate time to do so within their school community. An art educator can provide students with stress reducing artmaking experiences by allowing students to freely express themselves in mediums such as drawing, collaging, or working with clay (Martin, Oepen, Bauer, et al., 2018; Shultis, 2018).

\section{Summary}

"Risk is not destiny. We know that the brain, particularly in childhood, has an extraordinary ability to adapt and recover."

-Christopher Blodgett, Fostering Resilient Learners, pp. ix-xi.

The structural development that occurs in a child's brain is extremely susceptible to the environment in which that child lives, breathes, and grows up in. The connections that are formed within the first five years of a human's life sets the stage for a one's physical, mental, and emotional well-being throughout the rest of their life. When areas of the brain are affected by experiences such as trauma, there is not one set outcome or change that occurs. Rather, a 
PROMOTING COGNITIVE AND FINE MOTOR DEVELOPMENT

sequence is set in motion that can change the structure of the brain and the functions it produces. Exposure to adverse experiences, especially prolonged, can negatively impact a child's cognitive, physical, emotional and behavioral develop. In some circumstances, a child's only opportunity to rise above their environment and continue to develop normally comes from their education. Students with ACEs need the support of their teachers, peers, and community when their homelife cannot provide them with the safe and nurturing environment they need to thrive. Supporting these children begins with awareness of the problem, followed by interventions that help children heal and feel safe. Imagine if all art educators had the resources and necessary training to incorporate a trauma-informed and developmental approach to their art room. Imagine if all schools recognized the benefits of an art education for students, especially those exposed to trauma. Think of the changes that could occur in these students and how the quality of their learning experiences could help diminish the impact of trauma. 
PROMOTING COGNITIVE AND FINE MOTOR DEVELOPMENT

\section{Chapter 3: Methodology}

\section{Introduction}

Information for this study was gathered by researching the early developmental changes that occur because of adverse experiences and how trauma-informed school interventions, specifically in the art room, can encourage growth and resilience. This research was conducted to understand how an art educator could design specific artmaking activities in the kindergarten through second grade classroom to promote the cognitive and fine motor development of students exposed to trauma. Secondly, this research investigated the role art education could play in supporting these students within a trauma-informed school community. In order to discover how artmaking experiences could specifically promote cognitive and fine motor growth for students exposed to trauma, students from each grade level participated in a qualitative exploratory case study that resulted in the completion of two portraits inspired by the children's book When Pigasso met Mootisse. The cooperating teacher facilitated this research by introducing the book to the researcher. However, the researcher was solely responsible for creating and implementing the art project during her student teaching experiences. The first portrait was completed as a sketch and served as a guide for the final portrait. Table 1 provides a detailed description of the instructional strategies, student activities, learning tasks, and assessments used to for each class period, which will be further explained in the procedures section of this chapter. Qualitative data was collected from both portraits, along with photographs of participants throughout the progression of the project, informal interviews with participants and the school counselor, and in-class observations to determine how well students performed in the realms of cognitive and fine motor functions. 


\begin{tabular}{|c|c|c|c|c|}
\hline Class Period & Instructional Strategies & Student Activities & Learning Tasks & Assessment \\
\hline \multirow[t]{2}{*}{$\begin{array}{l}\text { Class Period 1 } \\
\text { Topic: Geometric } \\
\text { and Organic } \\
\text { Shapes }\end{array}$} & $\begin{array}{l}\text { Blackboard } \\
\text { Drawing Activity }\end{array}$ & $\begin{array}{l}\text { - Draw shapes on the } \\
\text { blackboard. }\end{array}$ & $\begin{array}{l}\text { Cognitive Development: } \\
\text { Retrieve learned information } \\
\text { - Identify and draw geometric } \\
\text { and organic shapes }\end{array}$ & $\begin{array}{l}\text { Informal: } \\
\text { Group Activity, } \\
\text { Visual }\end{array}$ \\
\hline & $\begin{array}{l}\text { Lego Shape Making } \\
\text { Activity }\end{array}$ & $\begin{array}{l}\text { - Students create } \\
\text { shapes using Lego } \\
\text { pieces }\end{array}$ & $\begin{array}{l}\text { Cognitive Development: } \\
\text { Retrieve learned information } \\
\text { - Create geometric and organic } \\
\text { shapes }\end{array}$ & $\begin{array}{l}\text { Informal: } \\
\text { Group Activity, } \\
\text { Visual }\end{array}$ \\
\hline \multirow[t]{2}{*}{$\begin{array}{l}\text { Class Period } 2 \\
\text { Topic: When } \\
\text { Pigasso Met } \\
\text { Mootisse }\end{array}$} & $\begin{array}{l}\text { Reading the book } \\
\text { aloud to the class }\end{array}$ & $\begin{array}{l}\text { - Make predictions } \\
\text { about the story } \\
\text { - Repeat important } \\
\text { phrases } \\
\text { - Pay close attention } \\
\text { to the pictures }\end{array}$ & $\begin{array}{l}\text { Cognitive Development: } \\
\text { Process new and important } \\
\text { information about the characters and } \\
\text { their styles of painting }\end{array}$ & $\begin{array}{l}\text { Informal: } \\
\text { Group Activity, } \\
\text { Verbal }\end{array}$ \\
\hline & $\begin{array}{l}\text { "Who Painted It? } \\
\text { Pigasso or } \\
\text { Mootisse" } \\
\text { PowerPoint Image } \\
\text { Game }\end{array}$ & $\begin{array}{l}\text { - "moo" or "oink" to } \\
\text { indicate whether a } \\
\text { picture was painted } \\
\text { by Pigasso or } \\
\text { Mootisse } \\
\text { - Articulate thoughts } \\
\text { and reasoning }\end{array}$ & $\begin{array}{l}\text { Cognitive Development: } \\
\text { Process new and important } \\
\text { information about each character's } \\
\text { individual style of painting- } \\
\text { - Identify specific elements of art } \\
\text { (line and shape) } \\
\text { - Compare and contrast artistic styles }\end{array}$ & $\begin{array}{l}\text { Informal: } \\
\text { Group Activity, } \\
\text { Verbal }\end{array}$ \\
\hline $\begin{array}{l}\text { Class Periods } 3 \\
\text { and } 4 \\
\text { Topic: Creating a } \\
\text { Pigasso or } \\
\text { Mootisse Sketch }\end{array}$ & $\begin{array}{l}\text { Demonstration: } \\
\text { - How to use the } \\
\text { shapes guide } \\
\text { sheets and cut- } \\
\text { out shapes }\end{array}$ & $\begin{array}{l}\text { - Create a portrait of } \\
\text { Pigasso or Mootisse } \\
\text { using art room } \\
\text { materials and } \\
\text { resources }\end{array}$ & $\begin{array}{l}\text { Fine Motor Development: } \\
\text { Trace or replicate shapes from the } \\
\text { book } \\
\text { Cognitive Development: } \\
\text { Incorporate Pigasso or Mootisse } \\
\text { specific elements into artwork } \\
\text { - Geometric or organic shapes } \\
\text { - Black outlines or colored/no } \\
\text { outlines } \\
\text { - Unusual or normal facial } \\
\text { features and positions }\end{array}$ & $\begin{array}{l}\text { Formal: } \\
\text { Performance } \\
\text { Based }\end{array}$ \\
\hline $\begin{array}{l}\text { Class Periods } 5 \\
\text { and } 6 \text { Topics: } \\
\text { Replicating a } \\
\text { sketch for a final } \\
\text { work of art, } \\
\text { collaging, } \\
\text { differentiated } \\
\text { instruction }\end{array}$ & $\begin{array}{l}\text { Demonstrations: } \\
\text { - Mrs. Mootisse } \\
\text { - Layering } \\
\text { - How to choose } \\
\text { collage papers } \\
\text { and recreate } \\
\text { elements from a } \\
\text { sketch }\end{array}$ & $\begin{array}{l}\text { - Replicate a sketch } \\
\text { to produce a final } \\
\text { work of art, } \\
\text { Collage, use art } \\
\text { room materials and } \\
\text { resources }\end{array}$ & $\begin{array}{l}\text { Fine Motor Development: } \\
\text { Trace, cut, arrange, and paste collage } \\
\text { pieces }\end{array}$ & $\begin{array}{l}\text { Formal: } \\
\text { Performance } \\
\text { Based }\end{array}$ \\
\hline $\begin{array}{l}\text { Class Period } 7 \\
\text { Topic: Complete } \\
\text { a work of art }\end{array}$ & $\begin{array}{l}\text { Review important } \\
\text { information and } \\
\text { artmaking } \\
\text { strategies }\end{array}$ & $\begin{array}{l}\text { - Complete two } \\
\text { works of art that } \\
\text { displays a portrait of } \\
\text { Pigasso or Mootisse } \\
\text { using specific } \\
\text { artistic elements and } \\
\text { style }\end{array}$ & $\begin{array}{l}\text { Cognitive Development: } \\
\text { Project completion }\end{array}$ & $\begin{array}{l}\text { Formal: } \\
\text { Performance } \\
\text { Based }\end{array}$ \\
\hline
\end{tabular}

Table 1. Class Periods: instructional strategies, student activities, learning tasks, $\&$ assessments. 


\section{PROMOTING COGNITIVE AND FINE MOTOR DEVELOPMENT}

\section{Participants and Site}

The site where the study took place is located in Morgantown, West Virginia. This particular elementary school was assigned to the researcher for her student teaching course at West Virginia University. The elementary school has a student population of 854 . The sole art educator of the school acted as the coordinating teacher as well as a facilitator for the student teacher and her research. The cooperating teacher is responsible for teaching all students within the kindergarten through fifth grade classes. During each school year, the kindergarten through second grade students are divided into six classes. In contrast, the third through fifth grade students are divided into five classes. Therefore, the art teacher is accountable for teaching 33 classes each school year and sees one class from each grade every school day. The school counseling department consists of two counselors for the entire student population. A key source of data collection for this research was the school counselor who specifically works with students between the preschool and second grade levels. The counselors at this school have both received trauma-informed training through West Virginia's Handle with Care program.

The groups in which the participants were divided among were predetermined by the classrooms they were assigned to at the beginning of the school year. Thus, the composition of each classroom and the art room schedule was not a controlled variable in this research. There were six kindergarten through second grade classes which consisted of a range of 18 to 23 total students per classroom. Out of the six classes and a total population of 398 kindergarten through second grade students, the researcher obtained written parental consent to observe and collect data from 218 participants. Through informal interviews with the school guidance counselor, two kindergarteners, three first graders, and three second graders were identified as having exposure to trauma. 
Within the assigned site, the research took place in the designated art classroom. This classroom consisted of eight rectangle tables that were arranged into one large workspace, wherein students sat around the perimeter during classes. The workspace was located in the front right area of the classroom and positioned in the middle of the section so students and teachers could safely walk around. The room was very large, which allowed materials for the project to be spaciously displayed throughout the classroom. Figure 1 provides a visual of the designated art classroom, which will be further discussed in the upcoming section.

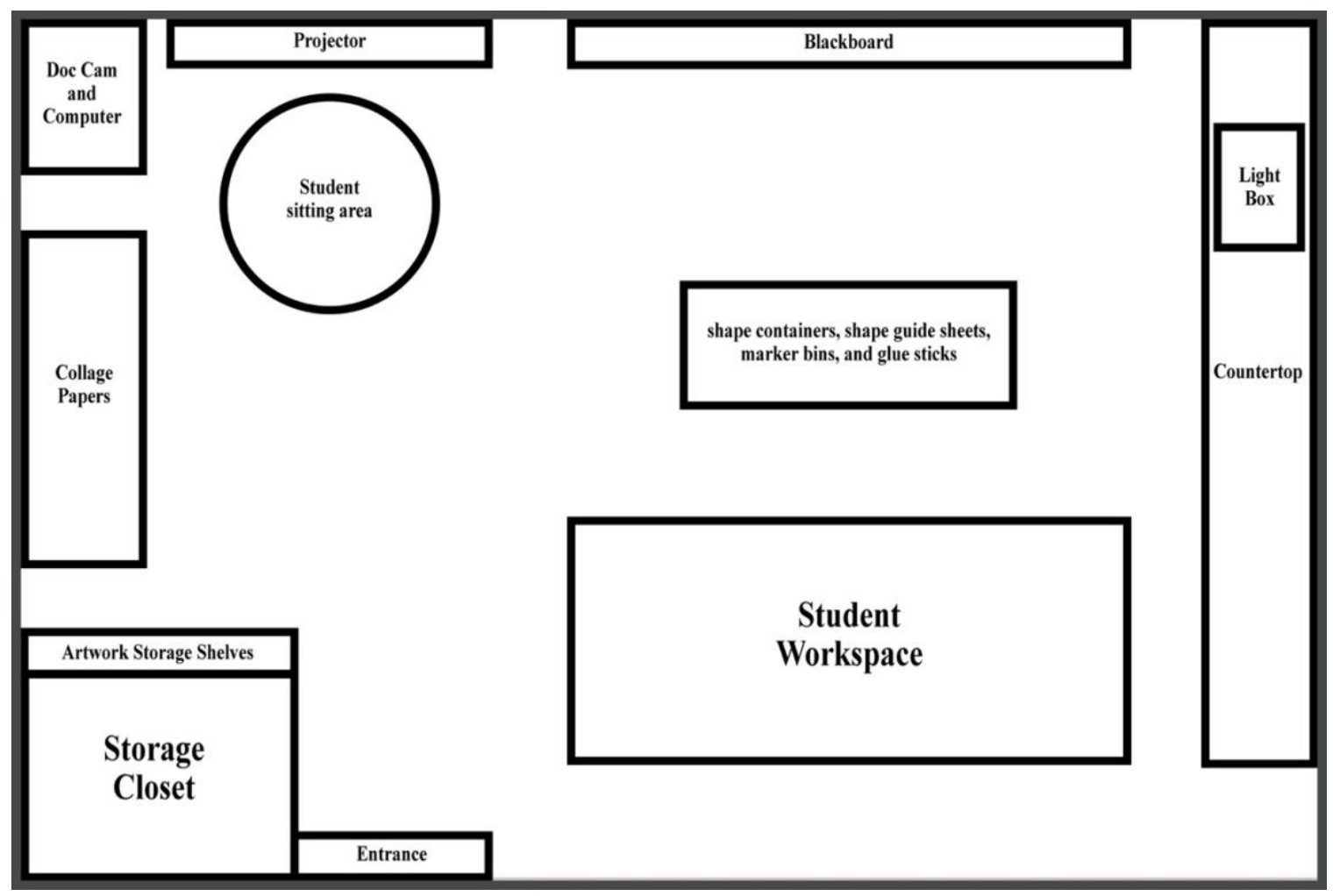

Figure 1. Site Setup. 
PROMOTING COGNITIVE AND FINE MOTOR DEVELOPMENT

\section{Procedures}

\section{Preparing the Environment}

Before the project began, the materials were organized into containers with labels and displayed on specific tables before students entered the classroom. The material bins were arranged on two large rectangle tables adjacent to the students' workspace (Figure 2). Each bin contained different cut out shapes that related to the characters' artistic styles and visual elements in the book. Along with the shapes, marker bins, glue sticks, and two groups of shapes guide sheets were placed on the tables for easy student access. The shapes and guide sheets will be further described in the sections to come. Along the left wall of the classroom was another rectangle table that displayed the different colors of paper used in the collage portion of the project (Figure 3). A blackboard positioned on the back wall of the classroom served as a display for teacher examples and important information pertaining to the project (Figures 4, 5, $6 \& 7$ ). The class projector and doc cam were also located on the back wall beside the blackboard. A countertop ran along the entirety of the ride side wall in the classroom. Some students chose to use a light box that was stationed on top of the countertop throughout the project (Figure 8). The table positions and location of resources remained consistent for the duration of this research. The only area to undergo significant change was the arrangement of the collage papers on the left wall. As students used full sheets of paper, reusable scrap sheets were returned to the table and reorganized by color and size. 
PROMOTING COGNITIVE AND FINE MOTOR DEVELOPMENT

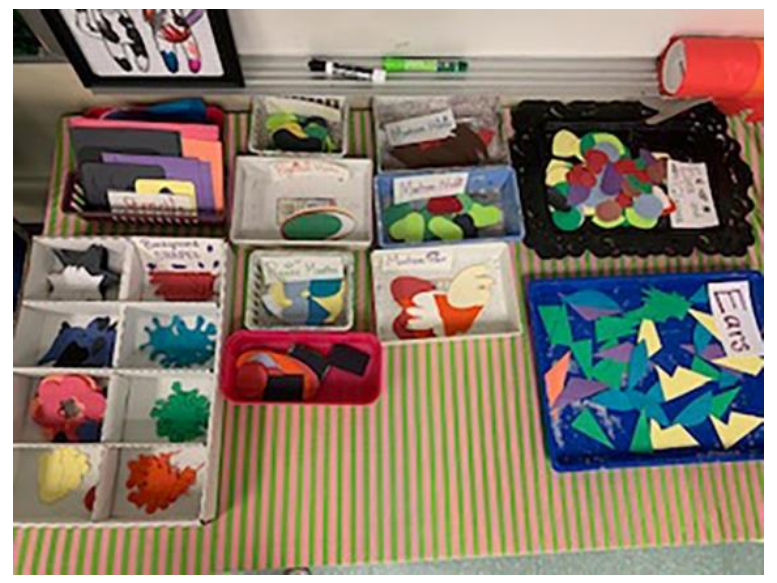

Figure 2. Cut-out Shape Containers.

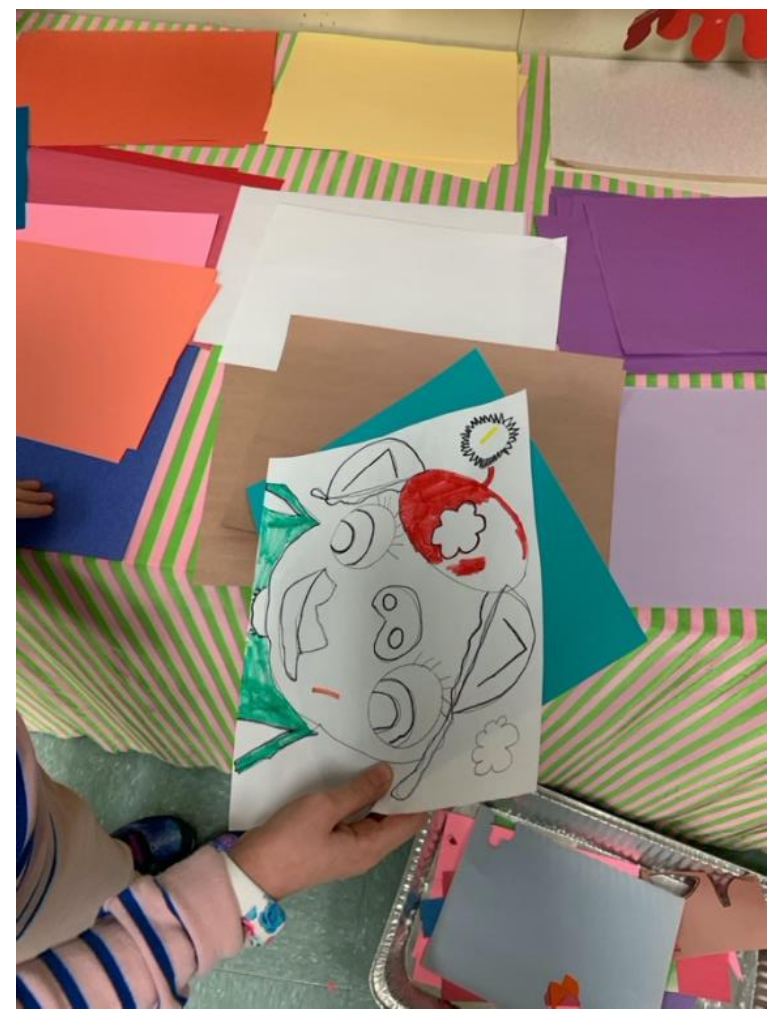

Figure 3. Collage Papers Setup. 


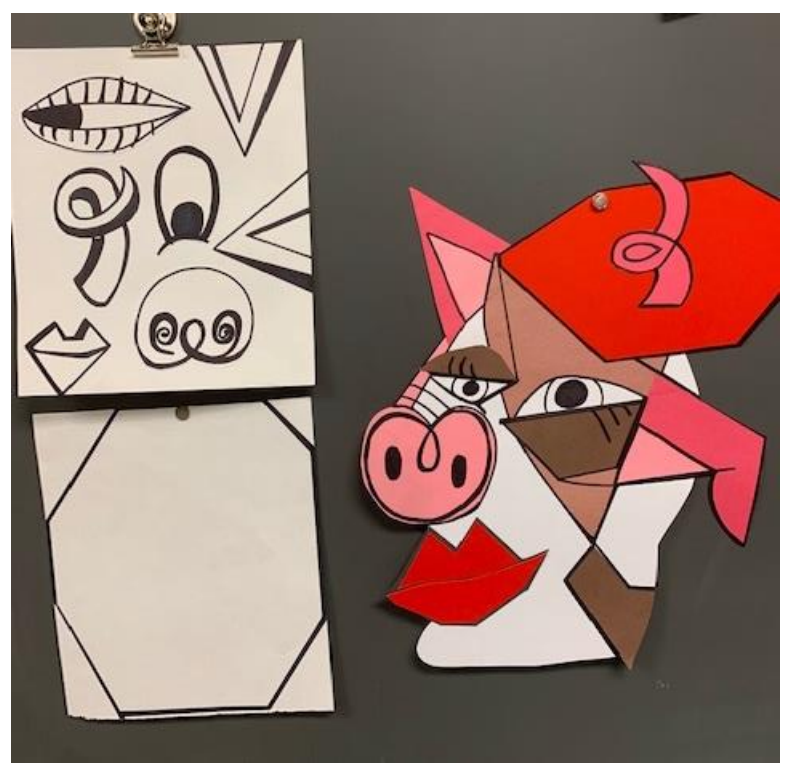

Figure 4. Cooperating Teacher's Pigasso Portrait Example.

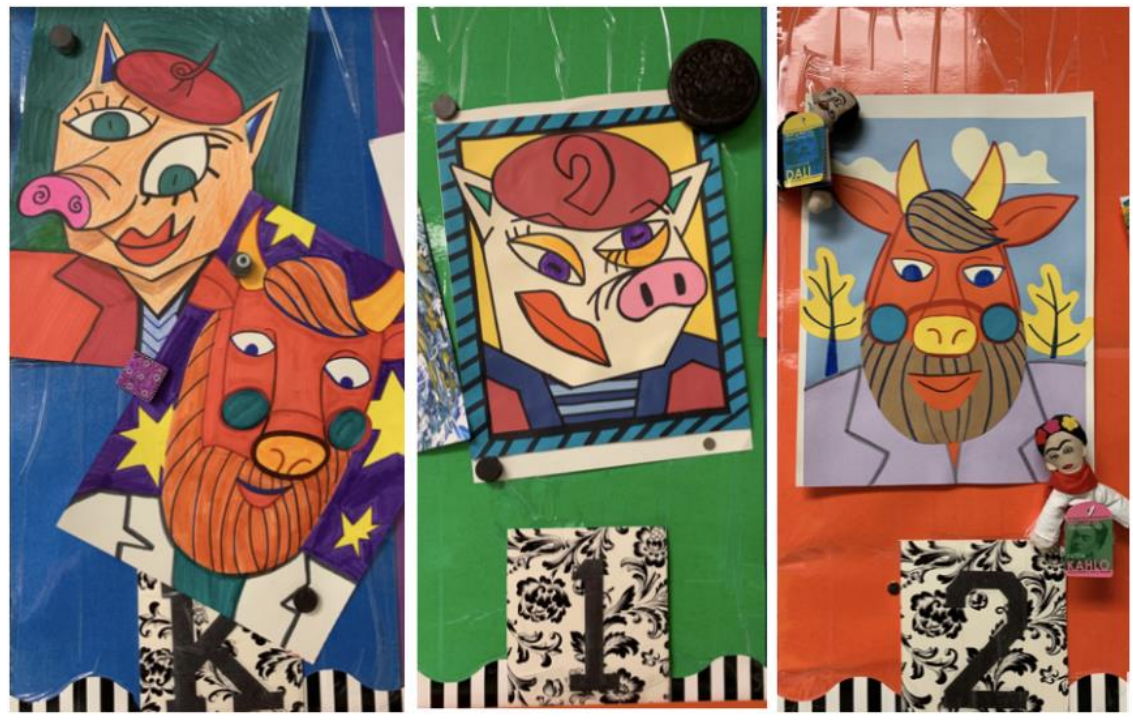

Figure 5. Student Teacher's Pigasso and Mootisse Portrait Examples. 


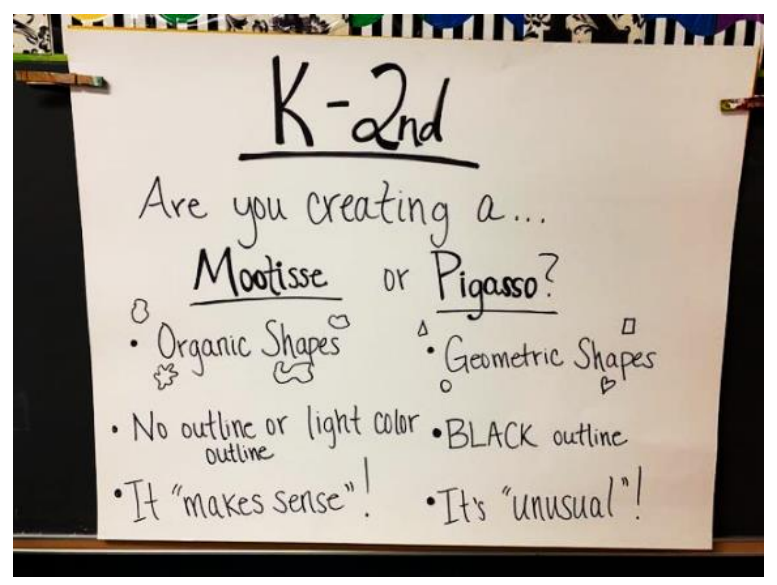

Figure 6. Blackboard Display of Assessment Tasks.

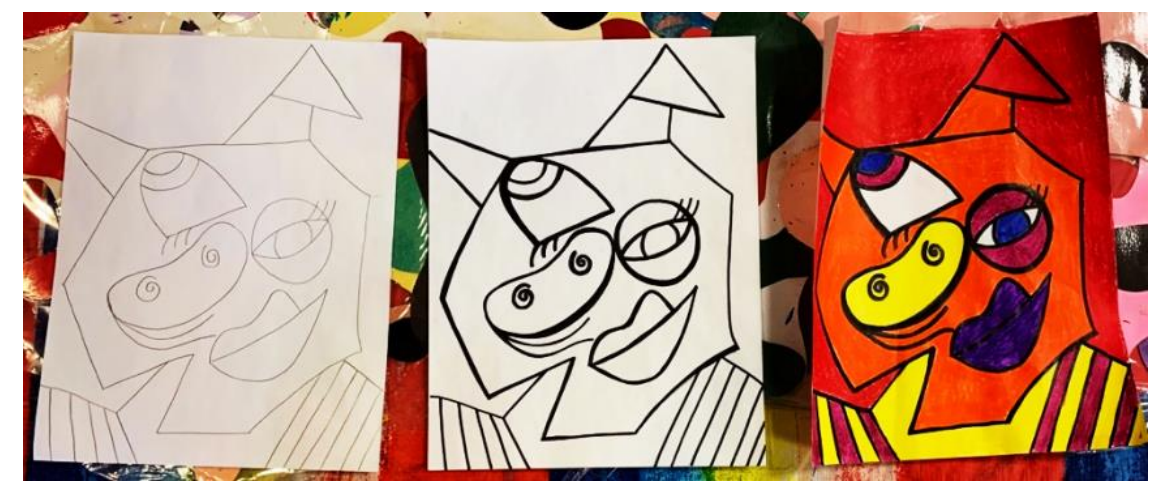

Figure 7. Student Teacher's Step-by-Step Portrait Example. 


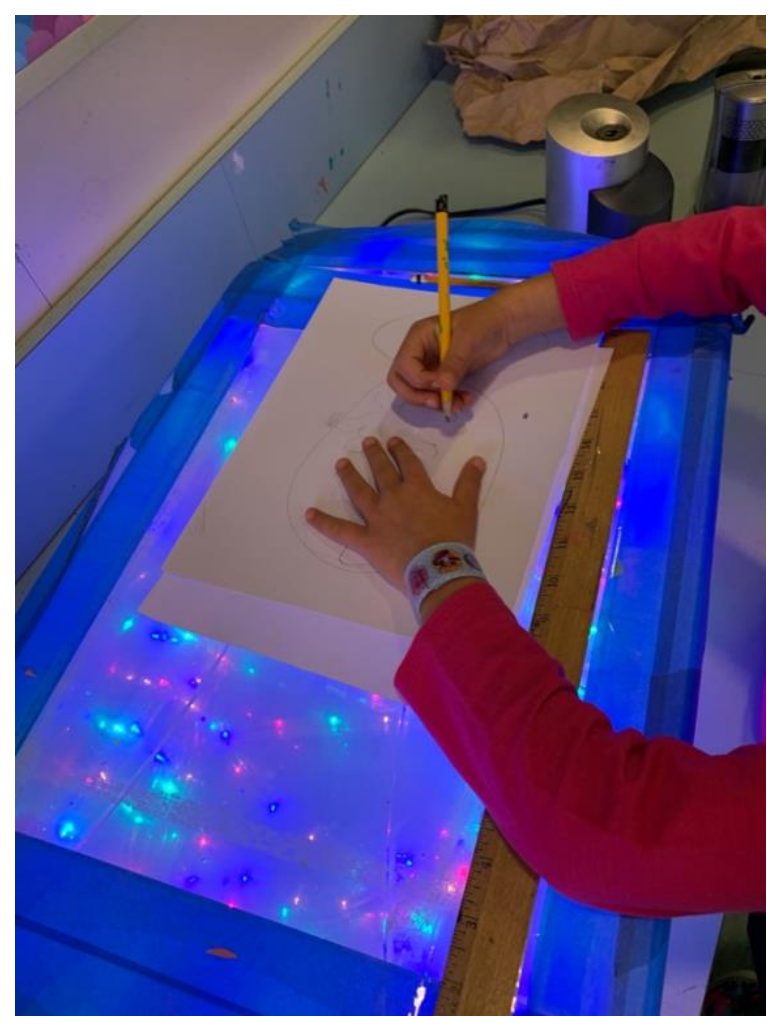

\section{Class Period 1}

Figure 8. Lightbox Display for Tracing.

During the first art class of each group, the students were introduced to the researcher and participated in a Lego shape activity as an informal preassessment of knowledge. Students did not begin working on their artworks until Class Period 3.

Geometric and Organic Shapes. Following the introduction, each class was asked to name the two types of shapes in art. After the teacher helped participants identify "geometric" and "organic" as the two types, she explained the differences between the two. Following this short discussion, the teacher addressed the class with questions such as, "who can draw an organic shape on the blackboard?" or "who can come up to the board and draw a geometric shape?". When students drew a geometric shape, they were asked to name the shape as well (Figure 9). This activity continued for 10 minutes. 


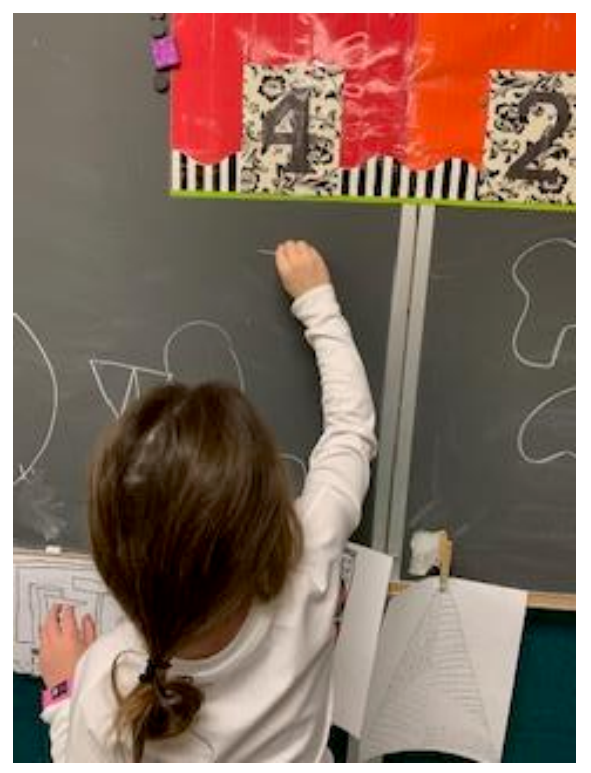

Figure 9. Class Period 1 Shape Drawing Activity.

After some participants took turns drawing on the board, they were separated into groups of fours and were given a container with Lego pieces. Similar to the activity on the board, students were instructed to create specific shapes out of their Lego pieces (Figures $10 \& 11$ ). As they created their shapes, the teacher walked around to observe students, providing them with verbal feedback and encouragement. According to the cooperating teacher, all grade levels previously learned about geometric and organic shapes in the art room during this school year or in previous years. This activity not only allowed the teacher to assess what the groups of students already knew, but it provided them with a review of information they would have already seen and would continue to discuss in the following classes. Through the perspective of information processing theory, students were engaging in elaborative rehearsal as well as priming. They were relating their understanding of shapes, which is information they have already seen, to their developing capabilities of building with Legos, which in theory allowed them to transfer gaining knowledge into long-term memory storage. Legos are popular toys and a station the cooperating teacher often implements during free time activities in the classroom. Not only were students 


\section{PROMOTING COGNITIVE AND FINE MOTOR DEVELOPMENT}

processing information by relating new knowledge to already learned information, they were also practicing their hand-eye coordination and building upon their fine motor skills.
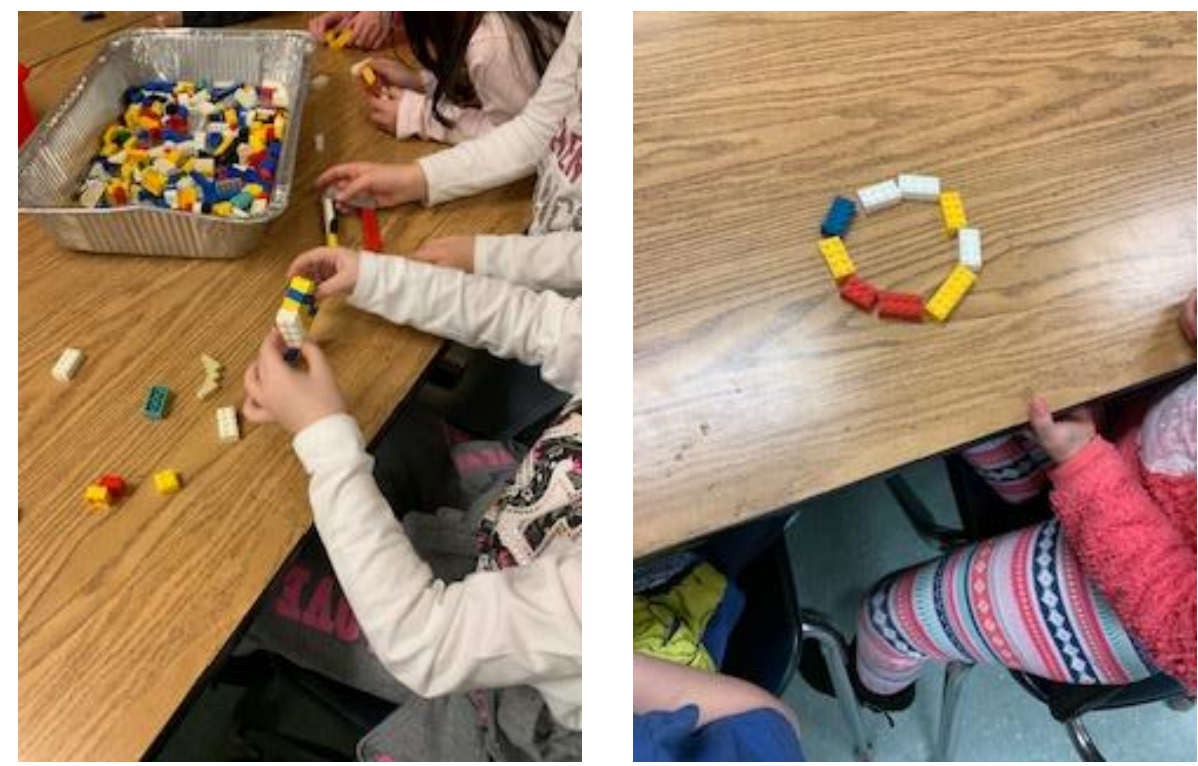

Figures $10 \& 11$. Class Period 1 Lego Shape Activity.

Moving Forward. In the classes to follow, each group began with a review of what they learned in the previous class, where to find materials for the project, and daily project goals. In some instances, such as when students began collaging their portraits, classes began with a teacher-led demonstration using the doc cam and projector. As students worked on their projects, the researcher walked around the workspace observing their progress and provided one-on-one assistance to struggling students. As each class came to a close, students were instructed to return their materials to their original bins and locations. Artworks were also collected and separated into labeled class shelves located to the left of the student workspace (Figure 1).

\section{Class Period 2}

In the following class, the student teacher read the book When Pigasso met Mootisse aloud. Students were primed on the information they would later process as they were instructed to pay very close attention to the pictures and how each artist painted within the story. Following 


\section{PROMOTING COGNITIVE AND FINE MOTOR DEVELOPMENT}

the completion of the book, students left the workspace and moved to the student sitting area where they discussed the pictures from the book (Figure 1). The purpose of this activity was to help students use the images they had already seen in the book to process incoming information about the artistic styles of each character.

When Pigasso met Mootisse. When Pigasso met Mootisse is a children's story book about a pig named Pigasso and a bull named Mootisse. Both characters are painters in the story and are based off the real-life modern artists Pablo Picasso and Henri Matisse. As both artists become frustrated with the hustle and bustle of the artworld, they move to the countryside and inadvertently become neighbors. What starts out as a proposal of friendship, quickly unravels into a rivalry as both artists cannot agree upon artistic styles. The artists call each other names, paint the front of their houses in their own styles as revenge, and ultimately end up building a wall that runs through the middle of the road. Shortly after the artists separate themselves, they begin missing each other and decide to paint opposite sides of the fence as a gesture of peace. Both artists unknowingly paint a modern art masterpiece of the same image in their respective styles. Thus, learning their friendship was much more important than their differing aesthetics.

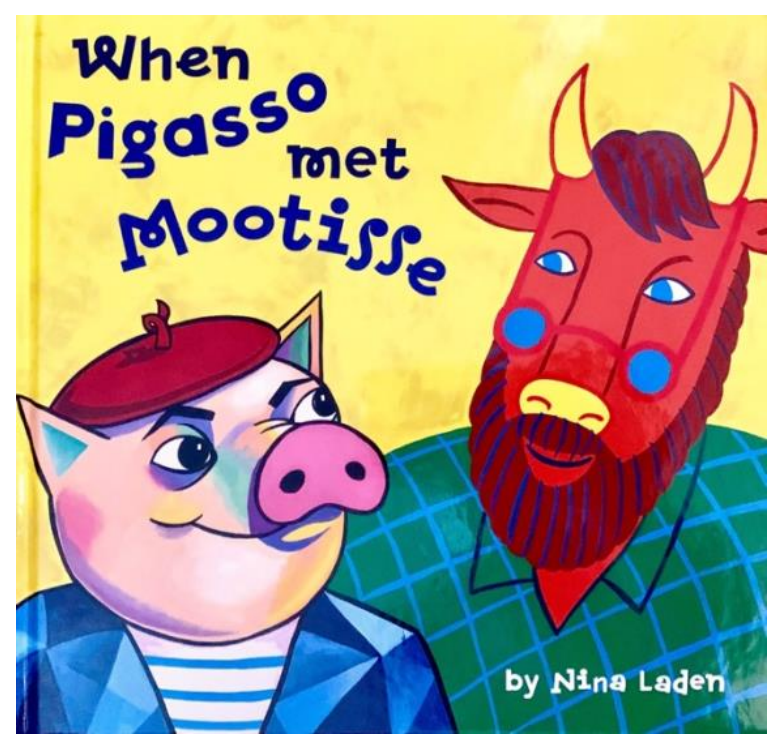




\section{PROMOTING COGNITIVE AND FINE MOTOR DEVELOPMENT}

Figure 12. When Pigasso met Mootisse Book Cover, Laden, 1998.

Before the book was read aloud to each class, participants as a group were asked to give predictions of the story based on the cover of the book (Figure 12). Asking students to make predictions is a cognitive strategy that engages readers in strategic and conscious thinking (Olson \& Land, 2007). Throughout the reading, students were asked to repeat specific information from the book pertaining to the styles of Pigasso and Mootisse. After the book was finished, students gather around the projector to play the game "Who Painted It? Pigasso or Mootisse?". Students were instructed and encouraged to "moo" or "oink" when a picture was displayed to indicate whether they thought it was a Pigasso or Mootisse painting. After students responded, they were asked to explain their answer. As the game progressed, the teacher discussed important visual elements that helped them identify the artist of each painting. The two elements of art discussed were line and shape along with an overall aesthetic demonstrated by each character.

Before discussing the elements of each painting, students were asked to identify the animal they saw. In the book, the characters almost always painted their own species. Thus, Pigasso usually painted pigs while Mootisse usually painted cows and bulls. The students were then asked about the shapes in each painting. Within the Mootisse painting, patterns of rose and paisley shapes cover the background behind the cow (Figure 13). Students were asked if these were organic or geometric shapes. Students learned organic shapes usually mimic shapes in nature such as leaves, flowers, or fruits, so they identified the shapes in the background as organic. At this point, the teacher explained to the class that they could identify a Mootisse painting by the organic shapes he uses. On the contrary, students could identify a Pigasso by recognizing geometric shapes like triangles, circles, and pentagons (Figure 14). Similar to 
Figure 13, students were asked to consider the type of animal and the shapes found in Figure 14.

Students were able to classify the animal as a pig.

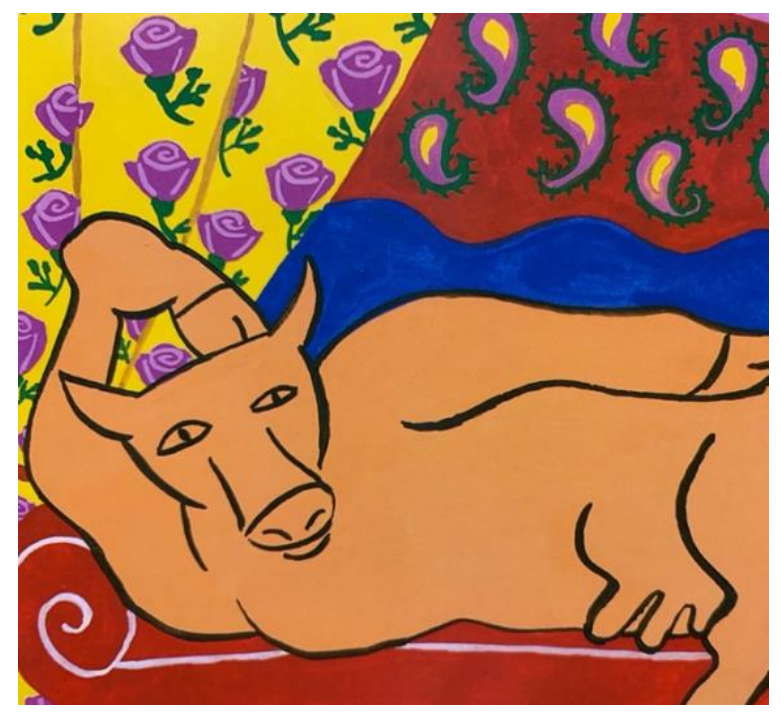

Figure 13. A Mootisse Painting, Laden, 1998, p. 2.

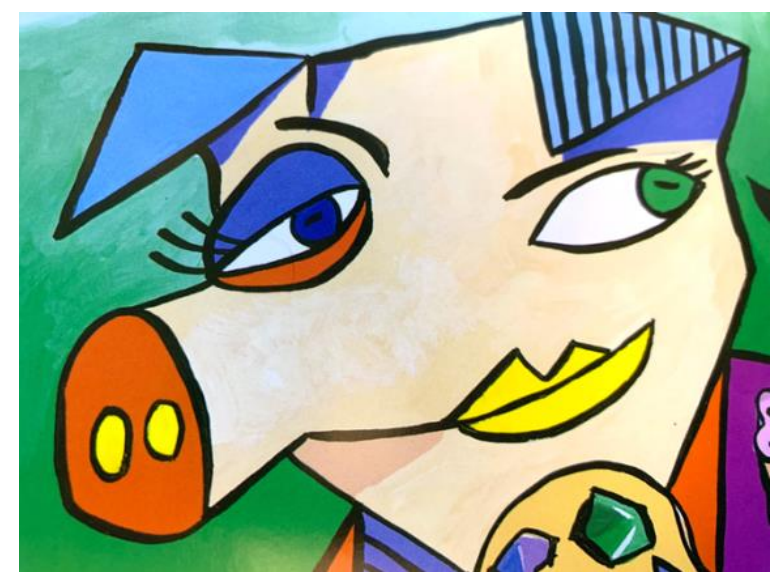

Figure 14. A Pigasso Painting, Laden, 1998, p. 1.

After building upon the types of animals and shapes, students were asked to describe the "look" of the image. Students were instructed to look at the colors of the mouth and the differing colors of the eyes in Pigasso's painting (Figure 14). The teacher asked, "Is this what a pig looks like in real life? Do they have yellow lips? Do they have different colored eyes? What about the size of the eyes?". After giving them time to respond, the teacher stated, "It is unusual right? It 
does not look like a real pig." At this point in the game, the students were reminded that Pigasso paints "unusual" and "crazy", thus referring back to words from the book. As the game progressed, students were also asked to identify the types of lines the characters used in their paintings. Students were led to see that Pigasso always uses a black outline around all of his shapes while Mootisse uses colored lines or mostly no outlines at all.

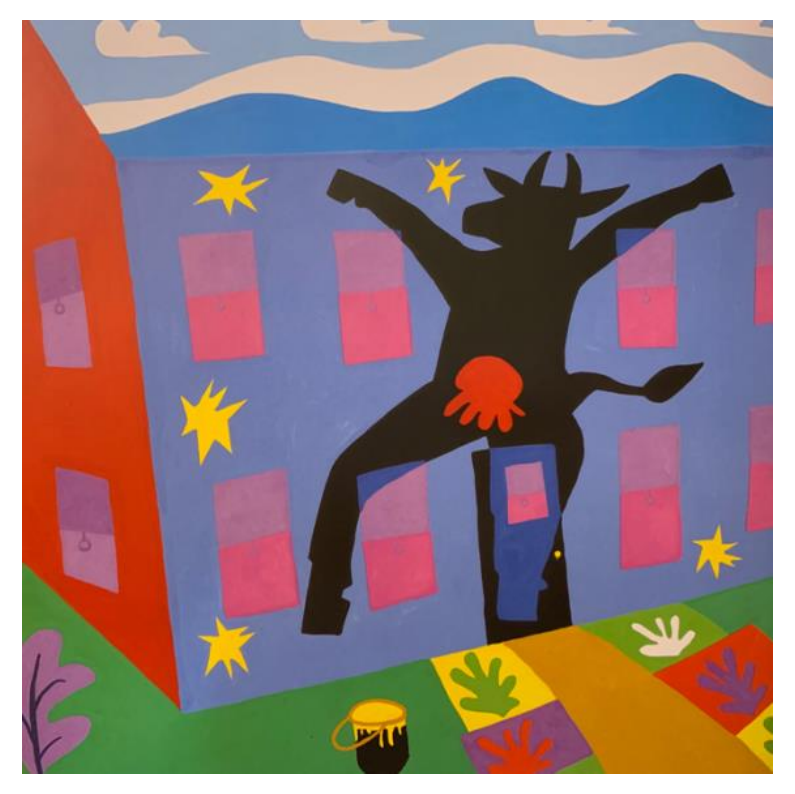

Figure 15. Mootisse's House, Laden, 1998, p. 15

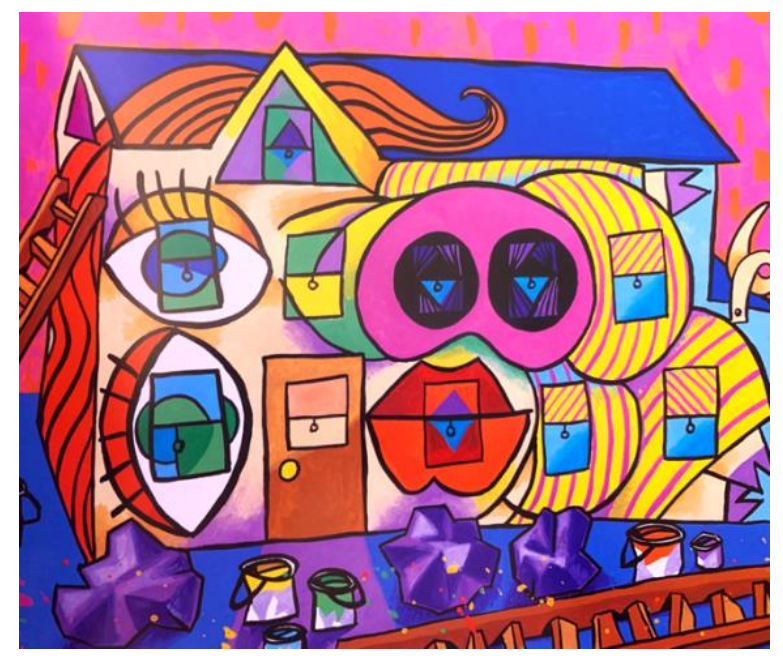

Figure 16. Pigasso's House, Laden, 1998, p. 18. 


\section{PROMOTING COGNITIVE AND FINE MOTOR DEVELOPMENT}

This game helped students gradually build upon the growing information by helping them specifically pay attention to important elements they needed to process in their memory. A normal practice within the art room is to teach students about famous artists by helping them understand their style and what art movement they belong to. However, this type of learning can be very difficult for young students to process as it requires them to apply abstract concepts to what they see with their eyes. As learned in Piaget's stages, students in the preoperational stage cannot engage in logical thought and reasoning (McLeod, 2018; Dwyer, 2010). Therefore, the teacher needs to help students process information using very concrete and clear instructional methods. To further explain, older students may be able to see a Picasso portrait and identify the artistic style as a Cubist or abstract artwork. However, younger students may see shapes but will not understand the painting is an abstract representation of an actual person. When looking at a Pigasso painting from the book, a student can understand that pigs do not have eyes in different places or positions on their faces. By classifying Pigasso's style as "unusual", students can discern the difference between what looks like a real animal and what looks like a strange animal.

Explaining the Project. Following the "Who Painted it?" game, students viewed the student and cooperating teachers' Pigasso and Mootisse portrait examples (Figures $4 \& 5$ ) and received an explanation of the art project they would be completing. The teacher explained the meaning of the term "portrait" to all grade levels and "collage" to the first and second grade levels. Each class began working on their first portrait in Class Period 3.

\section{Class periods 3 and 4}

At the beginning of Class Period 3, students were given instructions on where and how to find specific shapes for either Pigasso or Mootisse. As seen in Figure 1, these materials were 


\section{PROMOTING COGNITIVE AND FINE MOTOR DEVELOPMENT}

displayed on the tables adjacent to the student workspace. Participants were given a demonstration on how to properly use the shapes guide sheets and trace the cut-out shapes.

(Figures 17, 19, \& 20). Students could practice their hand-eye coordination by using the sheets as a guide for their drawings or they could place their paper on top of the guide sheets and practice tracing the shapes from below (Figure 18). Some students also used other art room materials such as paint palettes to trace larger shapes on their papers (Figure 21). Following this demonstration, students were each given a sheet of sketch paper and began drawing their portraits. As students started drawing, the researcher took photographs, interacted one-on-one with participants, provided assistance when needed, and kept supplies organized. Class Period 4 was a continuation of Class Period 3 and served as a full artmaking class period. This allowed students an appropriate amount of time to progress in their artwork.

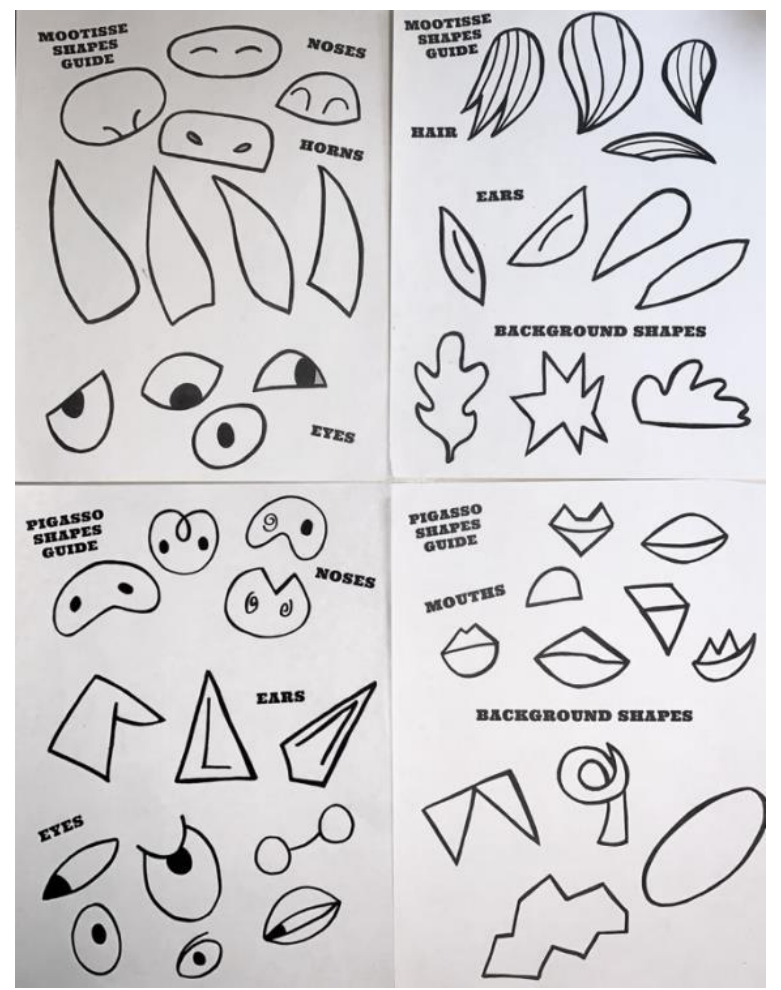

Figure 17. Mootisse and Pigasso Shapes Guide Sheets. 
PROMOTING COGNITIVE AND FINE MOTOR DEVELOPMENT

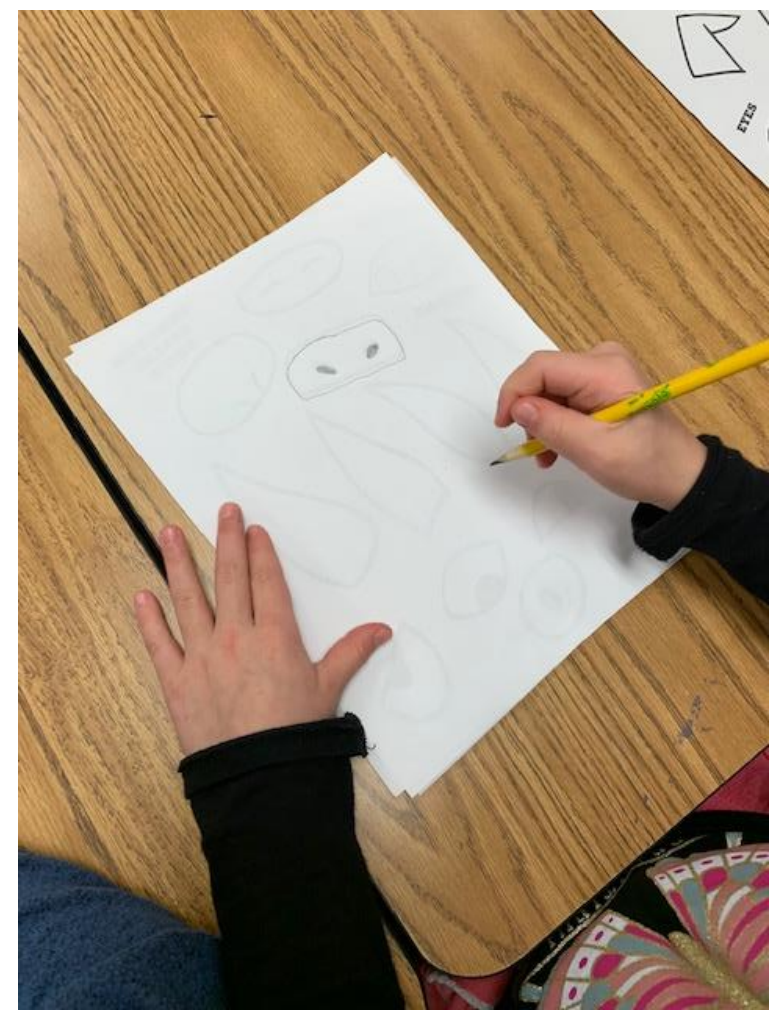

Figure 18. Student Tracing with Shapes Guide Sheet.

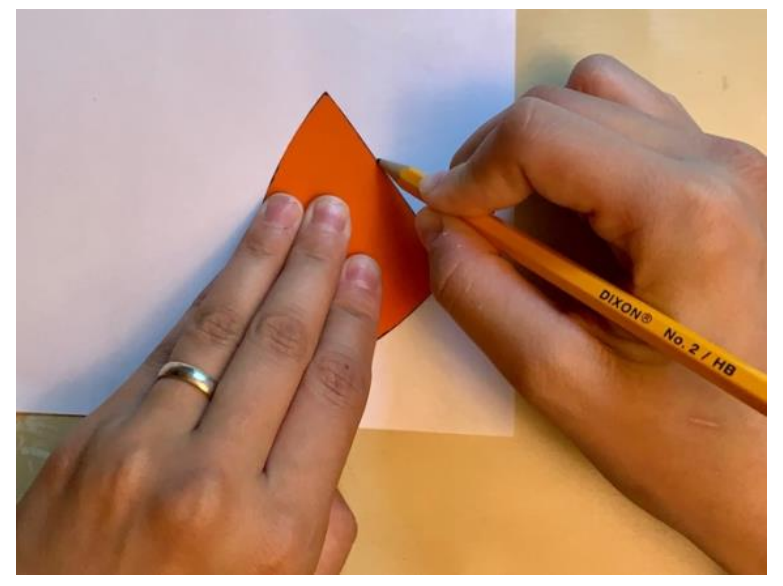

Figure 19. How to Trace Cut-out Shapes Step 1. 


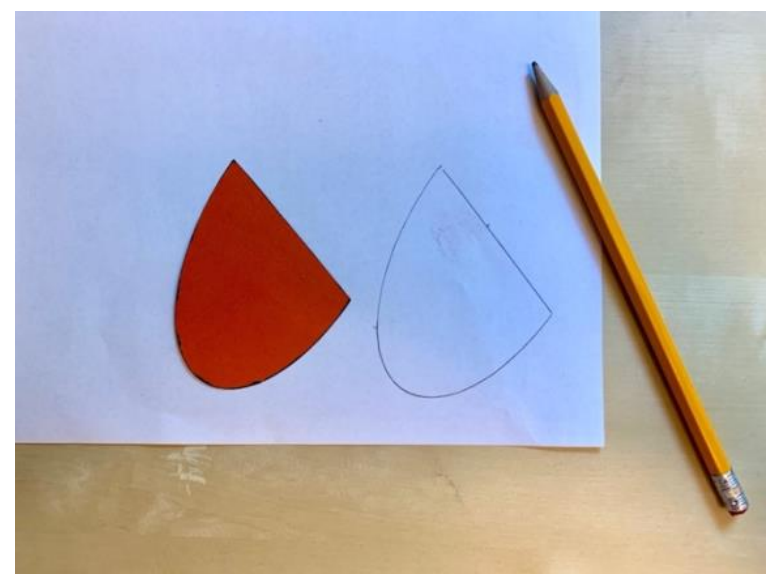

Figure 20. How to Trace Cut-out Shapes Step 2.

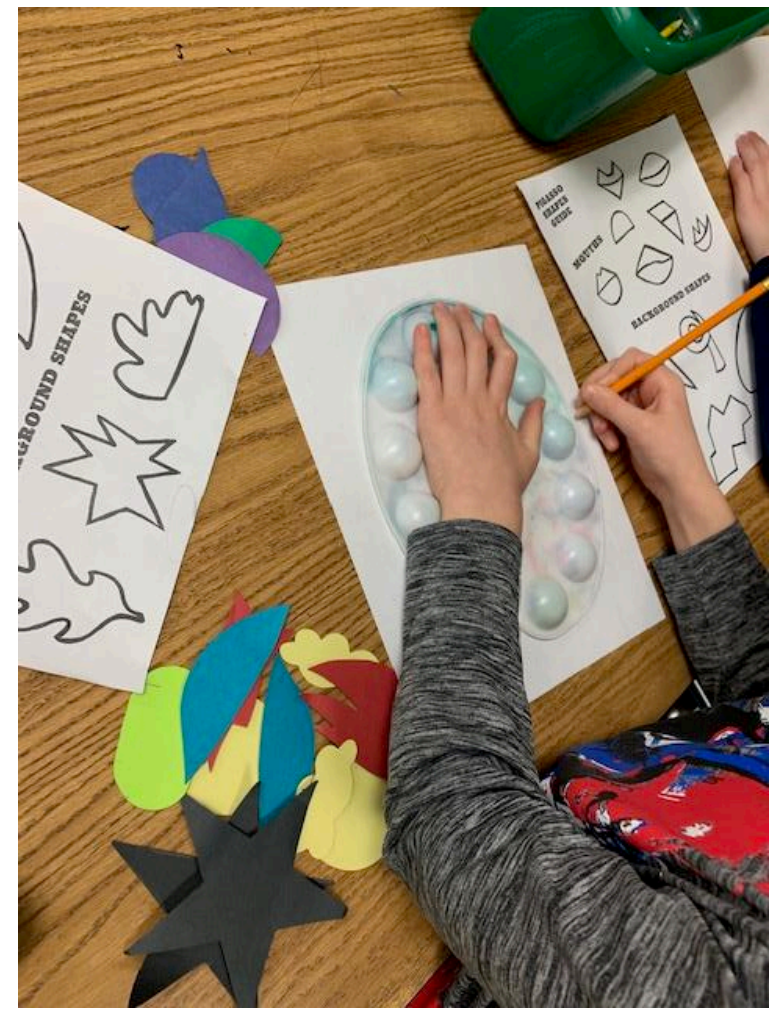

Figure 21. Student Tracing with Paint Palette.

\section{Class Period 5}

As students completed their first portrait, the student teacher began distributing pieces of cardstock paper to students so they could begin their second portrait. She gave students an explanation of the purpose of creating two artworks. In this explanation she discussed the 


\section{PROMOTING COGNITIVE AND FINE MOTOR DEVELOPMENT}

concepts of creating a plan for a work of art, practicing before moving on to a final portrait, and ways they could improve upon their first artwork.

Differentiated Instruction. Differentiated instruction refers to methods of teaching an educator implements within a classroom that factors in individuals' differing learning styles, abilities, interests, and readiness (Weselby, 2014). Author, former teacher and principal Betty Hollas (2005) in Differentiating Instruction in a Whole-Group Setting states differentiating instruction means "proactively creating different pathways to help all students be successful" (Hollas, 2005, p. 2). There are three ways a teach can differentiate instruction, which include varying content, process, and product (Tomlinson, 2017, p.92; Weselby, 2014). Since this particular research encompassed different grade levels creating artwork based on the same concept, the students demonstrated their performance and capabilities through a differentiated product. Originally, the researcher designed the lesson so that kindergarten students would complete two drawings while first and second grade students completed one drawing and one collage. However, not only were there varying capabilities between each grade level, but the researcher discovered varying capabilities between individuals within the same classes. After gaining more experience within the first-grade classes, the researcher adjusted the product for this grade level and gave students a choice to complete a final drawing or collage. Thus, the final product for first graders varied depending on their readiness to create a portrait using collage materials and methods.

Collaging. Once first and second grade students were ready to create their second portrait, they were taught how to construct a collage using Mrs. Mootisse (Figure 22). Mrs. Mootisse is an instructional reference created by the researcher and was constructed using cutout shapes and Velcro. This demonstration took place at the doc cam and projector for each class 
to view as a whole. At the beginning of the demonstration, all elements including the eyes, nose, head, ears, etc. were removed from the paper. The students were instructed to begin with a background color of their choice. Students were asked to first consider what background they created in their first portrait. Did they create a realistic background with a sky, clouds, and trees? Or did they create an abstract background with shapes and colors? Since Mrs. Mootisse's background represented a sky, the background consisted of full sheet of blue cardstock paper. Students were then asked to help the researcher put Mrs. Mootisse back together based on the concepts of layering and the vocabulary terms background, middle ground, and foreground.

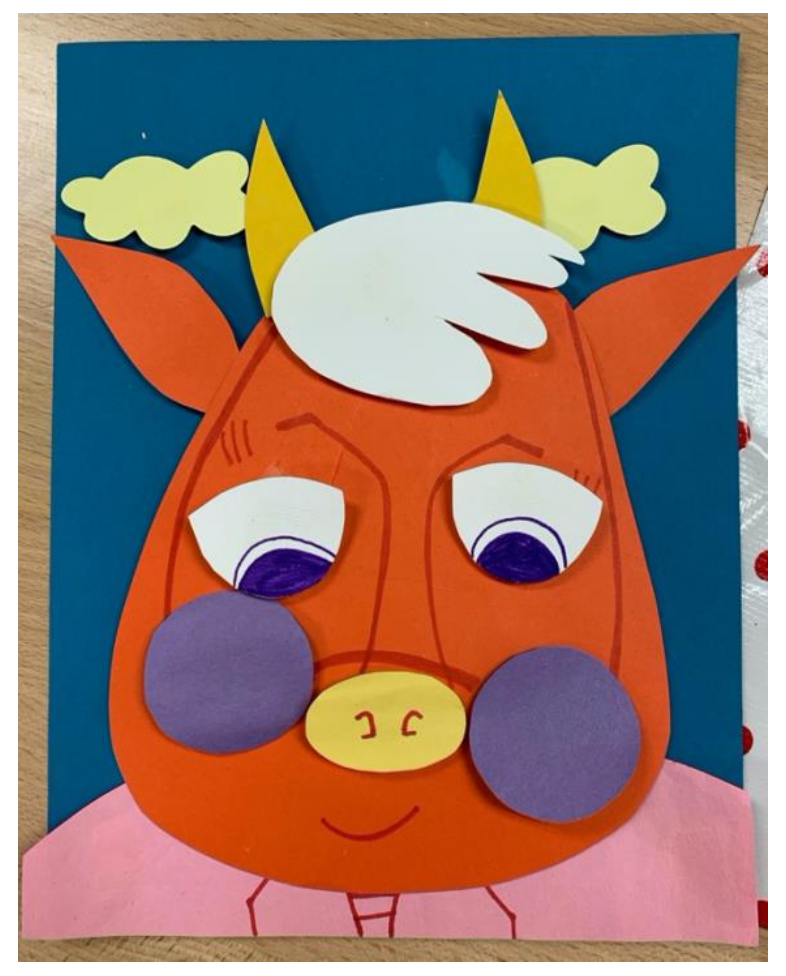

Figure 22. Mrs. Mootisse.

Following this activity, students needed to understand how to create the materials for their collage. They were instructed to first cut out all of their collage pieces before they glued any materials to their paper. For this portion of the demonstration, the researcher used the Pigasso Step-by-Step Portrait Examples (Figure 7). The researcher asked students, "What color 
is Pigasso's mouth?". As students responded "purple" they watched the researcher take a purple piece of paper, trace, and cut out the same mouth shape from the sketch. This gave students a visual example of how to choose colored papers for their collage, how to reuse cut-out shapes to replicate their sketch, and how to properly collect all the necessary materials before gluing (Figures 23, 24, 25, \& 26).

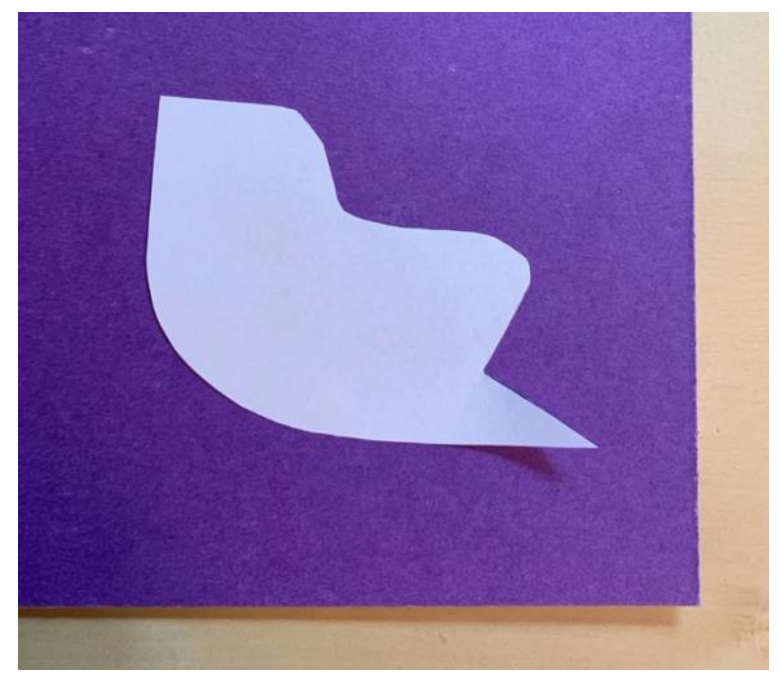

Figure 23. How to Create Shapes for Collaging Step 1.

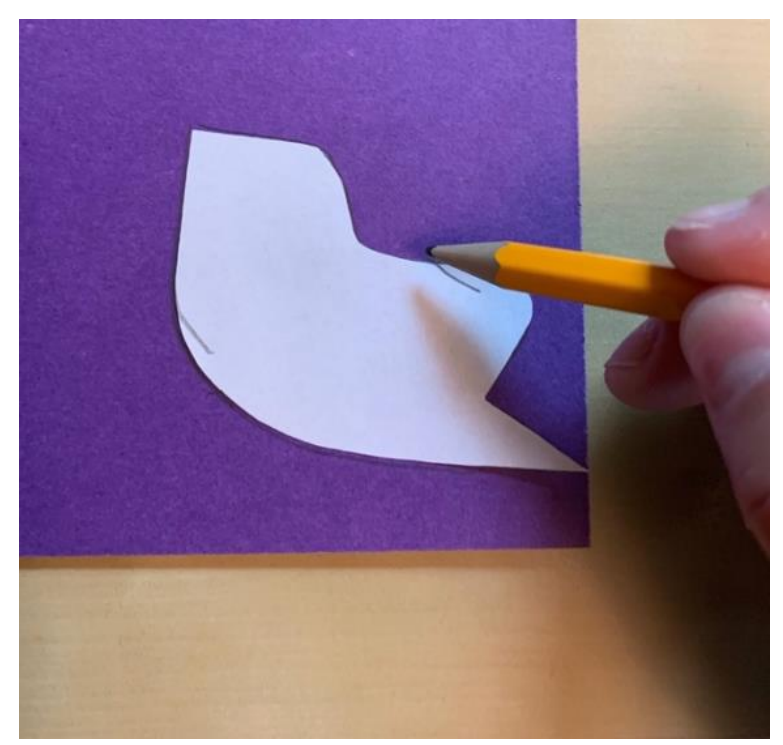

Figure 24. How to Create Shapes for Collaging Step 2. 1

1 Students at this age need to be repeatedly reminded to not cut a shape out in the middle of the paper and to use a pencil to trace the shape before cutting it out. 


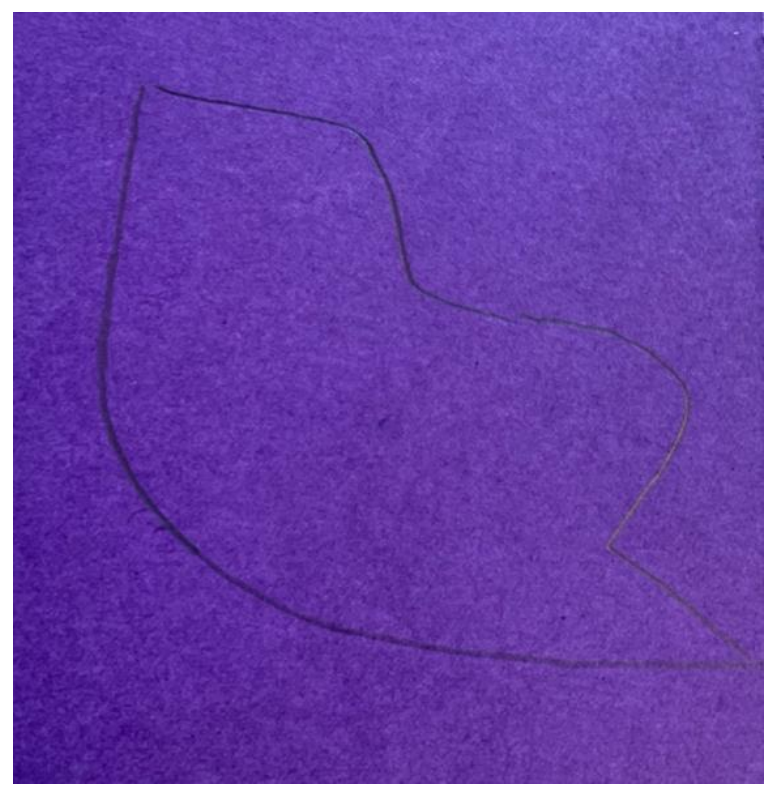

Figure 25. How to Create Shapes for Collaging Step 3.

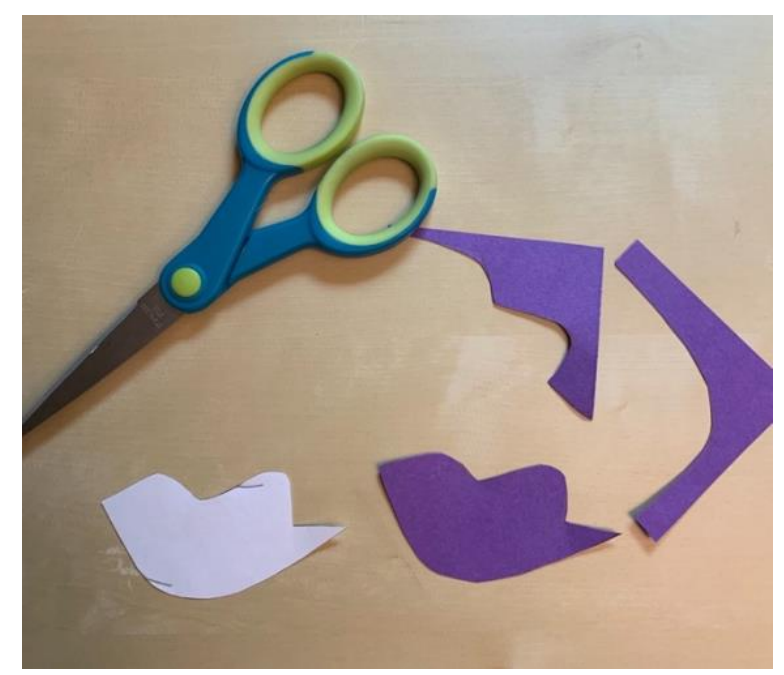

Figure 26. How to Create Shapes for Collaging Step 4.

\section{Class Period 6}

Class period 6 was a continuation of Class period 5 and served as a full artmaking class. This allowed students an appropriate amount of time to progress in their artwork. As students moved forward in their final portrait, the researcher took photographs, interacted one-on-one with participants, provided assistance when needed, and kept supplies organized. 
PROMOTING COGNITIVE AND FINE MOTOR DEVELOPMENT

\section{Class Period 7}

The Information Processing method of retrieving stored information was used during Class Period 7 because there was a two-month period where the students did not work on their artwork. The pause in research was due to the researcher completing her second student teaching placement at another school. When the researcher returned to complete the lesson, students had to engage in retrieval practice in order to complete their projects. To aid in this retrieval, the researcher conducted a review of the important information previously learned so students could remember what they needed to accomplish in their artworks at the closing of the lesson. As participants completed their artworks, the researcher took photographs, conducted informal interviews, and allowed students to free draw until their peers were done.

\section{Research Design}

This research used qualitative exploratory case studies to gain an in-depth understanding of how artmaking experiences with an art educator can promote the cognitive and fine motor development of trauma exposed students in the kindergarten through second grade classroom. Specifically, three exploratory case studies were created to analyze the collected data from each grade level. The purpose of the multiple case study design was to explore and describe the reallife phenomena that took place within the classrooms of participants who have been exposed to trauma and to determine how their developmental capabilities compared to their non-trauma exposed peers. The lesson was designed using knowledge obtained in the literature review and implemented within all eighteen classes. To increase the credibility of each case study and the richness of data, the researcher used the qualitative research method of triangulation (Salkind, 2010; Robson, 2011, p.58). Triangulation refers to the gathering of multiple sources of data to form more complex perspectives and concepts about the phenomenon that takes place within a 


\section{PROMOTING COGNITIVE AND FINE MOTOR DEVELOPMENT}

qualitative research study (Salkind, 2010; Lofland \& Lofland, 1984). Data was collected from existing research on child development, the impact of trauma on young children, and art education practices that can promote developmental growth. This data was presented in the Literature Review of this research. Along with existing literature, the researcher collected data using field notes and direct in-class observations, informal interviews with participants and the school guidance counselor, and photographs taken of participants throughout the duration and completion of the project. These methods of data collection are further explained in the upcoming section.

\section{Data Collection and Instruments}

The qualitative data collection methods for this research included field notes and direct in-class observations, informal interviews, and photographs. Direct observations of participants began in Class Period 1 and continued throughout the duration of the study. Field notes were taken as the researcher observed the abilities of each classroom as a whole. Between Class Periods 2 and 3, the researcher conducted informal interviews with the school guidance counselor to identify participants who have experienced trauma in their childhood. This data collecting tool was used to elicit information pertaining to the participants in the research, to gain a perspective of the children exposed to trauma, and how their adverse experiences at home could affect their ability to learn in the classroom. Following the interviews, the researcher began observing the participants with known trauma exposure to determine whether or not they demonstrated an ability to meet the project's cognitive and fine motor formal assessment tasks as they created their first artwork. When a student displayed difficulty with a task or was struggling to stay on task with the daily learning tasks, regardless of their background, the researcher engaged in one-on-one interactions to help individual participants progress forward in their 


\section{PROMOTING COGNITIVE AND FINE MOTOR DEVELOPMENT}

artwork. This allowed the researcher to better understand what areas of development specific students needed support in.

As participants completed their two portraits, the researcher conducted informal interviews with participants who were willing to talk about their artwork. This data collecting tool was used to gain insight about the artistic choices they made while creating their artworks. It was also used to gain a better idea of whether the participant was thinking about the story, the characters, and their styles or if they were creating their artwork based on their own interests. However, this data is not consistent as some students were more willing to talk about and describe their artwork than others. The students were asked questions such as, "Can you tell me what you drew in your artwork?", "What is happening in your artwork?", and "Why did you choose this element for your artwork?".

Students were formally assessed on their ability to incorporate the artistic characteristics of Pigasso or Mootisse, replicate their first artwork, as well as their fine motor capabilities. Each case study illustrates the performance of the trauma exposed students and discusses if these individuals displayed any cognitive or fine motor discrepancies compared to their peers. The results section also displays data collected from well performing participants' artworks and phenomenon that was witnessed during the researcher's time in the art room. While direct observations, field notes, and photographs were collected from all eighteen classes, the case studies only analyze phenomena that took place within the groups of the students identified with known exposure to trauma. The classrooms that included trauma exposed students were combined into one case study per grade level. The purpose of this method was to accurately determine the performance of trauma exposed compared to non-trauma exposed participants on 
PROMOTING COGNITIVE AND FINE MOTOR DEVELOPMENT

the basis of controlled conditions such as frequency and duration of art classes, teacher instruction, and experiences of students.

\section{Data Analysis}

\section{Cognitive Abilities}

Students' artworks were assessed on how well they were able to incorporate the indicated characteristics of the character they chose. If a student chose to create a Mootisse portrait, they were expected to use organic shapes, no outlines of shapes or colored outlines (specifically not black), and facial features arrangements that "made sense" or looked "normal" (Figure 27). If students created a Pigasso portrait they were expected to use geometric shapes, black outlines around their shapes, and facial features arrangements that looked "unusual" (Figure 28). "Unusual" and "normal" facial features referred to the arrangement of the portrait and the colors used within an artwork. A portrait that was "unusual" contained misplaced or unnatural facial features, or unnaturally colored elements. As discussed in Class Period 2, the researcher explained that animals do not usually have different colored facial features or strangely arranged faces. A portrait that was "normal" contained facial features that better represented real life. Therefore, the eyes, nose, mouth, and ears should have been arranged to resemble a real-life animal or human. Some students received an "undistinguishable" score within the results section which indicates they did not include any elements the researcher could use to visually identify a portrait as Mootisse or Pigasso. 


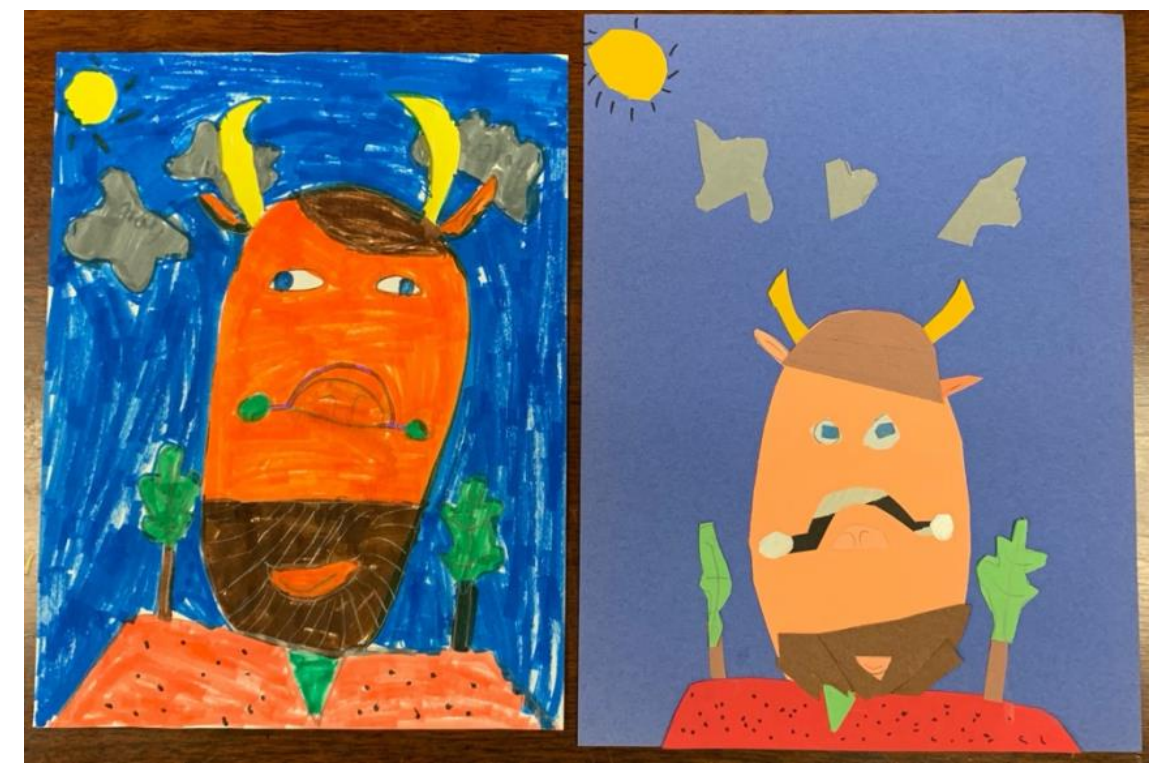

Figure 27. Student Example of Mootisse with Correct Elements and Style.2

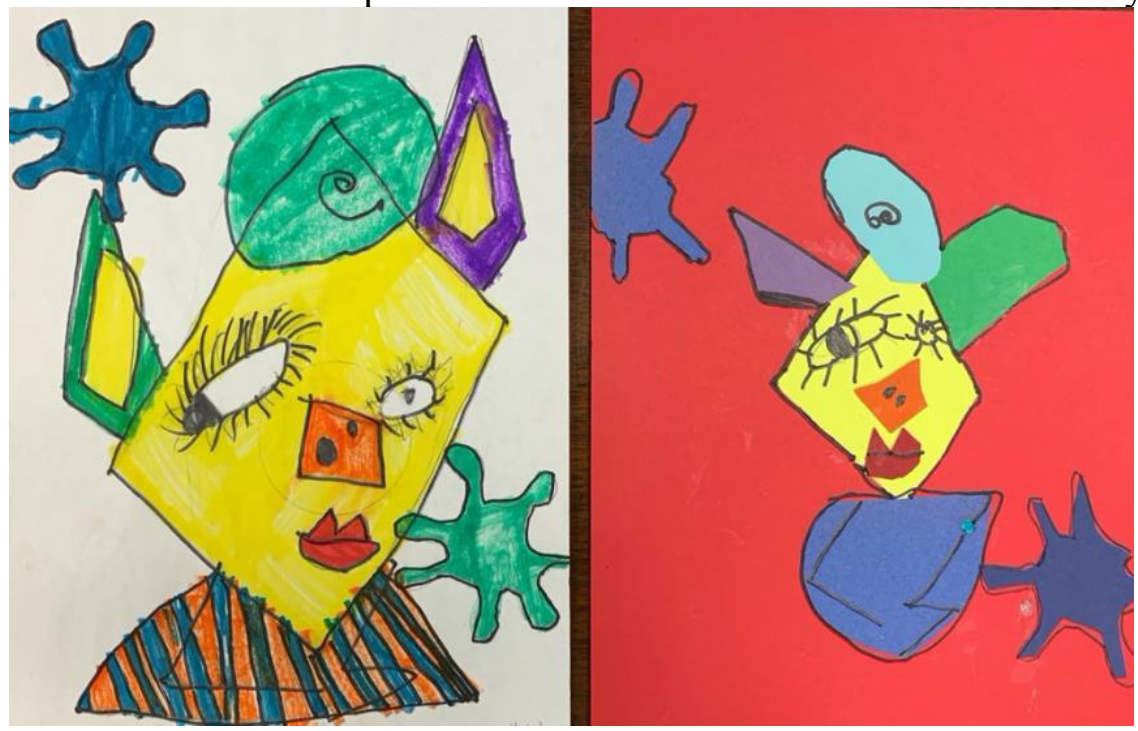

Figure 28. Student Example of Pigasso with Correct Elements and Style.3

Students were also assessed on how closely their second image resembled their first image. This data was divided into three categories labeled "same", "similar", and "different".

2 The portrait makes sense, has normal facial feature arrangements, contains little to no outlines of shapes, and organic shapes such as the clouds and trees in the background.

3 The portrait is unusual, contains unrealistic facial arrangements, black lines around all the shapes, geometric shapes such as rhombuses, ovals, and circles. 
This data analysis was ultimately one of the most difficult to determine in the project. For the purposes of this research, "same" artworks indicated that both portraits looked nearly identical (Figure 29). "Similar" artworks indicated close replication but had small variations such as different background colors, same facial features but different locations, or same shapes and positions but different colors (Figure 30). "Different" artworks referred to a participant who created two completely different portraits (Figure 31).

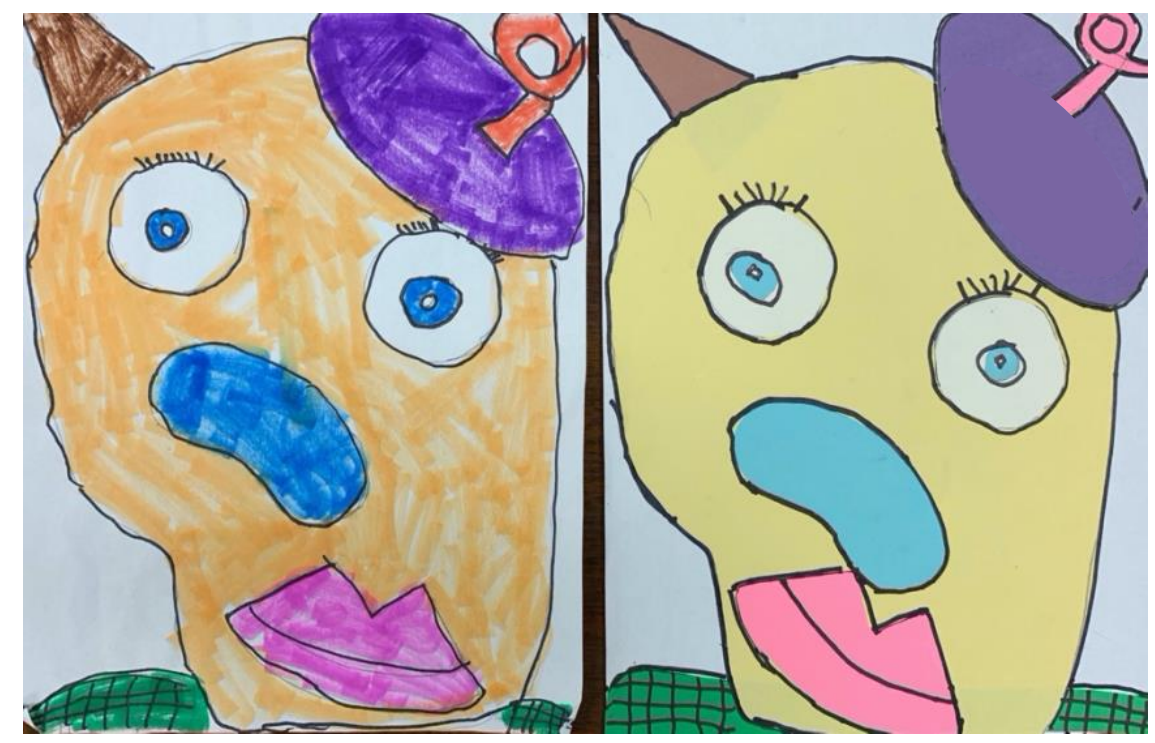

Figure 29. Student Example of Same Artworks.

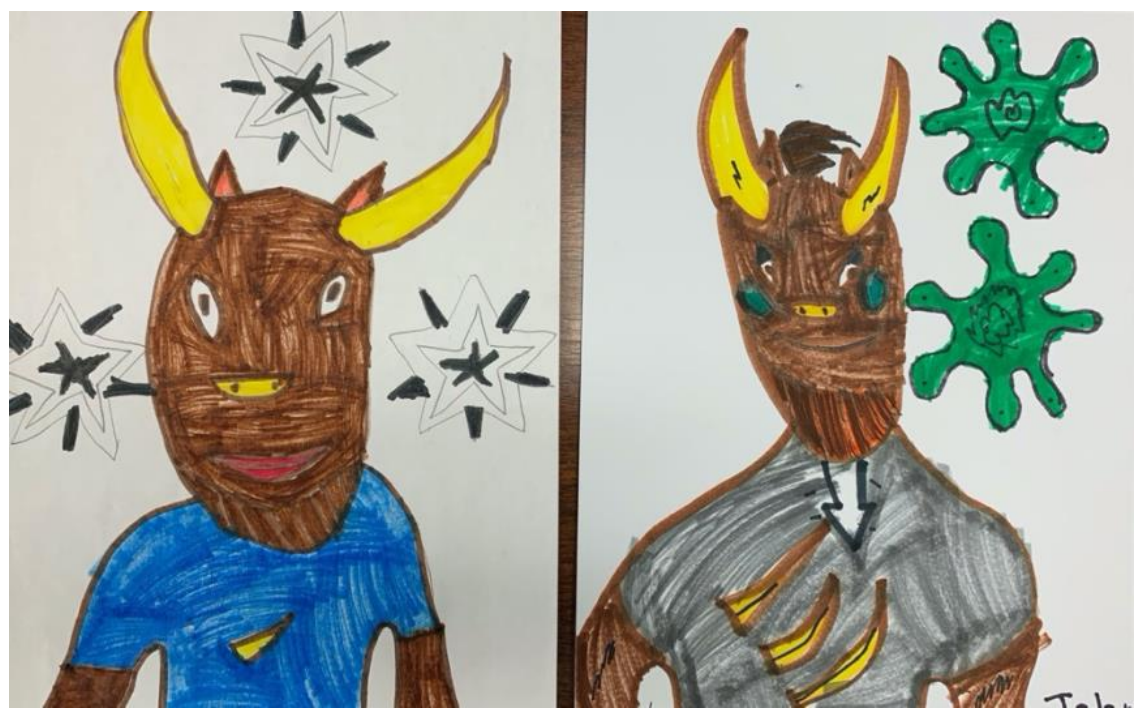


Figure 30. Student Example of Similar Artworks.4

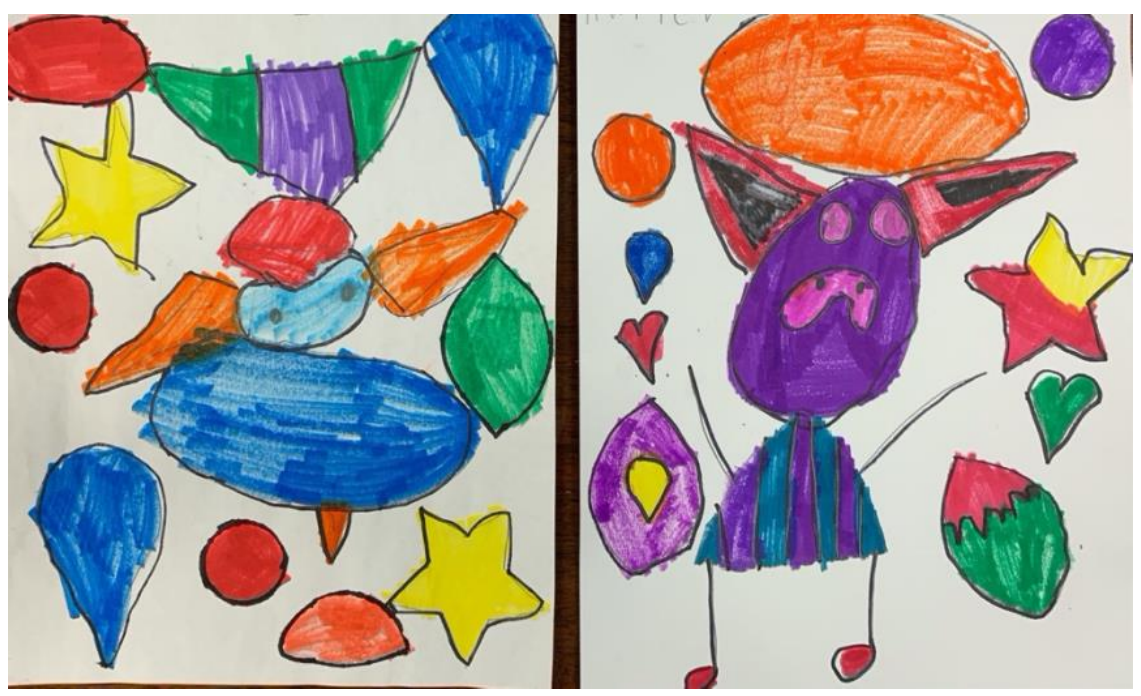

Figure 31. Student Example of Different Artworks.5

\section{Fine Motor Abilities}

Participants were also formally evaluated on their fine motor abilities. They received a score between 1 and 3 indicating how well they demonstrated their abilities to trace and color shapes within their artworks. Participants' fine motor scores were relative to their grade level (Figures 32, 33, \& 34). Thus, second grade students were expected to demonstrate more refined fine motor skills than first graders and kindergarteners. Students who scored a 1 demonstrated low fine motor abilities for their grade levels. Fine motor scores of 1 indicate that students exhibit extremely shaky lines around the shapes and coloring that is not consistent with lines and shapes made on the paper. Fine motor scores of 2 signify students exhibited some inconsistent

4 Portraits display the same idea and character but have different elements in the background, different colored shirts, and slightly different facial features.

5 Portraits are completely different from one another. Although there are similar elements such as the stars, ears, nose, and hat, they are not in the same arrangement and different colors were used. 
lines and coloring or pasting of shapes. Finally, fine motor scores of 3 indicate students clearly defined elements within the artwork, through consistent coloring of shapes and line making.
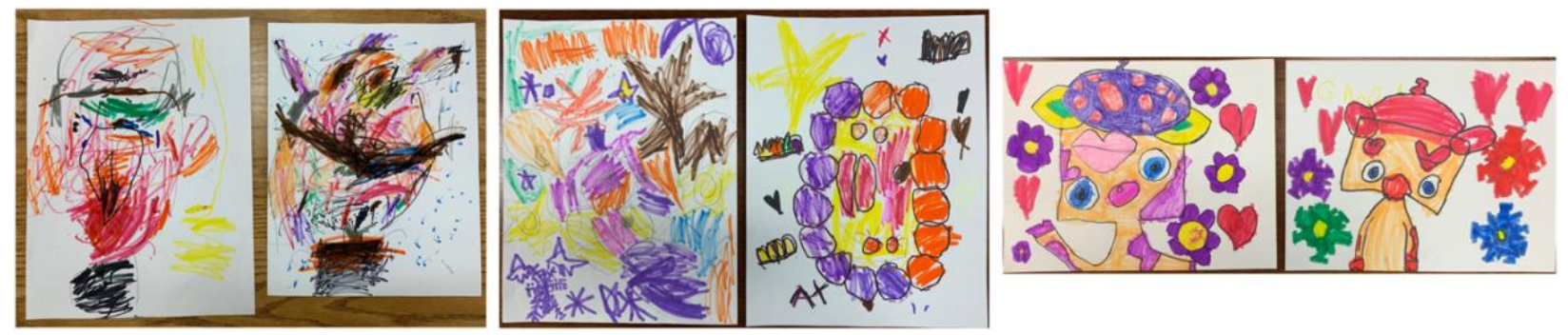

Figure 32. Progression of Fine Motor Scores in Kindergarten Student Artworks.
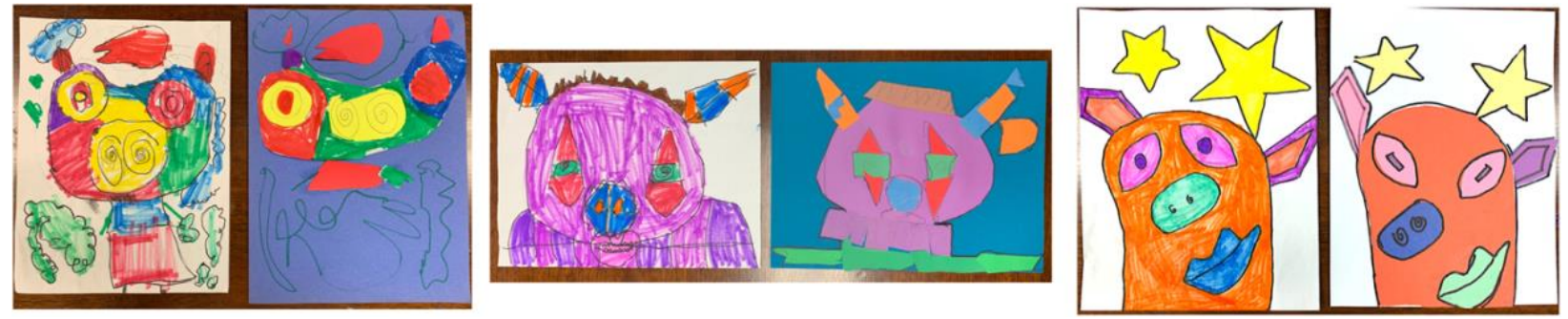

Figure 33. Progression of Fine Motor Scores in First Grade Student Artworks.
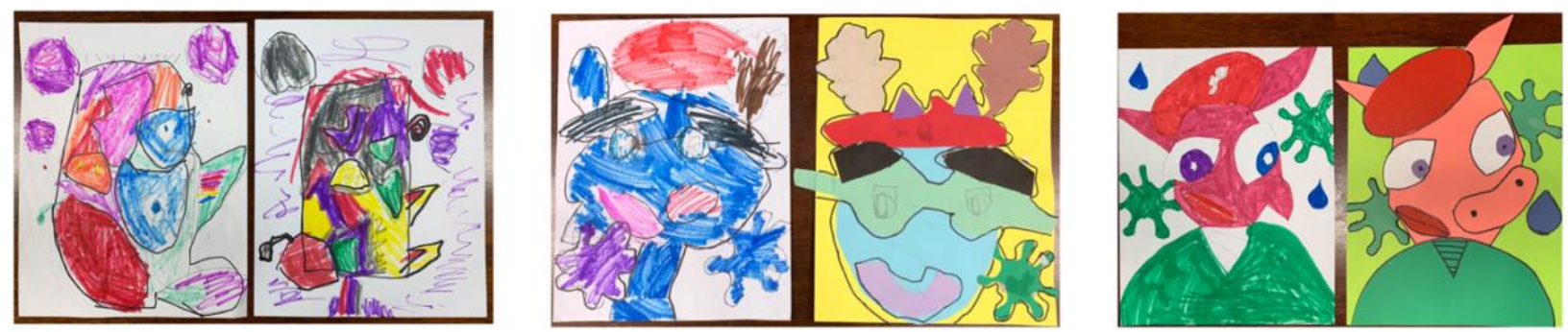

Figure 34. Progression of Fine Motor Scores in Second Grade Student Artworks.

\section{Summary}

This chapter has outlined the methodologies used in the creation of the art lesson, the duration of the project, as well as the data collection tools used to analyze the phenomenon that took place within the art room. The purpose of these methodologies was to formulate an understanding of how an art educator could promote cognitive and fine motor development for students in the kindergarten through second grade classroom who have been exposed to trauma. 
PROMOTING COGNITIVE AND FINE MOTOR DEVELOPMENT

This exploratory case study research design was used to determining how well students who were identified with known trauma exposure performed compared to their non-identified peers. By triangulating data and using multiple sources, the researcher was able to gain more insightful conclusions about the phenomenon that took place within this specific classroom and groups of participants. 
PROMOTING COGNITIVE AND FINE MOTOR DEVELOPMENT

\section{Introduction}

\section{Chapter 4: Results}

This body of research primarily focused on designing an art lesson that could promote cognitive and fine motor development for kindergarten through second grade students with known exposure to trauma. This chapter presents the findings from the collected data and presents the phenomenon that took place within the classes of trauma exposed students. This section is divided into three case studies which include data from kindergarten, first grade, and second grade classes. Each case study presents a summary of the grade level results as well as a comparison of a trauma exposed student's artworks with their well performing peers. As the researcher collected data and analyzed students' artworks, she further understood that in order to promote cognitive and fine motor growth, an art educator must first have knowledge of individual students' capabilities and needs.

To protect the identities of participants, no identifiable features were included in photographs and all participating students received pseudonyms throughout the duration of this research. The researcher only analyzed data from classrooms that included students with exposure to trauma with no indication of the classes they belong to at the participating school. In this study, students have been assigned numbers and are described as either having known exposure to trauma or having no known exposure to trauma. Tables displaying the performance and assessment tasks of each participant can be found in Appendices A through C.

\section{Exploratory Case Study 1: Kindergarten}

\section{Kindergarten Results}

Out of the six kindergarten classes, two contained students known to have been exposed to trauma. The two classes consisted of 26 kindergarten participants and had one identified 


\section{PROMOTING COGNITIVE AND FINE MOTOR DEVELOPMENT}

student per class. The students who were identified with known exposure to trauma are labeled as Student 16 and Student 22.

Kindergarten Participants with no Known Exposure to Trauma. When examining the first and second portraits of participants with no known exposure to trauma, 14 students created Pigassos, five students created Mootisses, and five students created undistinguishable artworks. When looking at the first portraits of the 19 students who created Pigasso or Mootisse characters, 17 students were able to include the correct facial features and arrangements, and 15 students were able to include the correct lines and shapes for their characters. When looking at the second portraits of the same 19 students, 16 were able to include the correct facial features and arrangements, 11 included the correct lines, and 14 included the correct shapes. Out of the 24 participants with no known exposure to trauma, one created two artworks that were the same, eight created similar artworks, and 15 created different artworks. Additionally, two students scored a 1, 16 students scored a 2, and six students scored a 3 in fine motor abilities.

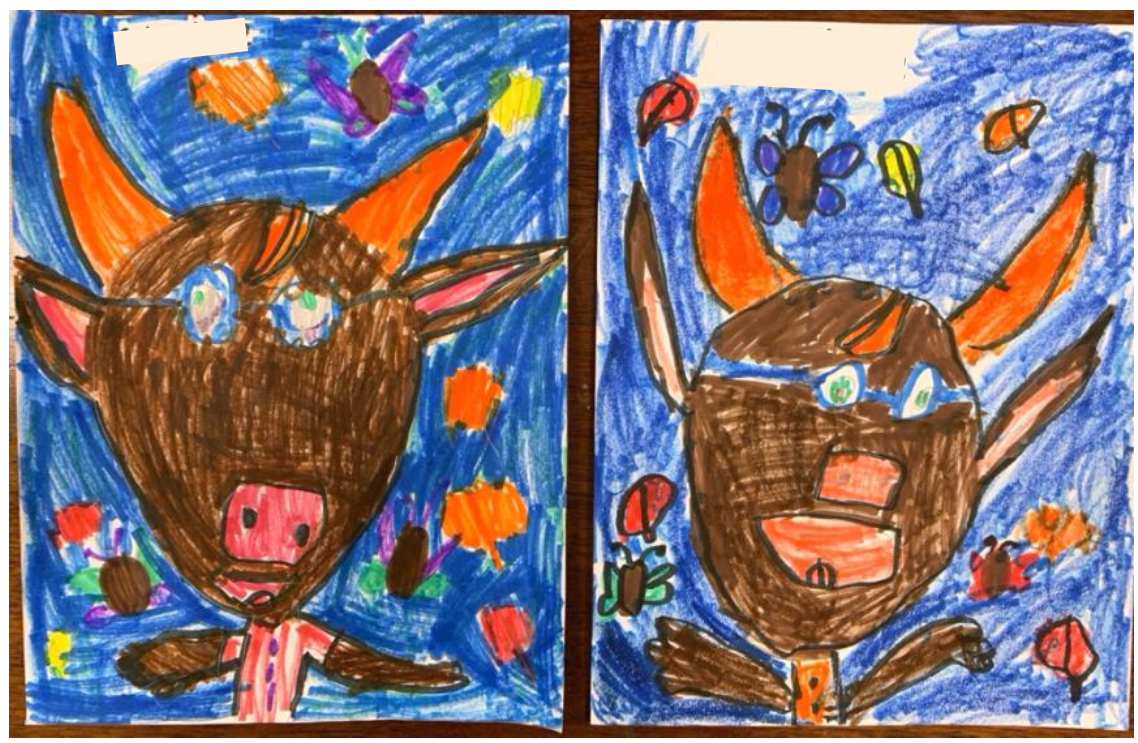

Figure 36. Kindergarten Student 24's Artworks. 
Student 24's Artwork Analysis. Student 24 has no known exposure to trauma. Their artwork is an example of a well performing student in kindergarten and in their class. Their portraits display the character Mootisse and include normally arranged facial features and several organic shapes within the background such as leaves and butterflies. The only element Student 24 did not include in their artworks was the correct use of lines, which is evidenced by use of black outlines in both portraits. Student 24's artworks are very similar to one another, indicating they understood the idea of replicating their sketch. This was a very rare occurrence in kindergarten. Additionally, they scored a 3 in fine motor abilities because they mostly created consistently straight lines and stayed within shapes when coloring.

Kindergarten Participants Identified with Exposure to Trauma. Students 16 and 22 were identified with known exposure to trauma. Student 16 created artworks that were undistinguishable while Student 22 created two Pigassos with varying differences between each portrait. Student 22 struggled mostly with staying focused in their final portrait and needed oneon-on assistance to help them stay on task during Class Periods 6 and 7.
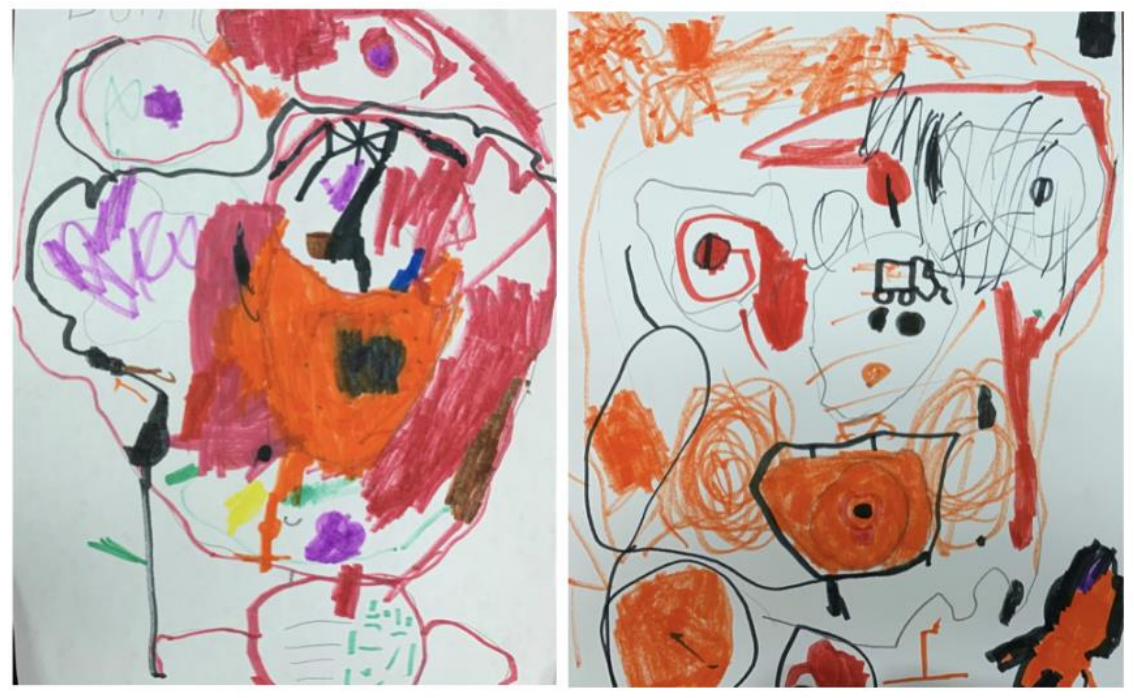

Figure 35. Kindergarten Student 16's Artworks. 
PROMOTING COGNITIVE AND FINE MOTOR DEVELOPMENT

Student 16's Exposure to Trauma. It was speculated by the school counselor that Student 16 had been exposed to domestic violence as well as possibly been neglected by members of their family. When the researcher returned to the site the school counselor reported one of their family members had recently been incarcerated.

Student 16's Artwork Analysis. Without speaking directly with the student about their artwork, it was very difficult to distinguish what character they drew. Both of student 16's portraits were scored as undistinguishable because although the colors used on the face in the first artwork appeared unusual, the use of black lines were inconsistent and there did not appear to be any attempt at drawing shapes that helped identify the character. Additionally, since the facial feature arrangements appeared relatively normal and they mainly used the color orange, it was difficult to discern what they were creating without asking them directly. While Student 16 was creating their artworks, the researcher provided repeated one-on-one assistance in an attempt to help them focus and stay on task. However, as soon as the researcher stepped away, they would lose focus on the requested tasks. Upon conducting an informal interview with Student 16, they stated that both artworks were pictures of Pigasso. In the first portrait they stated Pigasso was using lava to burn Mootisse; in the second portrait they stated Pigasso was eating a truck with a man inside because he was hungry. In addition to their cognitive abilities, the researcher was also concerned with their fine motor abilities. Although they were not the only student to receive an undistinguishable score for their artwork, they were one of the only students to score low in fine motor skills. Student 16 received a fine motor score of 1 because they did not show an ability to create shapes, color within shapes or lines, and many of their lines seemed to be more scribbling than purposeful.

\section{Exploratory Case Study 2: First Grade}


PROMOTING COGNITIVE AND FINE MOTOR DEVELOPMENT

\section{First Grade Results}

Out of the six first grade classes, three contained students who have been exposed to trauma. The three classes consisted of 35 first grade participants and had one identified student per class. The students who were identified with known exposure to trauma were labeled as Student 10, Student 15, and Student 31.

First Grade Participants with no Known Exposure to Trauma. When examining the first portraits of participants with no known exposure to trauma, 15 students created Pigassos, 14 students created Mootisses, and three students created undistinguishable artworks. When looking at the first artworks of the 29 students who created Pigasso or Mootisse portraits, 24 students included the correct facial features and arrangements, 27 students included the correct lines, and 26 students included the correct shapes for their characters. When examining the second portraits of participants with no known exposure to trauma, 14 students created Pigassos, 15 students created Mootisses, and three students created undistinguishable artworks. This result indicates one student changed characters between their first and second portraits. When looking at the second artworks of the 29 students who created Pigasso or Mootisse portraits, 24 students included the correct facial features and arrangements, and 24 students included the correct lines, and 24 students included the correct shapes for their characters. Out of the 32 participants with no known exposure to trauma, two created artworks that were the same, 17 created similar artworks, and 15 created different artworks. Additionally, six students scored a 1, 17 students scored a 2, and nine students scored a 3 in fine motor abilities. Finally, first grade students had the choice of creating a drawing or a collage for their second portrait. 19 out of 32 participants chose to create a drawing rather than a collage. 


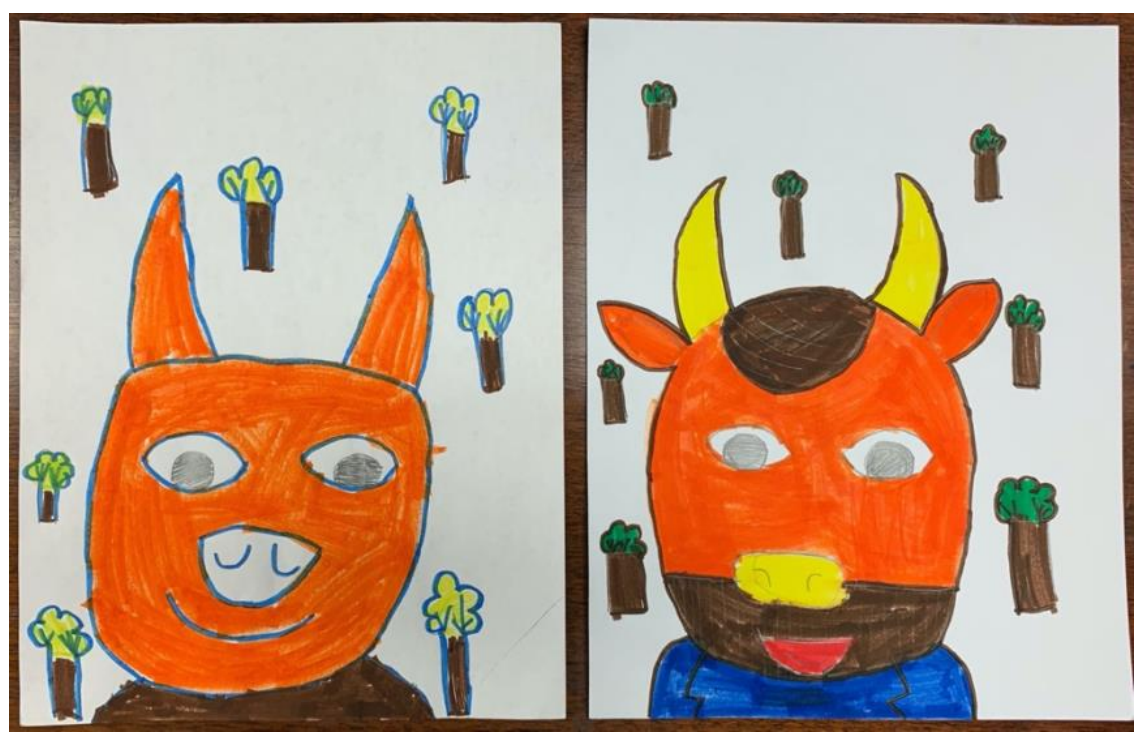

Figure 37. First Grade Student 2's Artwork.

Student 2's Artwork Analysis. Student 2 has no known exposure to trauma. Student 2's artwork is a great example of a well performing student in the first grade. Their portraits display the character Mootisse and include normally placed and colored facial features, blue and brown outlines, and organic tree shapes in the background. Although Student 2 was not ready to collage, they scored a 3 on fine motor abilities because they demonstrated excellent and clear lines and consistently stayed within the lines with coloring.

First Grade Participants Identified with Exposure to Trauma. Students 10, 15, and 31 were identified with having known exposure to trauma. Student 10 created a Pigasso for their first portrait and was able to incorporate the correct lines and shapes. However, their second portrait was undistinguishable. They chose to create a drawing for his final artwork, which was very different from their first. They also scored a 1 in fine motor abilities. Student 31 created Pigassos for both portraits that were similar to one another and contained the correct facial features, lines, and shapes. Although they drew their final artwork, they scored a 2 in fine motor abilities. 


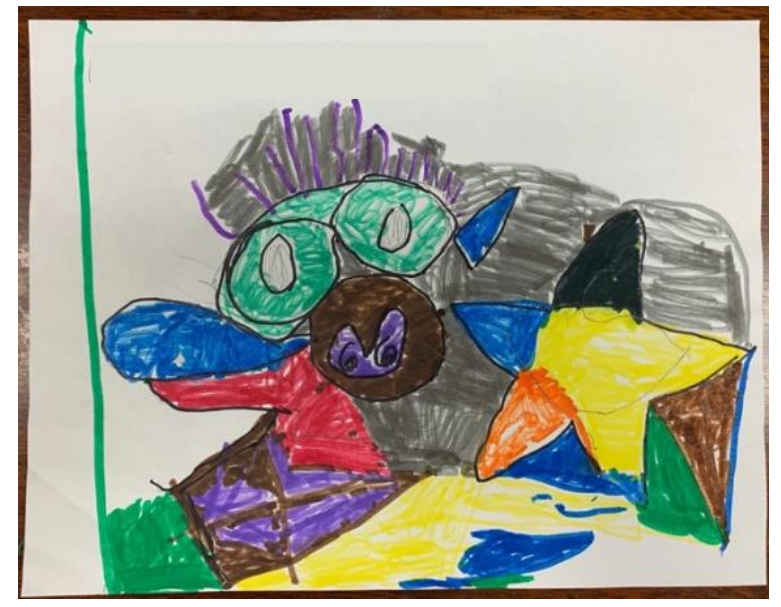

Figure 38. First Grade Student 15's Artwork.

Student 15's Exposure to Trauma. During the first interview with the school counselor, it was speculated that Student 15 had family members who were incarcerated, and they were living with a grandparent at the time. Student 15 has been diagnosed with mild autism spectrum disorder. The school counselor reported they are very quiet at school and does well when they are present in the classroom. However, Student 15 was absent for several school days during the time this research was being conducted. Upon returning to the site, the school counselor stated that they were still living with their grandparent.

Student 15's Artwork Analysis. Student 15 only had time to create their first portrait due to repeated absences. Their first artwork was a Pigasso portrait and displayed unusual facial features, black outlines, and geometric shapes such as the large star. Student 15 scored a 2 on fine motor abilities because they usually demonstrated an ability to create straight lines and stay within the lines when coloring, but some areas of their artwork displayed the opposite.

\section{Exploratory Case Study 3: Second Grade}

\section{Second Grade Results}


PROMOTING COGNITIVE AND FINE MOTOR DEVELOPMENT

Out of the six second grade classes, two contained students who have been exposed to trauma. The two classes consisted of 25 second grade participants and had one identified student in one class and two identified students in the other. The students who were identified with known exposure to trauma were labeled as Student 2, Student 18, and Student 21.

Second Grade Participants with no Known Exposure to Trauma. When examining the first portraits of participants with no known exposure to trauma, 15 students created Pigassos, seven students created Mootisses, and there were no undistinguishable artworks. When looking at the first artworks of all 22 participants, 22 students included the correct facial features and arrangements, 22 students included the correct lines, and 18 students included the correct shapes for their characters. When examining the second portraits of participants with no known exposure to trauma, 13 students created Pigassos, six students created Mootisses, one student created an undistinguishable artwork, and one student did not complete the project. When looking at the second artworks of the 20 students who created Pigasso or Mootisse portraits, 20 students included the correct facial features and arrangements, 15 students included the correct lines, and 18 students included the correct shapes for their characters. This result indicates five less students included the correct lines for their characters in the second portrait than in the first. Out of the 22 participants with no known exposure to trauma, two created artworks that were the same, 16 created similar artworks, and 4 created different artworks. Additionally, three students scored a 1, 14 students scored a 2, and five students scored a 3 in fine motor abilities. 


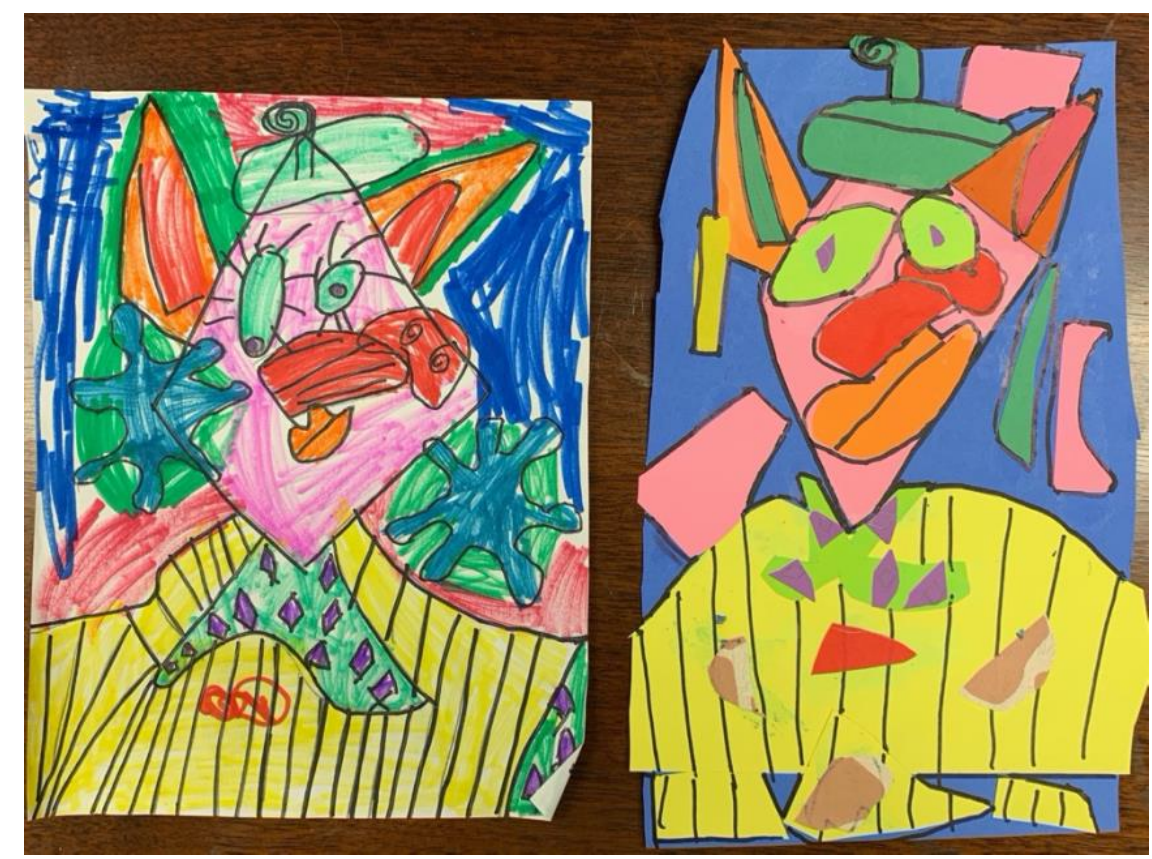

Figure 39. Second Grade Student 3's Artwork.

Student 3's Artwork Analysis. Student 3 has no known exposure to trauma. Student 3's artwork is a great example of a well performing student in the second grade. Their portraits display the character Pigasso and include unusually arranged facial features, black outlines, and geometric shapes such as the triangles, circles, ovals, and rhombus on Pigasso's face. Student 3 created very similar artworks and demonstrated an exceptional ability to collage. They scored a 2 in fine motor skills because they mostly drew and cut straight lines and stayed within the lines when coloring but needed to do so more consistently, specifically in the coloring they demonstrated in their sketch.

Second Grade Participants Identified with Exposure to Trauma. Students 2, 18, and 21 were identified with having known exposure to trauma. Students 2 and 21 created Mootisses for both of their portraits. Student 2 included the correct facial features and outlines but not the correct shapes for both artworks, whereas Student 21 struggled with the correct lines in both portraits and the correct shapes in their final artwork. Student 21 also created a drawing for their 
final portrait due to lack of focus and frustration during the collage making process. Both students created similar artworks and scored a 2 in fine motor abilities.

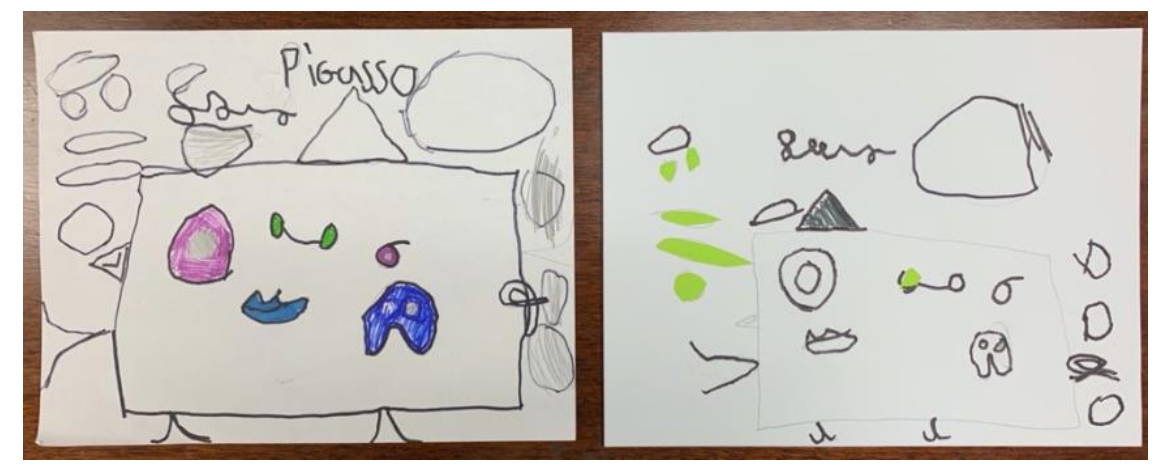

Figure 40. Second Grade Student 18's Artwork.

Student 18's Exposure to Trauma. Not much is known about Student 18's exposure to trauma. The school counselor did report that they were placed in foster care at the time of research. It was speculated that one of their immediate family members was engaging in an inappropriate relationship with a blood relative. When the researcher returned, the school counselor stated Student 18 was doing well in school and gaining more friends since they were placed in foster care.

Student 18's Artwork Analysis. Although Student 18's Pigasso portraits lacked color, they were able to incorporate unusual facial features, black outlines, and several geometric shapes in both artworks. Additionally, both portraits are very similar to one another. Student 18 struggled immensely with collaging, especially compared to their peers. To combat this issue, the researcher provided one-on-one assistance by asking the student to first draw his artwork. After they drew their second Pigasso portrait, the researcher instructed them to then cut out shapes from the drawing. They were able to cut out a few shapes from a green piece of paper to paste on top of their drawing. Although they struggled with collaging, they demonstrated a fine motor 
PROMOTING COGNITIVE AND FINE MOTOR DEVELOPMENT

score of 2 because they mostly drew and cut straight lines but needed to color more consistently within their shapes.

\section{Summary}

This chapter outlined the results that emerged from the collected data and was organized into three separate case studies. After discussing the results that surfaced within each grade level, the researcher compared the artworks of well performing nonidentified students to the artworks of students who were identified with known exposure to trauma. Every participant was evaluated on their ability to create a Pigasso or Mootisse portrait using the characters' respective visual elements and artistic styles. Additionally, students were assessed on how closely their final artworks related to their sketch. Finally, students were given a fine motor score that assessed how well they demonstrated their abilities to create lines and color within shapes in their artworks. Tables displaying the performance of each participant can be found within their corresponding case study in Appendices A through C. The following chapter will discuss and analyze the results that emerged within the case studies and provides an explanation of limitations and suggestions for future educators and researchers. 
PROMOTING COGNITIVE AND FINE MOTOR DEVELOPMENT

\section{Chapter 5: Discussion}

\section{Introduction}

The primary motive of this exploratory case study was to understand how an art educator can promote cognitive and fine motor development for young students exposed to trauma in the art room. To do so, the researcher first had to develop a theoretical understanding of the normal developmental milestones exhibited by students in the kindergarten through second grade classrooms. An additional factor was understanding how trauma may affect those milestones in the classroom. The findings in this exploratory case study appear to suggest that when creating lessons in the art room, an educator can create formal assessment tasks that indicate how well students perform given specific learning objectives. This is not a new process for art educators as most professionals engage in assessments while implementing lessons. However, since some states do not define art as an academic subject, it is necessary to develop more literature that displays how art educators can academically assess their students. By understanding the capabilities and needs of students with trauma exposure in the art room, an educator can target specific areas of development in future lessons to promote more growth. Summaries and interpretations of these findings are presented in this chapter along with an explanation of limitations and suggestions for further research.

\section{Exploratory Case Study Results}

This section discusses the results from each case study and includes summaries of students with and without known exposure to trauma. Specific performances and discussions about students with exposure to trauma will be further discussed in the sections to come. Most kindergarten students chose to create Pigassos, which may indicate that creating more realistic or "normal" facial features was not an interest to most students at this grade level. This result could 


\section{PROMOTING COGNITIVE AND FINE MOTOR DEVELOPMENT}

be attributed to the stage of cognitive development they are developing within. The information presented in the literature review of this research states that children in the preoperational stage enjoy creating elaborate characters because of their developing imaginative thoughts (Lumen Learning, n.d.). The first-grade classes had an almost even distribution of students who chose Pigasso or Mootisse as their characters for their artworks. This result could be an indication that students may be more inclined to create realistic portraits because of their developing abilities to draw recognizable human figures (Hurlock, 1956). Finally, second grade students had similar results to the kindergarten students in the fact that there were more Pigasso than Mootisse portraits.

As the grade levels progressed, less students created portraits that were undistinguishable. Kindergarten students had the highest occurrence of six undistinguishable artworks. However, only four students in first grade and only one student in second grade created artworks that could not be determined. This result could be attributed to either the fine motor developments that rapidly occur between the ages of five and seven years old (Hurlock, 1956) or that most students are exiting the preoperational stage of development by seven years old (Schonberg, 2013). Another factor that improved across grade levels was the number of students whose first portrait differed from their second. Although there was not a significant difference in the number of same artworks as the grade levels progressed, there was a significant leap in the occurrence of similar and different artworks. In kindergarten and first grade levels, 15 students created artworks that were different from one another. However, in second grade there were only four students who created different artworks.

When examining the fine motor skills of participants across grade levels, the researcher saw a significantly high occurrence of students who scored a 2 rating. Additionally, the 
PROMOTING COGNITIVE AND FINE MOTOR DEVELOPMENT

distribution of fine motor scores was very similar in regard to the students who scored a 1 versus students who scored a 3 . In each grade level, there was a higher occurrence of students scoring a 3 than a 1 in fine motor abilities. As Hurlock (1956) suggested in Child Development, motor development is one of the quickest forms of development, which could explain why the students had similar distributions of fine motor scores across grade levels. Based on the cumulative results and analysis of researcher field notes, important themes emerged from the analyzed case studies.

\section{Emerging Themes}

\section{All Struggling Students Deserve Help Tailored to Their Needs}

With the implementation of all-inclusive classrooms, it is no surprise that students' cognitive and fine motor developments varied within each grade level and classroom. With limited background information on participants who were not identified with known exposure to trauma by the school counselor, it is difficult to pinpoint what caused students to perform below average in their artworks. For example, confounding factors such as unidentified trauma exposure, undiagnosed disabilities, attention and interest in the project, or development delays could have played a role in students' ability to complete the project without the researchers knowledge. Additionally, since kindergarten students are still developing in the preoperational stage of cognitive development and second grade students are moving towards the concrete operational stage (Schonberg, 2013), it is not unusual that some students struggled to create distinguishable Pigasso or Mootisse portraits that included all of the assessment tasks.

Since this study took place within the constraints of student teaching experiences and within a classroom that contained nonparticipating students, the researcher had a moral and ethical obligation to help any student who needed extra assistance. Therefore, it is important to 


\section{PROMOTING COGNITIVE AND FINE MOTOR DEVELOPMENT}

recognize that the students who struggled, regardless of the causes behind their performance, still deserved one-on-one assistance that helped them progress forward with the project. One-on-one assistance included but was not limited to giving students additional materials and resources, holding down shapes while they traced, helping them pick out visual elements from the book, repeating instructions and demonstrations, and differentiating product requirements.

Since there was little to no background information about students who struggled but were not identified with known exposure to trauma, it is still possible these students have experienced traumatic events. Between 2015 and 2016, West Virginia saw a 22.3\% increase in reported child victims ("West Virginia's Children at a Glance", 2018, p.1). This statistic indicates the number of children who are exposed to trauma is not only increasing but also recognizes that there may be other childhood traumas that have not been reported. By taking a trauma-informed approach to teaching and addressing performance with the possibility that struggling students could be unidentified (McKlindon \& McInerney, 2014), students have a better chance of receiving the help they need to grow in any area of development.

\section{Students who have Experienced Trauma may not Always have Difficulty Performing}

\section{Cognitive and Fine Motor Tasks in the Classroom}

When analyzing the results of students who have been exposed to trauma, there was a wide variety of phenomena that took place. When analyzing the performance of trauma exposed students, Student 16 from Case Study 1 and Student 10 from Case Study 2 both created artworks that were undistinguishable. These two students also scored a 1 in fine motor abilities. When evaluating the students who created a drawing rather than a collage, Students 10 and 31 from Case Study 2 drew their final artwork. This result is not necessarily significant when comparing the two students with their peers. However, it may suggest they are average performing students 


\section{PROMOTING COGNITIVE AND FINE MOTOR DEVELOPMENT}

in the first grade. The more striking results come from Case Study 3. Two of the three students in second grade who were identified with exposure to trauma had significant difficulty with collage or chose to not use collage at all. Student 18 needed guided, one-on-one assistance in order to turn their drawing into a collage. On the contrary, Student 21 was more successful when given the opportunity to draw their final portrait instead of using collage. The school guidance counselor stated Student 21 often displayed difficulty focusing in school due to ongoing concern about drug abuse within their family. Research involving brain imaging studies have found evidence that trauma-induced changes to the brain can not only cause increased reactivity in the amygdala but can also cause children to have difficulty paying attention, focusing, and sleeping (Child Welfare Information Gateway, 2017). The symptoms Student 21 is exhibiting at school are often associated with children who have experienced trauma. Thus, their constant worrying is likely effecting their ability to focus in the classroom.

Similar to the results that surfaced with Student 21, the researcher's field notes, and direct observations indicated that several students, from all grade levels, lacked focus throughout the duration of the project, needing significant assistance to help them focus. For example, field notes indicated that Students 16 and 22 from Case Study 1 and Student 10 from Case Study 2 all had difficulties focusing at some point during the of the project. Moreover, most of these students showed less ability to focus in their second portrait than in their first one. Student 15 from Case Study 2 also had difficulty completing the project. However, their inability to create a second portrait was due to their frequent absences from school rather than their ability to focus. As indicated in the research of Blodgett and Lanigan (2018), children who have been identified as having three or more ACEs are more likely to have attendance problems compared to children with no known ACEs. (p.141) Although the number of ACEs for this student are not clear, it is 


\section{PROMOTING COGNITIVE AND FINE MOTOR DEVELOPMENT}

likely that Student 15's frequent absences could be a result of their homelife environment and the traumatic experiences they may endure.

These varying results do indicate that some students who have been exposed to trauma displayed difficulties with cognitive and fine motor tasks in this particular art room. These students needed consistent one-on-one assistance to help them progress in artmaking lessons. However, some trauma-exposed students were also average performers, like Student 31 from Case Study 2 and Student 2 from Case Study 3. These two students did not need as much assistance when creating their artworks. As seen in results across all grade levels, the majority of students in each classroom are average performers. Thus, trauma may not always be a clear indicator of students' abilities to meet lesson objectives and performance tasks in the classroom. Though, what is important to note is that none of the students in this study who had been identified with known exposure to trauma were categorized as well performing or above average performers. As stated in the literature review, trauma such as abuse, neglect, and maltreatment can affect a child's mood and behavior (Sykes Wylie, 2010), executive function capacities (Bick \& Nelson, 2016), and intellectual performance (Pechtel \& Pizzagalli, 2010). This is why it is necessary for educators to adopt a trauma-informed approach to viewing student behaviors and performance in the classroom (McKlindon \& McInerney, 2014).

\section{Fine Motor Skills Developed Quicker than Cognitive Functions}

As stated in the discussion of case study results, most students scored a 2 or 3 on fine motor abilities across grade levels. The results were relatively consistent especially compared to the cognitive assessments within this project. When analyzing students' cognitive abilities to incorporate the correct visual elements and artistic styles of their character into their portraits, the results were extremely varying. Although some patterns emerged in this data, such as one class 


\section{PROMOTING COGNITIVE AND FINE MOTOR DEVELOPMENT}

having more difficulty with lines than another, it is difficult to make generalized conclusions about students' cognitive abilities.

Some students displayed improved cognitive abilities between their first and second portraits, but the occurrences were much less consistent compared to the fine motor score results. These results seem to indicate that students are more likely to develop their fine motor abilities at a younger age, while their cognitive abilities continue to develop into later stages of their lives. This theme is consistent with Piaget's theory of cognitive development. Children between the ages of five and seven years old are moving through the preoperational stage of development, which means they still have two stages to develop through (Schonberg, 2013; Orey, 2010). Even further, Piaget's theory suggests children continue to cognitively develop well beyond 12 years of age (Schonberg, 2013).

\section{Promoting Cognitive and Fine Motor Development is a Gradual Process}

While the short duration of this research makes it difficult to conclusively confer whether or not students improved in cognitive and fine motor abilities, there were students who showed progress between their first and second images. No students who were identified with known trauma exposure showed obvious improvement but that does not mean this project did not help facilitate developmental growth. The art lesson and corresponding assessments allowed the researcher to see where students struggled or thrived within the project objectives. This helped determine what needs still needed to be addressed for students with varying cognitive and fine motor abilities. Students at this age are still rapidly developing their motor processes (Wassenberg et al., 2005, p. 1093; Ferrel-Chapus, Hay, Oliver, Bard, \& Fleury, 2002), which means they need clear instructional methods and age appropriate tools to help them achieve the artwork they desire to create. By giving students various tracing materials and resources, 


\section{PROMOTING COGNITIVE AND FINE MOTOR DEVELOPMENT}

students were able to create the artwork they desired and replicate shapes from their characters without getting too frustrated. Since children at this age can become easily discouraged with overwhelming tasks (Kuther, 2016), it was important to give them materials that allowed them to create shapes and characters with minimal difficulties. Similar to the use of age-appropriate art materials, it was necessary to teach students about artists and their artistic styles by using cognitively graspable concepts. Children at this age cannot engage in conceptual thinking (McLeod, 2018), therefore it was not appropriate to teach students that Picasso's Cubism is an abstract representation of reality. Therefore, to promote their cognitive growth, the researcher broke down the concepts of artistic styles and elements into small and understandable pieces of information. This strategy allowed students to process information more clearly and efficiently as well as manipulate the information for long-term memory storage (Huitt \& Hummel, 2003).

\section{Limitations}

Since this research took place within a real school setting, the participants within the study were in mixed groups with nonparticipating students. Due to this fact, the discussion of data must acknowledge that there were uncontrollable and unknown variables that could have affected the results of this study. The guidelines of the research had to be tailored to fit the specific setting of the cooperating school and art classroom. A significant limitation was the time frame students had to complete their artworks. As a student teacher, the researcher was assigned to the elementary school for an eight-week placement. Since the school's kindergarten through second grade related arts schedule rotates every sixth school day, it was difficult to complete the project within the allotted time. Due to the student teaching field experience taking place in the winter and early spring months, several school days were delayed or cancelled because of inclement weather. Thus, there were several unforeseen interruptions to the already restricted 


\section{PROMOTING COGNITIVE AND FINE MOTOR DEVELOPMENT}

relating arts schedule. On two-hour delay school days, students only attended art class for thirty minutes rather than forty minutes. Since there were significant breaks between art classes in some weeks, one can argue the students did not receive consistent or timely enough artmaking experiences to fully benefit their development. The researcher had to return to the location after her second placement to complete the projects with participants before they were dismissed for the summer months.

Another limitation to this research included generalizability of results from each case study. Since there were only eight students identified with known exposure to trauma, it is difficult to make overarching conclusions about all traumatized children and their experiences in the art classroom. Additionally, limited background information was obtained about the trauma exposed participants and no background information was obtained about children who have not been identified with known exposure to trauma by the school counselor. Thus, the results found in this study could come from multiple factors other than exposure to trauma, such as learning disabilities and school readiness. Trauma comes in many forms such as household substance abuse, divorce, abuse, mental illness, domestic violence, or incarceration of loved ones (“Adverse Childhood Experiences", 2015). Even further, the outcomes of traumatic experiences can be complicated and intertwined making it difficult to make conclusions about non-identified students' performance, behaviors, and developmental abilities in the classroom. It is important to note the conclusions that resulted from each case study explains the phenomenon that took place within this specific classroom. Although they may help other art educators tailor their lessons to meet the needs of trauma exposed students in the future, educators must be aware that their students' performance and behaviors in the classroom could be the result of unidentified 


\section{PROMOTING COGNITIVE AND FINE MOTOR DEVELOPMENT}

exposure to trauma. Therefore, art educators need to approach the classroom with a traumainformed perspective in order to help all students develop and grow.

\section{Suggestions}

If this research were to be replicated, it would be very beneficial for future researchers to obtain more information on individual students and control over the composition of classes. Furthermore, it would be easier to collect more consistent data with smaller class numbers and more one-on-one time with participants who have been identified as exposed to trauma. However, these issues are realities current educators, and especially related arts educators, face on a daily basis in school. Implementing trauma-informed programs into school communities is the first step in helping identify children who have experienced trauma and giving them the resources needed to heal. Students who have exposure to trauma can greatly benefit from early interventions and a trauma-informed classroom environment. This research suggests that creating lessons tailored to the needs of struggling students is possible and that development, specifically in the areas of fine motor and cognitive growth, can be promoted by being aware of the consequences trauma can evoke on young children.

In order to further promote the developmental growth of students who have experienced trauma, it is necessary for trauma-informed programs such as Handle with Care to expand into all areas of the country and provide educators with proper trauma-informed training. A traumainformed perspective to teaching can help an educator adopt the mindset that students' performance, behaviors, and developmental capabilities in the classroom could be resulting from their life experiences.

It is also necessary for trauma-informed school communities to recognize the benefits artmaking experiences can offer students who are struggling with the outcomes of their traumatic 


\section{PROMOTING COGNITIVE AND FINE MOTOR DEVELOPMENT}

life experiences. Implementing one-on-one artmaking sessions with art educators or more frequent art classes into trauma-informed resources can positively impact young students because it can help them find inner peace as well as reduce their stress levels (Losinski, Hughey, \& Maag, 2016; Kaimal, Ray, \& Muniz, 2016). Thus, more research should be conducted to further understand how specific artmaking experiences can directly benefit students with exposure to trauma and promote developmental growth.

\section{Conclusion}

The reality of contemporary teaching, especially for art teachers, is that children who come into the classroom have varying capabilities and personal struggles. Art educators know so little about students' realities outside of school or even outside of their art room. Furthermore, assessing how every student's experiences in life directly translate to the classroom is nearly impossible. That is why it is so essential to view each student through a trauma-informed lens. Hence, seeing a student struggle with an art project could be the result of a bad day, a disability, lack of interest, and so on. It could also be a result of exposure to trauma, which is a factor educator must be sensitive to. Untangling the ins and outs of trauma is not a simple endeavor. Behaviors overlap, symptoms vary, and it can be impossible to predict what will trigger a student. Society is just beginning to understand how complex and widespread the consequences of trauma can be.

Although this research focused exclusively on cognitive and fine motor development, this trauma-informed approach to art education can translate to other areas such as emotional and social development. This exploratory case study was meant to start the conversation of how to address the developmental issues that can accompany exposure to trauma for young students in the art room and how an art can be a vital pathway to fostering resilience, developmental growth, 
PROMOTING COGNITIVE AND FINE MOTOR DEVELOPMENT

and healing. Creating this kind of learning environment for students takes time, research, compassion, understanding, and ultimately an awareness of helpful resources and interventions. This research can help art educators better understand how to promote development and grown in the art room for students exposed to trauma. Even further, by making critical connections between the implementation of trauma-informed school communities and a trauma-informed approach in the art room in this research, hopefully law makers will realize how artmaking experiences can exceedingly benefit the students who have been exposed to trauma. 
PROMOTING COGNITIVE AND FINE MOTOR DEVELOPMENT

\section{References}

Allen, L. R., \& Kelly, B. B. (2015). Transforming the workforce for children birth through age 8: a unifying foundation. Institute of Medicine and National Research Council. Retrieved from https:/www.nap.edu/resource/19401/ProfKnowCompFINAL.pdf.

American Academy of Pediatrics. (2014). Adverse Childhood Experiences and the Lifelong Consequences of Trauma. American Academy of Pediatrics, 1-5. Retrieved from https://www.aap.org/en-us/documents/ttb_aces_consequences.pdf.

Andrus, L. (2006). Art education, art therapy, and therapeutic teaching. Gerber, B. \& Guay. D. (Eds.), Reaching and teaching students with special needs through art, 177-188.

Atkinson, R. C., \& Shiffrin, R. M. (1968). Chapter: Human memory: A proposed system and its control processes. In Spence, K. W., \& Spence, J. T. The psychology of learning and motivation (Volume 2). New York: Academic Press. pp. 89-195.

Baker, D. (2013). Art Integration and Cognitive Development. Journal for Learning through the Arts: A Research Journal on Arts Integration in Schools and Communities, 9(1), 1-17. doi: $10.21977 / \mathrm{d} 9912630$.

Barnea-Goraly, N., Menon V., Eckert M., Tamm L., Bammer R., Karchemskiy A., Dant C., Reiss A., White Matter Development During Childhood and Adolescence: A Crosssectional Diffusion Tensor Imaging Study, Cerebral Cortex, Volume 15, Issue 12, December 2005, Pages 1848-1854, https://doi.org/10.1093/cercor/bhi062.

Bick, J., \& Nelson, C. A. (2015). Early Adverse Experiences and the Developing Brain. Neuropsychopharmacology, 41(1), 177-196. doi: 10.1038/npp.2015.252.

Blodgett, C. (2016). Foreword. In Fostering Resilient Learners: Strategies for Creating a Trauma-Sensitive Classroom (pp. ix-xi). Alexandria, VA: ASCD. 


\section{PROMOTING COGNITIVE AND FINE MOTOR DEVELOPMENT}

Blodgett, C., \& Lanigan, J. (2018). The association between adverse childhood experience (ace) and school success in elementary school children. School Psychology Quarterly: The Official Journal of the Division of School Psychology, American Psychological Association, 33(1), 137-146. doi:10.1037/spq0000256.

Bolwerk, A., Mack-Andrick, J., Lang, F. R., Dörfler, A., \& Maihöfner, C. (2014). Correction: How Art Changes Your Brain: Differential Effects of Visual Art Production and Cognitive Art Evaluation on Functional Brain Connectivity. PLoS ONE, 9(12). doi: 10.1371/journal.pone.0116548.

Bransford, J. D. E., Cocking, R. R. E., \& Brown, A. L. E. (2000). How People Learn: Brain, Mind, Experience, and School (Expanded). Washington, DC: National Academies Press.

Bray, B. (2016, March 17). Handle with care: Addressing child trauma in West Virginia. Retrieved from https://ct.counseling.org/2015/05/handle-with-care-addressing-childtrauma-in-west-virginia/.

Bremner, J. D., Randall, P., Vermetten, E., Staib, L., Bronen, R. A., Mazure, C., ... Charney, D. S. (1997). Magnetic resonance imaging-based measurement of hippocampal volume in posttraumatic stress disorder related to childhood physical and sexual abuse--a preliminary report. Biological psychiatry, 41(1), 23-32. doi:10.1016/s00063223(96)00162-x

Brown, T., \& Jernigan, T. (2012). Brain development during the preschool years. Neuropsychology Review, 22(4), 313-333. doi:10.1007/s11065-012-9214-1.

Cameron, C. E., Brock, L. L., Murrah, W. M., Bell, L. H., Worzalla, S. L., Grissmer, D., \& Morrison, F. J. (2012). Fine motor skills and executive function both contribute to 


\section{PROMOTING COGNITIVE AND FINE MOTOR DEVELOPMENT}

kindergarten achievement. Child development, 83(4), 1229-1244. doi:10.1111/j.14678624.2012.01768.x.

Carrión, V. G., Haas, B. W., Garrett, A., Song, S., \& Reiss, A. L. (2010). Reduced hippocampal activity in youth with posttraumatic stress symptoms: an FMRI study. Journal of pediatric psychology, 35(5), 559-569. doi:10.1093/jpepsy/jsp112.

Centers for Disease Control and Prevention. (2019, April 9). About Adverse Childhood Experiences Retrieved July 30, 2019, from https://www.cdc.gov/violenceprevention/childabuseandneglect/acestudy/aboutace.html.

Center on the Developing Child (2017). Resilience. Retrieved from https://developingchild.harvard.edu/science/key-concepts/resilience/.

Center on the Developing Child (2017). Toxic Stress. Retrieved from https://developingchild.harvard.edu/science/key-concepts/toxic-stress/.

Center on the Developing Child. (2015). Brain Architecture. Retrieved from https://developingchild.harvard.edu/science/key-concepts/brain-architecture/.

Cheat Lake, WV (n.d.) Retrieved February 18, 2019, from https://datausa.io/profile/geo/cheatlake-wv\#demographics.

Cherry, K. (2019, July 15). The Location and Function of the Cerebellum in the Brain. Retrieved from https://www.verywellmind.com/what-is-the-cerebellum-2794964.

Child Development Network. (2003). Children's health fact sheets: Child Development Milestones. Retrieved from https://www.health.qld.gov.au/__data/assets/pdf_file/0018/427230/28134.pdf. 
PROMOTING COGNITIVE AND FINE MOTOR DEVELOPMENT

Child Welfare Information Gateway. (2013, February 22). ADVERSE CHILDHOOD

EXPERIENCES - looking at how ACES affect our lives \& society. Retrieved from https://vetoviolence.cdc.gov/apps/phl/resource_center_infographic.html.

Child Welfare Information Gateway. (2017). Supporting brain development in traumatized children and youth. Washington, DC: U.S. Department of Health and Human Services, Children's Bureau.

Child Welfare League of America. (2018). West Virginia's Children at a Glance. West Virginia's Children at a Glance. Retrieved from https:/www.cwla.org/wpcontent/uploads/2018/04/West-Virginia.pdf.

Childcare. (2019, August 15). Creative Art Helps Children Develop across Many Domains. Retrieved from https://childcare.extension.org/2019/08/creative-art-helps-childrendevelop-across-many-domains/.

Children's Therapy \& Family Resource Centre. (2011). Preschool Developmental Milestones. Retrieved from http://www.kamloopschildrenstherapy.org/fine-motor-skills-preschoolmilestones.

Cohen N.J., Lojkasek M., Zadeh Z.Y., Pugliese M., Kiefer H. (2008) Children adopted from China: a prospective study of their growth and development. J Child Psychol Psychiatry 49:458-468.

Cole, S. F., Greenwald O'Brien, J., Gadd, M. G., Ristuccia, J., Wallace, D. L., \& Gregory, M. (2005). Helping traumatized children learn supportive school environments for children traumatized by family violence. Boston, MA: Massachusetts Advocates for Children. Retrieved from https://traumasensitiveschools.org/trauma-and-learning/the-solutiontrauma-sensitive-schools. 


\section{PROMOTING COGNITIVE AND FINE MOTOR DEVELOPMENT}

Committee for Children,Committee for Children. (2012, November 8). The Recipe for Creating Positive Teacher-Student Relationships. Retrieved from https://www.cfchildren.org/blog/2012/11/the-recipe-for-creating-positive-teacherstudent-relationships/.

Crawford, M. J., \& Weber, B. (2013). Early intervention every day! Embedding activities in daily routines for young children and their families. Retrieved from https://ebookcentral.proquest.com.

Cynader, M.S., and B.J. Frost. 2000. Mechanisms of Brain Development: Neuronal Sculpting by the Physical and Social Environment. In D. Keating and C. Hertzman, eds. Developmental Health and the Wealth of Nations. New York: Guilford Press.

Danese, A., Moffitt, T. E., Harrington, H., Milne, B. J., Polanczyk, G., Pariante, C. M., ... Caspi, A. (2009). Adverse childhood experiences and adult risk factors for age-related disease: depression, inflammation, and clustering of metabolic risk markers. Archives of pediatrics \& adolescent medicine, 163(12), 1135-1143. doi:10.1001/archpediatrics.2009.214.

Davis, S. (2018, November 19). Adverse Childhood Experiences and the Changes to the Human Brain. Retrieved from https://cptsdfoundation.org/2018/11/19/adverse-childhoodexperiences-and-the-changes-to-the-human-brain/.

De Bellis MD, Hooper SR, Spratt EG, Woolley DP (2009) Neuropsychological findings in childhood neglect and their relationships to pediatric PTSD. J Int Neuropsychology Soc $15: 868-878$.

De Bellis MD. (2005). The Psychobiology of Neglect. Child Maltreatment, 10(2), 150-172. doi: $10.1177 / 1077559505275116$. 


\section{PROMOTING COGNITIVE AND FINE MOTOR DEVELOPMENT}

De Bellis, M. D. (2001). Developmental traumatology: The psychobiological development of maltreated children and its implications for research, treatment and policy. Development and Psychopathology, 13, 539-564.

De Bellis, M. D., \& Zisk, A. (2014). The biological effects of childhood trauma. Child and adolescent psychiatric clinics of North America, 23(2), 185-vii. doi:10.1016/j.chc.2014.01.002.

De Wilde, A., Koot, H.M. \& van Lier, P.A.C. Journal of Abnormal Child Psychology (2016) 44: 19. https://doi-org.www.libproxy.wvu.edu/10.1007/s 10802-015-0053-4.

Delima, J., \& Vimpani, G. (2011). The neurobiological effects of childhood maltreatment: An often overlooked narrative related to the long-term effects of early childhood trauma? Family Matters, 89, 42-52.

Diamond, A. (2000). Close Interrelation of Motor Development and Cognitive Development and of the Cerebellum and Prefrontal Cortex. Child Development, 71(1), 44-56. doi: $10.1111 / 1467-8624.00117$

Durham, H. (2016). School Leadership in the Wake of a Natural Disaster: Healing Through Creative Expression. Education Week, 36(15), 22. Retrieved from https://www.edweek.org/ew/articles/2016/12/14/how-art-can-help-children-overcometrauma.html

Dwyer H. (2010). Stages of Development. Curriculum connections psychology: Cognitive development. London, UK: Brown Bear Books Ltd. Retrieved from http://www.libproxy.wvu.edu/login?url=https://search.credoreference.com/content/entry/ bbbcd/stages_of_development/0?institutionId=735. 


\section{PROMOTING COGNITIVE AND FINE MOTOR DEVELOPMENT}

Echo. (2018, December 17). We love science! Retrieved from https://www.echotraining.org/welove-science/.

Education Commission of the States and Arts Education Partnership, Art Scan at a Glance:

Connecting the States and Arts Education Policy, retrieved March 12, 2018 from https://www.ecs.org/wp-content/uploads/2018_ArtScan-at-a-Glance.pdf.

Ferrel-Chapus, C., Hay, L., Olivier, I., Bard, C., \& Fleury, M. (2002). Visuomanual coordination in childhood: Adaptation to visual distortion. Experimental Brain Research, 144(4), 506517.

Fields, R. D. (2008). White Matter. Scientific American, 54-61. Retrieved from https://pdfs.semanticscholar.org/20c6/460d03c850cf9b7bdaff52a1e5cbd87a565a.pdf.

Filley, C. M., \& . (2003). White Matter Disorders. In Neuropsychiatry (2nd ed., pp. 991-1017). Philadelphia, PA: Lippincott Williams \& Wilkins.

Fischer, K. W., \& Immordino-Yang, M. (2008). The Jossey-Bass reader on the brain and learning (1st ed.). San Francisco: Jossey-Bass.

Folger AT, Eismann EA, Stephenson NB, et al. Parental Adverse Childhood Experiences and Offspring Development at 2 Years of Age. Pediatrics. 2018;141(4):e20172826.

Gaines Lewis, J. (2015, February 11). This Is How the Brain Filters Out Unimportant Details. Retrieved from https://www.psychologytoday.com/us/blog/brain-babble/201502/is-howthe-brain-filters-out-unimportant-details.

Gill, K. (2018, January 3). What Is Synaptic Pruning? Retrieved from https://www.healthline.com/health/synaptic-pruning.

Greutman, H. (2017). Basics of fine motor skills: developmental activities for kids. Place of publication not identified: Growing Hands-on Kids, LLC. 


\section{PROMOTING COGNITIVE AND FINE MOTOR DEVELOPMENT}

Handle with Care. (n.d.). Retrieved August 1, 2019, from http://www.handlewithcarewv.org/handle-with-care.php.

Harris, Y. (2005). Cognitive development. In N. J. Salkind (Ed.), Encyclopedia of human development (pp. 276-280). Thousand Oaks, CA: SAGE Publications, Inc. doi: 10.4135/9781412952484.n138.

Hart, H., \& Rubia, K. (2012). Neuroimaging of child abuse: a critical review. Frontiers in human neuroscience, 6, 52. doi:10.3389/fnhum.2012.00052.

Heerema, E. (2019, August 15). Elaborative Rehearsal: A Better Way to Memorize. Retrieved from https://www.verywellhealth.com/elaborative-rehearsal-a-better-way-to-memorize98694.

Hoffman, A. (2013, November 13). 10 Toys and Household Items to Help Develop Fine Motor Skills - Friendship Circle - Special Needs Blog. Retrieved from https://www.friendshipcircle.org/blog/2012/12/19/10-toys-and-household-items-to-helpdevelop-fine-motor-skills/.

Hollas, B. (2007). Differentiating Instruction in a Whole-Group Setting: Taking the Easy First Steps into Differentiation, grades 7-12. Peterborough, NH: Crystal Springs Books.

Hoon Oh, D. (2012). Traumatic Experiences Disrupt Amygdala - Prefrontal Connectivity. Intech Open. Retrieved from https://www.intechopen.com/books/the-amygdala-a-discretemultitasking-manager/traumatic-experiences-disrupt-amygdala-prefrontal-connectivity.

Hughes, M., \& Tucker, W. (2018). Poverty as an adverse childhood experience. North Carolina medical journal, 79(2), 124-126. 


\section{PROMOTING COGNITIVE AND FINE MOTOR DEVELOPMENT}

Huitt, W., \& Hummel, J. (2003). Piaget's theory of cognitive development. Educational Psychology Interactive. Valdosta, GA: Valdosta State University. Retrieved from http://www.edpsycinteractive.org/topics/cognition/piaget.html.

Hunter, E. (2018, January 18). 'Children are like little sponges': early learning can set them up for life. Retrieved from https://theirworld.org/news/early-learning-sets-up-youngchildren-for-life.

Hurlock, E. B. (1956). Child Development (3rd ed.). New York, NY: McGraw-Hill Book Company.

Hurlock, E. B. (1972). Child Development (5th ed.). New York, NY: McGraw-Hill Book Company.

Kaimal, G., Ray, K., \& Muniz, J. (2016). Reduction of Cortisol Levels and Participants' Responses Following Art Making. Art therapy : journal of the American Art Therapy Association, 33(2), 74-80. doi:10.1080/07421656.2016.1166832.

Kuther, T. L. (2016). Lifespan development: lives in context (1st ed.). Retrieved from http://edge.sagepub.com/sites/default/files/07_KUTHER.pdf.

Kuther, T. L. (2019). Lifespan development in context: a topical approach. Thousand Oaks, CA: SAGE. pp. 239-274.

Laden, N. (2009). When Pigasso met Mootisse. San Francisco: Chronicle Books.

Lally, M., Valentine-French, S., \& Open Textbook Library. (2019). Lifespan Development : A psychological perspective. Retrieved August 2019, from http://dept.clcillinois.edu/psy/LifespanDevelopment.pdf.

Larsen, P. D., \& Stensaas, S. S. (2019). Developmental Anatomy. Retrieved from https://neurologicexam.med.utah.edu/pediatric/html/dev_anatomy.html. 
PROMOTING COGNITIVE AND FINE MOTOR DEVELOPMENT

Lofland, J., \& Lofland, L. H. (1984). Analyzing Social Settings: A Guide to Qualitative Observation and Analysis. Wadsworth Publishing Company.

Loman M.M., Wiik K.L., Frenn K.A., Pollak S.D., Gunnar M.R. (2009) Post institutionalized children's development: growth, cognitive, and language outcomes. J Dev Behav Pediatr $30: 426-434$.

Losinski, M., Hughey, J., \& Maag, J. W. (2016). Therapeutic Art: Integrating the Visual Arts into Programming for Students with Emotional and Behavioral Disorders. Beyond Behavior, 25(1), 27-34. https://doi.org/10.1177/107429561602500105.

Lourenco, O., \& Machado, A. (1996). In Defense of Piaget's Theory: A Reply to 10 Common Criticisms. The American Psychological Association: Psychological Review, 103, 143164. Retrieved from https://pdfs.semanticscholar.org/2dec/e70e2b917d7e3f846db9285878811d1ddbe3.pdf.

Lumen Learning. (n.d.). Introduction to Psychology. Retrieved from https://courses.lumenlearning.com/waymaker-psychology/chapter/reading-childhood/.

Lumen Learning. (n.d.). Piaget's Theory of Cognitive Development. Retrieved from https://courses.lumenlearning.com/teachereducationx92x1/chapter/piagets-theory-ofcognitive-development/.

Majute, E. (2018, April 18). Self-Care Skills and Child Development - AZOPT Kids Place. Retrieved from https://azopt.net/self-care-skills/.

Marr, D., Cermak, S., Cohn, E. S., \& Henderson, A. (2003). Fine Motor Activities in Head Start and Kindergarten Classrooms. American Journal of Occupational Therapy, 57(5), 550557. doi: 10.5014/ajot.57.5.550. 


\section{PROMOTING COGNITIVE AND FINE MOTOR DEVELOPMENT}

Martin, L., Oepen, R., Bauer, K., Nottensteiner, A., Mergheim, K., Gruber, H., \& Koch, S. C. (2018). Creative Arts Interventions for Stress Management and Prevention-A Systematic Review. Behavioral sciences (Basel, Switzerland), 8(2), 28. doi:10.3390/bs8020028.

Matusov, E., \& Hayes, R. (2000). Sociocultural critique of Piaget and Vygotsky. New Ideas in Psychology, 18(2-3), 215-239. doi: 10.1016/s0732-118x(00)00009-x.

McKlindon, A., \& McInerney, M. (December 2014). Unlocking the Door to Learning: TraumaInformed Classrooms \& Transformational Schools (pp. 1-24). Education Law Center. Retrieved from https://www.elc-pa.org/wp-content/uploads/2015/06/Trauma-Informedin-Schools-Classrooms-FINAL-December2014-2.pdf.

Mclaughlin, K. A., Sheridan, M. A., \& Lambert, H. K. (2014). Childhood adversity and neural development: Deprivation and threat as distinct dimensions of early experience. Neuroscience \& Biobehavioral Reviews, 47, 578-591. doi: 10.1016/j.neubiorev.2014.10.012.

McLaughlin, K., Sheridan, M., Gold, A., Duys, A., Lambert, H., Peverill, M., . . Pine, D. (2016). Maltreatment exposure, brain structure, and fear conditioning in children and adolescents. Neuropsychopharmacology : Official Publication of the American College of Neuropsychopharmacology, 41(8), 1956-64. doi:10.1038/npp.2015.365.

McLeod, S. (2009). Short Term Memory. Retrieved from https://www.simplypsychology.org/short-term-memory.html.

McLeod, S. (2017). Memory: A-level Revision Notes AQA(A). Retrieved from https://www.simplypsychology.org/a-level-memory.html.

McLeod, S. A. (2018). Preoperational stage. Retrieved from https://www.simplypsychology.org/preoperational.html. 


\section{PROMOTING COGNITIVE AND FINE MOTOR DEVELOPMENT}

Miller-Karas, E. (2015). Building resilience to trauma: the trauma and community resiliency models. New York: Routledge, Taylor \& Francis Group.

Molnar, A. \& Hertenstein, M. (2005). Piaget, jean (1896-1980). In N. J. Salkind (Ed.), Encyclopedia of human development (pp. 1008-1008). Thousand Oaks, CA: SAGE Publications, Inc. doi: 10.4135/9781412952484.n486.

Morin, A. (2015). Developmental Delays: What You Need to Know. Retrieved from https://www.understood.org/en/learning-attention-issues/treatments-approaches/earlyintervention/what-you-need-to-know-about-developmental-delays.

Morin, A. (2019, June 23). What You Need to Know About Your 5-Year-Old's Development. Retrieved from https://www.verywellfamily.com/5-year-old-developmental-milestones620713

Musiek, F. E. (1986). Neuroanatomy, Neurophysiology, and Central Auditory Assessment. Part III. Ear and Hearing, 7(6), 349-358. doi: 10.1097/00003446-198612000-00001.

National Center for Mental Health Promotion and Youth Violence Prevention. (n.d.). Childhood Trauma and its Effect on Healthy Development [Brochure]. Author. Retrieved August 13, 2019, from

http://www.promoteprevent.org/sites/www.promoteprevent.org/files/resources/childhood trauma_brief_in_final.pdf.

National Child Traumatic Stress Network Schools Committee (October 2008). Child Trauma

Toolkit for Educators. Los Angeles, CA \& Durham, NC: National Center for Child Traumatic Stress.

National Child Traumatic Stress Network. (2017). Creating, Supporting, and Sustaining Trauma-Informed Schools; A system framework. Los Angeles, CA, \& Durham, NC: 
PROMOTING COGNITIVE AND FINE MOTOR DEVELOPMENT

National Center for Child Traumatic Stress. Retrieved from

https://www.nctsn.org/sites/default/files/resources/creating_supporting_sustaining_traum

a_informed_schools_a_systems_framework.pdf.

National Coalition for Core Arts Standards. (2014). Retrieved from

http://www.nationalartsstandards.org/sites/default/files/Visual Arts at a Glance - new copyright info.pdf.

National Core Arts Standards: A Conceptual Framework for Arts Learning. (n.d.). Retrieved from https://www.nationalartsstandards.org/content/national-core-arts-standards.

National Institute of Neurological Disorders and Stroke. (2019, August). Brain Basics: The Life and Death of a Neuron. Retrieved from https://www.ninds.nih.gov/Disorders/PatientCaregiver-Education/Life-and-Death-Neuron.

Olson, C. B., \& Land, R. (2007). A Cognitive Strategies Approach to Reading and Writing Instruction for English Language Learners in Secondary School. Research in the Teaching of English, 41, 269-303. Retrieved from https://www.nwp.org/cs/public/download/nwp_file/8538/Booth_Olson,_Carol,_et_al.pdf ?x-r=pcfile_d.

Orey, M. (2010). Emerging perspectives on learning, teaching and technology. Place of publication not identified: CreateSpace.

Oswalt Morelli, A. (n.d.). Attention, Memory and Meta-Cognition. Retrieved from https://www.gracepointwellness.org/1272-child-development-theory-middle-childhood8-11/article/37681-attention-memory-and-meta-cognition. 


\section{PROMOTING COGNITIVE AND FINE MOTOR DEVELOPMENT}

Pechtel, P., \& Pizzagalli, D. A. (2010). Effects of early life stress on cognitive and affective function: an integrated review of human literature. Psychopharmacology, 214(1), 55-70. doi: 10.1007/s00213-010-2009-2.

Polloni, A. (2019, January 10). Children are like Sponges. Retrieved from http://everydaylanguage.qwriting.qc.cuny.edu/2014/01/10/children-are-like-sponges/

Poverty and Adverse Childhood Experiences (ACEs). (2018, September 27). Retrieved from https://www.children1 st.org.uk/who-we-are/news/blog/poverty-and-adverse-childhoodexperiences-aces/.

Preschool Developmental Milestones. (2011). Retrieved from http://www.kamloopschildrenstherapy.org/fine-motor-skills-preschool-milestones.

Preston, A. R., \& Eichenbaum, H. (2013). Interplay of hippocampus and prefrontal cortex in memory. Current biology : CB, 23(17), R764-R773. doi:10.1016/j.cub.2013.05.041.

Robertson, S. (2018, August 23). What is Grey Matter? Retrieved from https://www.newsmedical.net/health/What-is-Grey-Matter.aspx.

Robson, C. (2011). Real world research: a resource for social scientists and practitionerresearchers (3rd ed.). Oxford: Blackwell.

Romero, V. E., Robertson, R., \& Warner, A. (2018). Building Resilience in Students Impacted by Adverse Childhood Experiences: A Whole-Staff Approach (1st ed.). Corwin.

Rutter M., O’Connor T.G. (2004) Are there biological programming effects for psychological development? Findings from a study of Romanian adoptees. Dev Psychol 40:81-94.

Salkind, N. J. (2010). Encyclopedia of research design Thousand Oaks, CA: SAGE Publications, Inc. doi: $10.4135 / 9781412961288$. 


\section{PROMOTING COGNITIVE AND FINE MOTOR DEVELOPMENT}

Salkind, N. J. (Ed.) (2005). Encyclopedia of human development Thousand Oaks, CA: SAGE Publications, Inc. doi: 10.4135/9781412952484.

Schonberg, C. (2013, April 21). Psychology Classics: Piaget's Stages of Cognitive Development. Retrieved from https://www.psychologyinaction.org/psychology-in-action1/2013/04/21/piagets-stages-of-cognitive-development.

Shore, R. (1997). Rethinking the Brain: New Insights into Early Development. New York, NY: Families and Work Institute, pp. 16-17.

Shultis, J. (2018, January 3). 20 Art Therapy Activities You Can Try at Home to Destress. Retrieved from https://www.lifehack.org/articles/lifestyle/20-art-therapy-activities-youcan-try-home-destress.html.

Sleep, Learning, and Memory. (2007, December 18). Retrieved from http://healthysleep.med.harvard.edu/healthy/matters/benefits-of-sleep/learning-memory

Sloan, W. M. (2012). What is the Purpose of Education? ASCD Education Update, 54(7). Retrieved from http://www.ascd.org/publications/newsletters/educationupdate/jul12/vol54/num07/What-Is-the-Purpose-of-Education $\varnothing$.aspx.

Snaidero, N., \& Simons, M. (2014). Myelination at a glance. Journal of Cell Science, 127(14), 2999-3004. doi: 10.1242/jcs. 151043.

Stiles, J., \& Jernigan, T. L. (2010). The Basics of Brain Development. Neuropsychology Review, 20(4), 327-348. doi: 10.1007/s11065-010-9148-4.

Substance Abuse and Mental Health Services Administration, U.S. Department of Health and Human Services. (n.d.). Retrieved August 14, 2019, from http://www.recognizetrauma.org/statistics.php.

Sykes Wylie, M. (2010). The Long Shadow of Trauma. Psychotherapy Networker, (34), 20-54. 


\section{PROMOTING COGNITIVE AND FINE MOTOR DEVELOPMENT}

Teicher, M. H. (2000, October 1). Wounds That Time Won't Heal: The Neurobiology of Child Abuse. Retrieved from http://www.dana.org/Cerebrum/2000/Wounds_That_Time_Won't_Heal_The_Neurobiol ogy_of_Child_Abuse/.

Thorne, G. (2003, January 1). What Strategies Can Be Used to Increase Memory? Retrieved from https:/www.cdl.org/articles/what-strategies-can-be-used-to-increase-memory/.

Toga, A. W., Thompson, P. M., \& Sowell, E. R. (2006). Mapping Brain Maturation. Trends in Neurosciences, 29(3), 148-159. Retrieved from https:/www-sciencedirectcom.www.libproxy.wvu.edu/science/article/pii/S0166223606000245.

Tomlinson, C. A. (2017). How to differentiate instruction in academically diverse classrooms. Alexandria, VA: ASCD.

Trauma-Informed Strategies to Use in Your Classroom. (2018, January 24). Retrieved from https:/education.cu-portland.edu/blog/classroom-resources/trauma-informed-strategies/.

Van der Kolk, B. (2015). The body keeps the score: brain, mind, and body in the healing of trauma. NY, NY: Penguin Books.

Villines, Z. (2015, September 17). Gray Matter vs. White Matter in the Brain. Retrieved from https://www.spinalcord.com/blog/gray-matter-vs-white-matter-in-the-brain.

Vythilingam, M., Heim, C., Newport, J., Miller, A. H., Anderson, E., Bronen, R., ... Bremner, J. D. (2002). Childhood trauma associated with smaller hippocampal volume in women with major depression. The American journal of psychiatry, 159(12), 2072-2080. doi:10.1176/appi.ajp.159.12.2072.

Walkley, M., \& Cox, T. L. (2013). Building Trauma-Informed Schools and Communities. Children \& Schools, 35(2), 123-126. doi: 10.1093/cs/cdt007. 


\section{PROMOTING COGNITIVE AND FINE MOTOR DEVELOPMENT}

Wassenberg, R., Feron, F. J. M., Kessels, A. G. H., Hendriksen, J. G. M., Kalff, A. C., Kroes, M., ... Vles, J. S. H. (2005). Relation Between Cognitive and Motor Performance in 5- to 6-Year-Old Children: Results from a Large-Scale Cross-Sectional Study. Child Development, 76(5), 1092-1103. doi: 10.1111/j.1467-8624.2005.00899.x.

Weselby, C. (2018, August 21). What is Differentiated Instruction? Examples of Strategies. Retrieved from https://education.cu-portland.edu/blog/classroom-resources/examples-ofdifferentiated-instruction/.

WEST VIRGINIA CODE. §18-5-18a. (n.d.). Retrieved July 29, 2019, from http://www.wvlegislature.gov/wvcode/chapterentire.cfm?chap=18\&art=5§ion=18a

West Virginia Department of Health \& Human Resources Bureau for Public Health (2015). Adverse Childhood Experiences. Retrieved from http://www.wvdhhr.org/bph/hsc/pubs/briefs/030/Brief30_Adverse_Childhood_Experienc es.pdf.

West, J., Denton, K., \& Germino-Hausken, E. (2000). Americas kindergartners: findings from the Early Childhood Longitudinal Study, kindergarten class of 1998-99, fall 1998. Washington, DC: U.S. Dept. of Education, Office of Educational Research and Improvement, National Center for Education Statistics.

Westby, C. (2018). Adverse Childhood Experiences: What Speech-Language Pathologists Need to Know. Word of Mouth, 30(1), 1-4. doi:10.1177/1048395018796520.

Wlassoff, V. (2015, January 25). How Does Post-Traumatic Stress Disorder Change the Brain? Retrieved from http:/www.brainblogger.com/2015/01/24/how-does-post-traumaticstress-disorder-change-the-brain/. 
PROMOTING COGNITIVE AND FINE MOTOR DEVELOPMENT

Woods-Jaeger, B. A., Cho, B., Sexton, C. C., Slagel, L., \& Goggin, K. (2018). Promoting Resilience: Breaking the Intergenerational Cycle of Adverse Childhood Experiences. Health Education \& Behavior, 45(5), 772-780. doi: 10.1177/1090198117752785. 


\section{Appendix A}

\section{Exploratory Case Study 1: Kindergarten Results}

\begin{tabular}{|c|c|c|c|c|}
\hline \multicolumn{5}{|c|}{ Kindergarten Results: First Portrait } \\
\hline Students & Pigasso or Mootisse & Facial Features & Lines & Shapes \\
\hline Student 1 & undistinguishable & undistinguishable & undistinguishable & undistinguishable \\
\hline Student 2 & Pigasso & yes & yes & yes \\
\hline Student 3 & Mootisse & yes & yes & no \\
\hline Student 4 & Mootisse & yes & yes & yes \\
\hline Student 5 & Pigasso & yes & no & yes \\
\hline Student 6 & undistinguishable & undistinguishable & undistinguishable & undistinguishable \\
\hline Student 7 & undistinguishable & undistinguishable & undistinguishable & undistinguishable \\
\hline Student 8 & Pigasso & yes & yes & no \\
\hline Student 9 & Pigasso & yes & yes & yes \\
\hline Student 10 & Pigasso & yes & yes & yes \\
\hline Student 11 & Pigasso & yes & yes & yes \\
\hline Student 12 & Mootisse & yes & yes & yes \\
\hline Student 13 & Pigasso & no & no & yes \\
\hline Student 14 & Pigasso & yes & yes & yes \\
\hline Student 15 & Pigasso & yes & no & yes \\
\hline Student 16 & undistinguishable & undistinguishable & undistinguishable & undistinguishable \\
\hline Student 17 & undistinguishable & undistinguishable & undistinguishable & undistinguishable \\
\hline Student 18 & Pigasso & yes & yes & no \\
\hline Student 19 & Pigasso & yes & yes & yes \\
\hline Student 20 & Pigasso & yes & yes & no \\
\hline Student 21 & Mootisse & yes & yes & yes \\
\hline Student 22 & Pigasso & no & yes & yes \\
\hline Student 23 & Pigasso & yes & yes & yes \\
\hline Student 24 & Mootisse & yes & no & yes \\
\hline Student 25 & undistinguishable & undistinguishable & undistinguishable & undistinguishable \\
\hline Student 26 & Pigasso & yes & yes & yes \\
\hline
\end{tabular}

Table 2. Kindergarten First Portrait Results

Blue highlight indicates students identified with known exposure to trauma Yellow highlight indicates well performing student with no known exposure to trauma 


\begin{tabular}{|c|c|c|c|c|}
\hline \multicolumn{5}{|c|}{ Kindergarten Results: Second Portrait } \\
\hline Students & Pigasso or Mootisse & Facial Features & Lines & Shapes \\
\hline Student 1 & undistinguishable & undistinguishable & undistinguishable & undistinguishable \\
\hline Student 2 & Mootisse & yes & yes & yes \\
\hline Student 3 & Mootisse & yes & yes & no \\
\hline Student 4 & Pigasso & yes & yes & yes \\
\hline Student 5 & undistinguishable & undistinguishable & undistinguishable & undistinguishable \\
\hline Student 6 & undistinguishable & undistinguishable & undistinguishable & undistinguishable \\
\hline Student 7 & undistinguishable & undistinguishable & undistinguishable & undistinguishable \\
\hline Student 8 & Pigasso & yes & yes & yes \\
\hline Student 9 & Pigasso & yes & yes & yes \\
\hline Student 10 & Pigasso & yes & no & no \\
\hline Student 11 & Pigasso & yes & yes & yes \\
\hline Student 12 & Pigasso & yes & yes & yes \\
\hline Student 13 & Pigasso & no & yes & yes \\
\hline Student 14 & Pigasso & yes & no & yes \\
\hline Student 15 & Pigasso & yes & yes & yes \\
\hline Student 16 & undistinguishable & undistinguishable & undistinguishable & undistinguishable \\
\hline Student 17 & undistinguishable & undistinguishable & undistinguishable & undistinguishable \\
\hline Student 18 & Pigasso & yes & yes & yes \\
\hline Student 19 & Pigasso & yes & no & yes \\
\hline Student 20 & Mootisse & yes & no & no \\
\hline Student 21 & Mootisse & yes & yes & yes \\
\hline Student 22 & Pigasso & yes & yes & yes \\
\hline Student 23 & Pigasso & yes & no & yes \\
\hline Student 24 & Mootisse & yes & no & yes \\
\hline Student 25 & undistinguishable & undistinguishable & undistinguishable & undistinguishable \\
\hline Student 26 & Pigasso & yes & yes & yes \\
\hline
\end{tabular}

Table 3. Kindergarten Second Portrait Results

Blue highlight indicates students identified with known exposure to trauma Yellow highlight indicates well performing student with no known exposure to trauma 
PROMOTING COGNITIVE AND FINE MOTOR DEVELOPMENT

\begin{tabular}{ccc}
\hline & Kindergarten Results: Completed Project \\
\hline Students & First \& Second Compared & Fine Motor Score \\
\hline Student 1 & similar & 1 \\
Student 2 & different & 2 \\
Student 3 & similar & 2 \\
Student 4 & different & 3 \\
Student 5 & different & 3 \\
Student 6 & similar & 3 \\
Student 7 & similar & 2 \\
Student 8 & different & 2 \\
Student 9 & same & 3 \\
Student 10 & similar & 2 \\
Student 11 & similar & 2 \\
Student 12 & different & 2 \\
Student 13 & different & 2 \\
Student 14 & different & 3 \\
Student 15 & different & 2 \\
Student 16 & different & 1 \\
Student 17 & different & 2 \\
Student 18 & different & 2 \\
Student 19 & different & 2 \\
Student 20 & different & 2 \\
Student 21 & different & 2 \\
Student 22 & different & 2 \\
Student 23 & different & 2 \\
Student 24 & similar & 3 \\
Student 25 & different & 2 \\
Student 26 & similar & \\
\hline & & 2 \\
\hline & & 2 \\
\hline
\end{tabular}

Table 4. Kindergarten Completed Project Results

Blue highlight indicates students identified with known exposure to trauma Yellow highlight indicates well performing student with no known exposure to trauma 


\section{Appendix B}

\section{Exploratory Case Study 2: First Grade Results}

\begin{tabular}{|c|c|c|c|c|}
\hline \multicolumn{5}{|c|}{ First Grade Results: First Portrait } \\
\hline Students & Pigasso or Mootisse & Facial Features & Lines & Shapes \\
\hline Student 1 & Pigasso & yes & yes & yes \\
\hline Student 2 & Mootisse & yes & yes & yes \\
\hline Student 3 & Pigasso & no & yes & yes \\
\hline Student 4 & Pigasso & yes & yes & yes \\
\hline Student 5 & Mootisse & yes & yes & yes \\
\hline Student 6 & Pigasso & yes & yes & no \\
\hline Student 7 & undistinguishable & undistinguishable & undistinguishable & undistinguishable \\
\hline Student 8 & Mootisse & yes & yes & yes \\
\hline Student 9 & undistinguishable & undistinguishable & undistinguishable & undistinguishable \\
\hline Student 10 & Pigasso & no & yes & yes \\
\hline Student 11 & Pigasso & yes & yes & yes \\
\hline Student 12 & Pigasso & yes & yes & yes \\
\hline Student 13 & Pigasso & yes & yes & yes \\
\hline Student 14 & Mootisse & yes & yes & yes \\
\hline Student 15 & Pigasso & yes & yes & yes \\
\hline Student 16 & undistinguishable & undistinguishable & undistinguishable & undistinguishable \\
\hline Student 17 & Pigasso & yes & yes & yes \\
\hline Student 18 & Mootisse & yes & no & no \\
\hline Student 19 & Mootisse & no & yes & yes \\
\hline Student 20 & Mootisse & yes & yes & yes \\
\hline Student 21 & Mootisse & no & no & yes \\
\hline Student 22 & Pigasso & yes & no & yes \\
\hline Student 23 & Mootisse & yes & yes & yes \\
\hline Student 24 & Mootisse & yes & yes & yes \\
\hline Student 25 & Mootisse & yes & yes & yes \\
\hline Student 26 & Mootisse & yes & yes & yes \\
\hline Student 27 & Pigasso & yes & yes & yes \\
\hline Student 28 & Mootisse & yes & yes & yes \\
\hline Student 29 & Mootisse & yes & yes & yes \\
\hline Student 30 & Pigasso & yes & no & yes \\
\hline Student 31 & Pigasso & yes & yes & yes \\
\hline Student 32 & Pigasso & yes & yes & yes \\
\hline Student 33 & Pigasso & no & yes & yes \\
\hline Student 34 & Pigasso & yes & yes & yes \\
\hline Student 35 & Pigasso & no & no & no \\
\hline
\end{tabular}

Table 5. First Grade First Portrait Results

Blue highlight indicates students identified with known exposure to trauma Yellow highlight indicates well performing student with no known exposure to trauma 
PROMOTING COGNITIVE AND FINE MOTOR DEVELOPMENT

\begin{tabular}{|c|c|c|c|c|}
\hline \multicolumn{5}{|c|}{ First Grade Results: Second Portrait } \\
\hline Students & Pigasso or Mootisse & Facial Features & Lines & Shapes \\
\hline Student 1 & Pigasso & yes & yes & yes \\
\hline Student 2 & Mootisse & yes & yes & yes \\
\hline Student 3 & Pigasso & no & yes & yes \\
\hline Student 4 & Pigasso & yes & yes & yes \\
\hline Student 5 & Mootisse & yes & yes & yes \\
\hline Student 6 & Pigasso & yes & yes & no \\
\hline Student 7 & Pigasso & yes & yes & yes \\
\hline Student 8 & Mootisse & yes & yes & yes \\
\hline Student 9 & undistinguishable & undistinguishable & undistinguishable & undistinguishable \\
\hline Student 10 & undistinguishable & undistinguishable & undistinguishable & undistinguishable \\
\hline Student 11 & undistinguishable & undistinguishable & undistinguishable & undistinguishable \\
\hline Student 12 & Pigasso & yes & yes & yes \\
\hline Student 13 & Pigasso & yes & yes & yes \\
\hline Student 14 & Mootisse & yes & yes & yes \\
\hline Student 15 & did not create & did not create & did not create & did not create \\
\hline Student 16 & undistinguishable & undistinguishable & undistinguishable & undistinguishable \\
\hline Student 17 & Pigasso & yes & yes & yes \\
\hline Student 18 & Mootisse & yes & no & no \\
\hline Student 19 & Mootisse & no & yes & yes \\
\hline Student 20 & Mootisse & yes & yes & yes \\
\hline Student 21 & Mootisse & no & no & yes \\
\hline Student 22 & Mootisse & yes & yes & no \\
\hline Student 23 & Mootisse & yes & no & yes \\
\hline Student 24 & Mootisse & yes & yes & no \\
\hline Student 25 & Mootisse & yes & yes & yes \\
\hline Student 26 & Mootisse & yes & yes & yes \\
\hline Student 27 & Pigasso & yes & yes & yes \\
\hline Student 28 & Mootisse & yes & yes & yes \\
\hline Student 29 & Mootisse & yes & yes & yes \\
\hline Student 30 & Pigasso & yes & no & yes \\
\hline Student 31 & Pigasso & yes & yes & yes \\
\hline Student 32 & Pigasso & yes & yes & yes \\
\hline Student 33 & Pigasso & no & yes & yes \\
\hline Student 34 & Pigasso & yes & yes & yes \\
\hline Student 35 & Pigasso & no & no & no \\
\hline
\end{tabular}

Table 6. First Grade Second Portrait Results

Blue highlight indicates students identified with known exposure to trauma Yellow highlight indicates well performing student with no known exposure to trauma 
PROMOTING COGNITIVE AND FINE MOTOR DEVELOPMENT

\begin{tabular}{|c|c|c|c|}
\hline \multicolumn{4}{|c|}{ First Grade Results: Completed Project } \\
\hline Students & Collage or Drawing & First \& Second Compared & Fine Motor Score \\
\hline Student 1 & drawing & same & 2 \\
\hline Student 2 & drawing & similar & 3 \\
\hline Student 3 & drawing & similar & 3 \\
\hline Student 4 & collage & different & 1 \\
\hline Student 5 & drawing & similar & 3 \\
\hline Student 6 & collage & different & 2 \\
\hline Student 7 & drawing & different & 1 \\
\hline Student 8 & collage & similar & 2 \\
\hline Student 9 & collage & different & 1 \\
\hline Student 10 & drawing & different & 1 \\
\hline Student 11 & collage & different & 1 \\
\hline Student 12 & collage & same & 2 \\
\hline Student 13 & drawing & similar & 3 \\
\hline Student 14 & collage & similar & 2 \\
\hline Student 15 & $n / a$ & $n / a$ & 2 \\
\hline Student 16 & collage & similar & 2 \\
\hline Student 17 & drawing & different & 3 \\
\hline Student 18 & drawing & similar & 2 \\
\hline Student 19 & drawing & different & 1 \\
\hline Student 20 & collage & different & 2 \\
\hline Student 21 & collage & similar & 2 \\
\hline Student 22 & drawing & different & 2 \\
\hline Student 23 & collage & similar & 2 \\
\hline Student 24 & drawing & different & 2 \\
\hline Student 25 & drawing & similar & 3 \\
\hline Student 26 & drawing & similar & 2 \\
\hline Student 27 & drawing & similar & 3 \\
\hline Student 28 & collage & different & 3 \\
\hline Student 29 & collage & different & 1 \\
\hline Student 30 & drawing & similar & 3 \\
\hline Student 31 & drawing & similar & 2 \\
\hline Student 32 & drawing & different & 2 \\
\hline Student 33 & drawing & similar & 2 \\
\hline Student 34 & drawing & similar & 2 \\
\hline Student 35 & drawing & different & 2 \\
\hline
\end{tabular}

Table 7. First Grade Complete Project Results

Blue highlight indicates students identified with known exposure to trauma Yellow highlight indicates well performing student with no known exposure to trauma 
PROMOTING COGNITIVE AND FINE MOTOR DEVELOPMENT

\section{Appendix C}

\section{Exploratory Case Study 3: Second Grade Results}

\begin{tabular}{|c|c|c|c|c|}
\hline \multicolumn{5}{|c|}{ Second Grade Results: First Portrait } \\
\hline Students & Pigasso or Mootisse & Facial Features & Lines & Shapes \\
\hline Student 1 & Pigasso & yes & yes & yes \\
\hline Student 2 & Mootisse & yes & yes & no \\
\hline Student 3 & Pigasso & yes & yes & yes \\
\hline Student 4 & Mootisse & yes & yes & no \\
\hline Student 5 & Mootisse & yes & yes & yes \\
\hline Student 6 & Pigasso & yes & yes & yes \\
\hline Student 7 & Pigasso & yes & yes & no \\
\hline Student 8 & Pigasso & yes & yes & yes \\
\hline Student 9 & Pigasso & yes & yes & yes \\
\hline Student 10 & Pigasso & yes & yes & yes \\
\hline Student 11 & Pigasso & yes & yes & yes \\
\hline Student 12 & Pigasso & yes & yes & yes \\
\hline Student 13 & Mootisse & yes & yes & no \\
\hline Student 14 & Mootisse & yes & yes & yes \\
\hline Student 15 & Pigasso & yes & yes & yes \\
\hline Student 16 & Pigasso & yes & yes & no \\
\hline Student 17 & Pigasso & yes & yes & yes \\
\hline Student 18 & Pigasso & yes & yes & yes \\
\hline Student 19 & Mootisse & yes & yes & yes \\
\hline Student 20 & Pigasso & yes & yes & yes \\
\hline Student 21 & Mootisse & yes & no & yes \\
\hline Student 22 & Mootisse & yes & yes & yes \\
\hline Student 23 & Mootisse & yes & yes & yes \\
\hline Student 24 & Pigasso & yes & yes & yes \\
\hline Student 25 & Pigasso & yes & yes & yes \\
\hline
\end{tabular}

Table 8. Second Grade First Portrait Results

Blue highlight indicates students identified with known exposure to trauma Yellow highlight indicates well performing student with no known exposure to trauma 
PROMOTING COGNITIVE AND FINE MOTOR DEVELOPMENT

\begin{tabular}{|c|c|c|c|c|}
\hline \multicolumn{5}{|c|}{ Second Grade Results: Second Portrait } \\
\hline Students & Pigasso or Mootisse & Facial Features & Lines & Shapes \\
\hline Student 1 & Pigasso & yes & yes & yes \\
\hline Student 2 & Mootisse & yes & yes & no \\
\hline Student 3 & Pigasso & yes & yes & yes \\
\hline Student 4 & Mootisse & yes & yes & yes \\
\hline Student 5 & Mootisse & yes & yes & yes \\
\hline Student 6 & Pigasso & yes & yes & yes \\
\hline Student 7 & Pigasso & yes & no & no \\
\hline Student 8 & Pigasso & yes & no & yes \\
\hline Student 9 & Pigasso & yes & no & yes \\
\hline Student 10 & Pigasso & yes & no & yes \\
\hline Student 11 & Pigasso & yes & yes & yes \\
\hline Student 12 & Pigasso & yes & yes & yes \\
\hline Student 13 & Mootisse & yes & yes & no \\
\hline Student 14 & Mootisse & yes & yes & yes \\
\hline Student 15 & Pigasso & yes & yes & yes \\
\hline Student 16 & Pigasso & yes & yes & yes \\
\hline Student 17 & Pigasso & yes & yes & yes \\
\hline Student 18 & Pigasso & yes & yes & yes \\
\hline Student 19 & unfinished & unfinished & unfinished & unfinished \\
\hline Student 20 & Pigasso & yes & no & yes \\
\hline Student 21 & Mootisse6 & yes & yes & no \\
\hline Student 22 & Mootisse & yes & yes & yes \\
\hline Student 23 & Mootisse & yes & yes & yes \\
\hline Student 24 & Pigasso & yes & yes & yes \\
\hline Student 25 & undistinguishable & undistinguishable & undistinguishable & undistinguishable \\
\hline
\end{tabular}

Table 9. Second Grade Second Portrait Results

Blue highlight indicates students identified with known exposure to trauma Yellow highlight indicates well performing student with no known exposure to trauma

6 Student created a drawing instead of a collage. 
PROMOTING COGNITIVE AND FINE MOTOR DEVELOPMENT

\begin{tabular}{ccc}
\hline & Second Grade Results: Completed Project \\
\hline Students & First \& Second Compared & Fine Motor Score \\
\hline Student 1 & same & 2 \\
Student 2 & similar & 2 \\
Student 3 & similar & 2 \\
Student 4 & similar & 2 \\
Student 5 & same & 2 \\
Student 6 & similar & 3 \\
Student 7 & similar & 1 \\
Student 8 & similar & 2 \\
Student 9 & similar & 2 \\
Student 10 & similar & 2 \\
Student 11 & similar & 3 \\
Student 12 & similar & 3 \\
Student 13 & different & 2 \\
Student 14 & similar & 2 \\
Student 15 & similar & 2 \\
Student 16 & different & 2 \\
Student 17 & similar & 3 \\
Student 18 & similar & 2 \\
Student 19 & similar & 2 \\
Student 20 & similar & 2 \\
Student 21 & similar & 2 \\
Student 22 & similar & 1 \\
Student 23 & similar & 2 \\
Student 24 & different & 1 \\
Student 25 & different & 3 \\
\hline
\end{tabular}

Table 10. Second Grade Complete Project Results

Blue highlight indicates students identified with known exposure to trauma Yellow highlight indicates well performing student with no known exposure to trauma 